\title{
Standardisation of eddy-covariance flux measurements of methane and nitrous oxide
}

\author{
Eiko Nemitz ${ }^{1}$ *, Ivan Mammarella ${ }^{2}$, Andreas Ibrom ${ }^{3}$, Mika Aurela $^{4}$, George G. Burba ${ }^{5,6}$, Sigrid Dengel', \\ Bert Gielen ${ }^{8}$, Achim Grelle ${ }^{9}$,Bernard Heinesch ${ }^{10}$, Mathias Herbst ${ }^{11}$, Lukas Hörtnagl ${ }^{12}$, Leif Klemedtsson ${ }^{13}$, \\ Anders Lindroth ${ }^{14}$, Annalea Lohila ${ }^{4}$, Dayle K. McDermitt ${ }^{15}$, Philip Meier ${ }^{12}$, Lutz Merbold ${ }^{12,16}$, David Nelson ${ }^{17}$, \\ Giacomo Nicolini ${ }^{18}$, Mats B. Nilsson ${ }^{19}$, Olli Peltola ${ }^{2}$,Janne Rinne ${ }^{14}$, and Mark Zahniser ${ }^{17}$
}

${ }^{1}$ Centre for Ecology and Hydrology, Bush Estate, Penicuik, EH26 0QB, UK

${ }^{2}$ Institute for Atmospheric and Earth System Research/Physics, Faculty of Science, P.O. Box 68, FI-00014 University of Helsinki, Finland

${ }^{3}$ Department of Environmental Engineering, Technical University of Denmark, Bygningstorvet, 2800 Kgs. Lyngby, Denmark

${ }^{4}$ Finnish Meteorological Institute, P.O. Box 503, 00101, Helsinki, Finland

${ }^{5}$ R\&D, LI-COR Biosciences, Lincoln, Nebraska, NE 68504, USA

${ }^{6}$ Bio-Atmospheric Sciences, University of Nebraska, Lincoln, Nebraska, NE 68508, USA

${ }^{7}$ Climate Sciences, Lawrence Berkeley National Laboratory, One Cyclotron Rd, Berkeley, CA, 94720, USA

${ }^{8}$ Research Centre of Excellence Plants and Ecosystems (PLECO), University of Antwerp, Wilrijk, Belgium

${ }^{9}$ Department of Ecology, Swedish University of Agricultural Sciences, SE-750 07 Uppsala, Sweden

${ }^{10}$ TERRA Teaching and Research Centre, Gembloux Agro-Bio Tech, 33 University of Liege, B-5030, Gembloux, Belgium

${ }^{11}$ Zentrum für Agrarmeteorologische Forschung Braunschweig (ZAMF), Deutscher Wetterdienst, Bundesallee 50, 38116, Braunschweig, Germany

${ }^{12}$ Department of Environmental Systems Science, Institute of Agricultural Sciences, ETH Zurich, Universitätstrasse 2, 8092 Zürich, Switzerland

${ }^{13}$ Department of Earth Sciences, University of Gothenburg, P-O. Box 460, SE 40530 Gothenburg, Sweden

${ }^{14}$ Department of Physical Geography and Ecosystem Science, Lund University, Sölvegatan 12, 22362 Lund, Sweden

${ }^{15}$ Agronomy and Horticulture, University of Nebraska, Lincoln, NE 68508, USA

${ }^{16}$ Mazingira Centre, International Livestock Research Institute (ILRI), P.O. Box 30709, 00100 Nairobi, Kenya

${ }^{17}$ Aerodyne Research, Inc., 45 Manning Road, Billerica, MA, USA 01821-3976

${ }^{18}$ Department for Innovation in Biological Agro-food and Forest systems, University of Tuscia, Via San Camillo de Lellis, 01100 Viterbo, Italy

${ }^{19}$ Department of Forest Ecology and Management, Swedish University of Agricultural Sciences, SE-116 90183, Umeå, Sweden

Received March 16, 2018; accepted August 27, 2018

Abstract. Commercially available fast-response analysers for methane $\left(\mathrm{CH}_{4}\right)$ and nitrous oxide $\left(\mathrm{N}_{2} \mathrm{O}\right)$ have recently become more sensitive, more robust and easier to operate. This has made their application for long-term flux measurements with the eddycovariance method more feasible. Unlike for carbon dioxide $\left(\mathrm{CO}_{2}\right)$ and water vapour $\left(\mathrm{H}_{2} \mathrm{O}\right)$, there have so far been no guidelines on how to optimise and standardise the measurements. This paper reviews the state-of-the-art of the various steps of the measurements and discusses aspects such as instrument selection, setup and maintenance, data processing as well as the additional measurements needed to aid interpretation and gap-filling. It presents the methodological protocol for eddy covariance measurements of $\mathrm{CH}_{4}$ and $\mathrm{N}_{2} \mathrm{O}$ fluxes as agreed for the ecosystem station network of the pan-European Research Infrastructure Integrated Carbon Observation System and provides a first international standard that is suggested to be adopted more widely. Fluxes can be episodic and the processes controlling the fluxes are complex, preventing simple mechanistic gap-filling strategies. Fluxes are often near or below the detection limit, requiring additional care during data processing. The protocol sets out the best practice for these conditions to avoid biasing the results and long-term budgets. It summarises the current approach to gap-filling.

Keywords: ICOS, protocol, micrometeorology, greenhouse gas exchange, standardisation 


\section{INTRODUCTION}

Methane $\left(\mathrm{CH}_{4}\right)$ and nitrous oxide $\left(\mathrm{N}_{2} \mathrm{O}\right)$ are the second and third most important greenhouse gases after carbon dioxide $\left(\mathrm{CO}_{2}\right)$. Methane has a lifetime of about 12.4 years and a global warming potential (GWP) of 34 (over the 100year horizon), whilst $\mathrm{N}_{2} \mathrm{O}$ has a lifetime of about 121 years, with a GWP of 298 (IPCC, 2013). As a result, although their fluxes tend to be considerably smaller than that of $\mathrm{CO}_{2}$, they often significantly alter the net greenhouse gas balance of terrestrial and aquatic systems with the atmosphere. Because concentrations and fluxes of these non- $\mathrm{CO}_{2}$ greenhouse gases (GHGs) are smaller than those of $\mathrm{CO}_{2}$, this imposes additional challenges for the instrumentation used for their measurement and data processing.

Instrumentation has been available for more than three decades to make eddy-covariance(EC) flux measurements of $\mathrm{CO}_{2}$ and water vapour $\left(\mathrm{H}_{2} \mathrm{O}\right)$, that is reliable and reasonably affordable in terms of purchase and operation. As a result of this, and also reflecting the importance of $\mathrm{CO}_{2}$, fluxes of $\mathrm{CO}_{2}$ are measured across large regional networks and significant effort has gone into the harmonisation of approaches and development of best practices (Aubinet et al., 2000, 2012).

By contrast, the first EC flux measurements of $\mathrm{CH}_{4}$ and $\mathrm{N}_{2} \mathrm{O}$ were not made until the 1990s and initially with tunable diode laser absorption spectrometers that had relatively high noise levels and required regular cooling with liquid nitrogen and were difficult to maintain long-term. Fast response analysers for measuring $\mathrm{CH}_{4}$ and $\mathrm{N}_{2} \mathrm{O}$ fluxes that are easy-to-deploy in the field have only become available during the past decade. As a result, the number of existing long-term measurements and experience in instrument setup, instrument long-term performance, data processing and evaluation of non- $\mathrm{CO}_{2}$ flux estimates remains comparatively limited and approaches have not yet been standardised. This is further exacerbated by the limited success of reproducing the underlying biogeochemical processes of $\mathrm{CH}_{4}$ and in particular $\mathrm{N}_{2} \mathrm{O}$ exchange with simple empirical relationships (for more details please see Butterbach-Bahl et al., 2013; Eugster and Merbold, 2015). Because older instrumentation could only detect relatively large fluxes and even the more recent instrumentation is deployed to target the largest fluxes, much of the current experience is based on so-called high-emission ecosystems, e.g. $\mathrm{CH}_{4}$ emissions from wetlands and $\mathrm{N}_{2} \mathrm{O}$ emissions in agricultural fields. An overview of studies that focused on EC flux measurements of $\mathrm{CH}_{4}$ and/or $\mathrm{N}_{2} \mathrm{O}$ is given in Table 1, with particular emphasis on studies more recent than the overview of EC results up to 2012 provided by Nicolini et al. (2013).
With the latest generation of analysers it is now possible to measure $\mathrm{CH}_{4}$ and $\mathrm{N}_{2} \mathrm{O}$ fluxes near their background level, which can still add up to a considerable fraction of the annual budget. Still significantly more expensive than comparable sensors for $\mathrm{CO}_{2}$, the newer instruments are much more stable and cost-efficient to operate, and no longer require continuous cooling with liquid nitrogen, a major challenge in field applications. This makes them increasingly deployable across large-scale networks such as the Integrated Carbon Observation System (ICOS), a panEuropean research infrastructure (as described in the introductory paper to this issue), and the National Ecological Observatory Network (NEON) in the US. Within ICOS, EC flux measurements of $\mathrm{CH}_{4}$ and $\mathrm{N}_{2} \mathrm{O}$ are mandatory for all Class-1 Stations (ibid.) and further recommended for Class-2 Stations, but only if $\mathrm{CH}_{4}$ and $\mathrm{N}_{2} \mathrm{O}$ fluxes are relevant to the overall GHG budget of the site. Guidelines on the relevance criteria are given below.

This paper provides a first step towards a best practice in the set-up and data processing associated with measuring EC fluxes of $\mathrm{CH}_{4}$ and $\mathrm{N}_{2} \mathrm{O}$, focusing on those considerations that are additional or different to those for making $\mathrm{CO}_{2}$ flux measurements, where one reoccurring issue is the measurement of fluxes close to the limit of detection (LOD) of the instruments. Besides the measurements of $\mathrm{CH}_{4}$ and $\mathrm{N}_{2} \mathrm{O}$, it is crucial to complement GHG flux measurements with specific ancillary data. Such data are important for two reasons: (1) to explain measured flux values and thereby generate additional knowledge about which variables drive the underlying processes and (2) to provide ancillary variables that may be crucial for potential gap-filling approaches. Gap-filling can be done with simple averaging methods, leading to large uncertainties or with more complex approaches, including artificial neural networks, multiple imputation techniques, as well as process-based biogeochemical models. Yet, gap-filling of discontinuous measurements is crucial to derive the full GHG budget of a site.

One key difference that distinguishes fluxes of $\mathrm{CH}_{4}$ and $\mathrm{N}_{2} \mathrm{O}$ from those of $\mathrm{CO}_{2}$ is that the $\mathrm{CO}_{2}$ flux tends to be strongly bi-directional over the diurnal cycle and that the annual budget for ecosystems tends to be a small difference between a large downward component during the day and a large upward component during the night, which makes it particularly important to quantify both components correctly. The flux of $\mathrm{N}_{2} \mathrm{O}$ tends to be upward for most of the time (the uptake rates are generally so low that they will be within the noise level), whilst for $\mathrm{CH}_{4}$ both uptake (oxidation) and emission are observed, but changes typically occur between sites or seasons, rather than following a diurnal cycle. Thus, the annual budget of $\mathrm{CH}_{4}$ and $\mathrm{N}_{2} \mathrm{O}$ is much less sensitive to the accuracy of corrections that preferentially apply during day or night-time. By contrast, for $\mathrm{N}_{2} \mathrm{O}$ in particular, the flux can be highly episodic, and annual emission can be entirely dominated by the fluxes 
Table 1. Overview of selected existing eddy-covariance studies on $\mathrm{CH}_{4}$ and $\mathrm{N}_{2} \mathrm{O}$ exchange, with focus on those published since the review of Nicolini et al. (2013)

\begin{tabular}{|c|c|}
\hline Ecosystem & References \\
\hline \multicolumn{2}{|r|}{ Methane } \\
\hline Peatland & $\begin{array}{l}\text { Hargreaves and Fowler (1998); Hargreaves et al. (2001); Kormann et al. (2001); Rinne et al. (2007); } \\
\text { Gažovič et al. (2010); Long et al. (2010); Forbrich et al. (2011); Baldocchi et al. (2012); Hatala et al. } \\
\text { (2012b); Nadeau et al. (2013); Olson et al. (2013); Peltola et al. (2013); Pypker et al. (2013); Sun et } \\
\text { al. (2013); Brown et al. (2014); Hommeltenberg et al. (2014); Strack et al. (2014); Knox et al. } \\
\text { (2015); Koebsch et al. (2015); Franz et al. (2016); Rinne et al. (2018) }\end{array}$ \\
\hline Forest & $\begin{array}{l}\text { Pattey et al. (2006); Smeets et al. (2009); Wang et al. (2013a); Shoemaker et al. (2014); Lohila et al. } \\
\text { (2016); Tang et al. (2018) }\end{array}$ \\
\hline Rice & $\begin{array}{l}\text { Werle and Kormann (2001); Tseng et al. (2010); Detto et al. (2011); Meijide et al. (2011); Hatala et } \\
\text { al. (2012a); Alberto et al. (2014); Bhattacharyya et al. (2014); Knox et al. (2015); Knox et al. (2016); } \\
\text { Ge et al. (2018) }\end{array}$ \\
\hline $\begin{array}{l}\text { Grassland } \\
\text { (incl. on peat) }\end{array}$ & $\begin{array}{l}\text { Hendriks et al. (2010); Kroon et al. (2010); Schrier-Uijl et al. (2010); Detto et al. (2011); Merbold et } \\
\text { al. (2013); Hörtnagl and Wohlfahrt (2014); Merbold et al. (2014); Peltola et al. (2014); Knox et al. } \\
\text { (2015); Hörtnagl et al. (2018); Wang et al. (2017) }\end{array}$ \\
\hline $\begin{array}{l}\text { Grazing ruminants, } \\
\text { feedlots }\end{array}$ & Dengel et al. (2011); Felber et al. (2015); Prajapati and Santos (2017); Coates et al. (2018) \\
\hline Tundra & $\begin{array}{l}\text { Sachs et al. (2008); Wille et al. (2008); Zona et al. (2009); Parmentier et al. (2011); Zona et al. } \\
\text { (2016); Marushchak et al. (2016) }\end{array}$ \\
\hline Cropland (other than rice) & Chu et al. (2014) \\
\hline Marshland / wetland & Detto et al. (2011); Herbst et al. (2011); Herbst et al. (2013); Yu et al. (2013); Lee et al. (2017) \\
\hline Water bodies/ mangroves & $\begin{array}{l}\text { Eugster et al. (2011); Schubert et al. (2012); Jha et al. (2014); Podgrajsek et al. (2014); Jammet et al. } \\
\text { (2015); Podgrajsek et al. (2016); Erkkilä et al. (2017); Jammet et al. (2017); Li et al. (2018) }\end{array}$ \\
\hline Urban environment & Gioli et al. (2012); Helfter et al. (2016); Pawlak and Fortuniak (2016) \\
\hline Landfill & $\begin{array}{l}\text { Laurila et al. (2005); Lohila et al. (2007); Eugster and Plüss (2010); Schroth et al. (2012); Xu et al. } \\
\text { (2014) }\end{array}$ \\
\hline $\begin{array}{l}\text { Mixed landscape / tall } \\
\text { tower }\end{array}$ & Desai et al. (2015); Peltola et al. (2015); Sayres et al. (2017) \\
\hline \multicolumn{2}{|r|}{ Nitrous oxide } \\
\hline Grassland & $\begin{array}{l}\text { Scanlon and Kiely (2003); Di Marco et al. (2004); Leahy et al. (2004); Hsieh et al. (2005); Neftel et } \\
\text { al. (2007); Kim et al. (2010); Kroon et al. (2010); Mishurov and Kiely (2010); Neftel et al. (2010); } \\
\text { Jones et al. (2011); Merbold et al. (2013); Merbold et al. (2014); Hörtnagl and Wohlfahrt (2014); } \\
\text { Wolf et al. (2015); Cowan et al. (2016); Hörtnagl et al. (2018) }\end{array}$ \\
\hline Croplands & $\begin{array}{l}\text { Christensen et al. (1996); Skiba et al. (1996); Hargreaves et al. (1996); Pattey et al. (2008); } \\
\text { Molodovskaya et al. (2012); Wang et al. (2013b); Huang et al. (2014); Shurpali et al. (2016); Brown } \\
\text { et al. (2017) }\end{array}$ \\
\hline Forest & $\begin{array}{l}\text { Pihlatie et al. (2005); Eugster et al. (2007); Mammarella et al. (2010); Mishurov and Kiely (2010); } \\
\text { Pihlatie et al. (2010); Zona et al. (2013a); Zona et al. (2013b); Zenone et al. (2016) }\end{array}$ \\
\hline Landfill & Rinne et al. (2005) \\
\hline Urban environment & Famulari et al. (2010); Jarvi et al. (2014); Helfter et al. (2016) \\
\hline $\begin{array}{l}\text { Mixed landscape / tall } \\
\text { tower }\end{array}$ & Haszpra et al. (2018) \\
\hline
\end{tabular}

during a few days (Zona et al., 2013a, 2013b; Zenone et al., 2016), e.g. related to fertiliser applications, rain episodes or freeze-thaw cycles (Matzner and Borken, 2008; Groffman et al., 2009; Molodovskaya et al., 2012; Wagner-Riddle et al., 2017). As a result, unlike chamber approaches, the EC method is ideally suited for capturing the high emission events with good spatial representativeness and temporal coverage, but it may well be challenged by the small fluxes during the remainder of the year.
Open-path measurements of $\mathrm{CH}_{4}$ and other gases with fluxes relatively small in comparison to their typical atmospheric concentrations are subject to large correction terms for density fluctuations caused by fluxes of sensible and latent heat (referred to as the WPL correction; Webb et al., 1980), the uncertainty of which dominates the effective detection limit of these instruments. For this reason, and because of data loss by precipitation, open-path sensors for $\mathrm{CH}_{4}$ are not accepted for ICOS ecosystem Class 1 Stations. 
Nevertheless, they may be appropriate in some situations and may be the only option for the remote and low-power installations (Appendix 1 on how to minimise errors in the WPL correction through care in setup, operation and processing of the measurements of all components). Whilst open-path analysers are not yet commercially available for $\mathrm{N}_{2} \mathrm{O}$, developments are underway to reduce pumping requirements for closed-path systems (Brown et al., 2017).

In general, the ICOS methodology will further develop over time, by reformulating measurement requirements according to the experiences and implementation of new technological achievements. This is particularly true for this protocol on EC flux measurements of $\mathrm{CH}_{4}$ and $\mathrm{N}_{2} \mathrm{O}$ because it seeks to develop the first international standard of its kind. Analysers and experience with their long-term operation are currently developing at speed.

In this paper, we aim to provide guidelines for $\mathrm{EC}$ flux measurements of $\mathrm{CH}_{4}$ and $\mathrm{N}_{2} \mathrm{O}$, and state for which ecosystem types either measurement is feasible, together with guidelines for selecting instruments that are capable of measuring these non- $\mathrm{CO}_{2} \mathrm{GHG}$ fluxes. We further provide recommendations on the setup of EC flux measurements, maintenance and calibration intervals as well as a list of recommended ancillary variables that should be measured. At the end of this paper, we highlight crucial steps that need to be undertaken when processing $\mathrm{CH}_{4}$ and $\mathrm{N}_{2} \mathrm{O}$ flux data, which quality criteria should be applied and how potential gaps in data could be filled.

Throughout the paper the focus is on those aspects that need to be considered additionally when making and interpreting EC measurements of $\mathrm{CH}_{4}$ and $\mathrm{N}_{2} \mathrm{O}$, besides the aspects that are covered by energy and $\mathrm{CO}_{2}$ flux measurements already (see protocols for ICOS flux station setup and EC data processing in this issue).

\section{METHODOLOGY}

\section{Instrument sensitivity and ecosystem applicability}

\section{Measurement method}

At the time of writing, all fast response analysers for $\mathrm{CH}_{4}$ and $\mathrm{N}_{2} \mathrm{O}$ available are based on a range of optical absorption techniques. Methane flux measurements have also been made with a flame ionisation detector (FID) (Fan et al., 1992; Laurila et al., 2005; Lohila et al., 2007), but this approach is sensitive also to non-methane hydrocarbons and thus not sufficiently specific for general application in an EC setup. Of the closed-path instruments based on optical absorption techniques, most (with the exception of the Campbell Scientific TGA) use multi-pass cells and include tunable infrared laser differential absorption spectrometers (TILDAS) (e.g. Aerodyne Res. Inc.; Campbell Scientific), cavity ring-down spectrometers (CRDS; e.g. Picarro Res. Inc.) and off-axis integrated cavity output spectroscopy (Los Gatos Research, LGR). These may deploy lead-salt lasers (older instruments), telecom lasers $\left(\mathrm{CH}_{4}\right.$ only) or quantum cascade lasers and typically target $\mathrm{CH}_{4}$ and $\mathrm{N}_{2} \mathrm{O}$ on absorption features in the mid-infrared range. Depending on the exact absorption features (wavelength range) used, the same instruments may measure several compounds at the same time, e.g. $\mathrm{CH}_{4}$ only, $\mathrm{CH}_{4} / \mathrm{CO}_{2}, \mathrm{~N}_{2} \mathrm{O} / \mathrm{CH}_{4}, \mathrm{~N}_{2} \mathrm{O}$ / $\mathrm{CO}_{2}, \mathrm{~N}_{2} \mathrm{O} / \mathrm{CO}$. Most current instruments also derive $\mathrm{H}_{2} \mathrm{O}$ mole fraction, which is needed for internal corrections, while some legacy instruments and the current TGA200A (Campbell Scientific) do not. With absorption features differing in intensity, the different options target $\mathrm{CH}_{4}$ and $\mathrm{N}_{2} \mathrm{O}$ with varying sensitivity. Table 2 compiles the instruments known to be available at the time of writing, together with their specifications, bearing in mind that this is a fastmoving field. Other commercial instruments exist, but have not been demonstrated to be sufficiently fast for EC flux measurements. In addition to the closed-path sensors, the LI-COR LI-7700 is currently the only commercial openpath sensor available. Based on wavelength modulation technology it targets $\mathrm{CH}_{4}$ only. Similar non-commercial open and closed-path flux instruments exist in a number of research laboratories and universities.

\section{Measured quantities}

The key measurement for the calculation of EC fluxes is a highly time-resolved measurement of $\mathrm{N}_{2} \mathrm{O}$ and/or $\mathrm{CH}_{4}$. A scalar intensity of an atmospheric constituent $s$ may be described by several metrics (ISO80000-9:2009(E)) (ISO, 2009): "mass concentration $\left(\rho_{\mathrm{s}}, \mathrm{kg} \mathrm{m}^{-3}\right)$ " or "concentration $\left(c_{s}, \mathrm{~mol} \mathrm{~m}^{-3}\right)$ " representing the mass or the amount of substance of $s$ per volume of air, respectively. The "mass fraction $\left(\mathrm{kg} \mathrm{kg}^{-1}\right)$ " is the ratio of the mass of $s$ divided by the mass of the mixture, whilst the "mole fraction $\left(\chi_{s}\right.$, mol $\left.\mathrm{mol}^{-1}\right)$ " is the ratio of the amount of substance of $s$ divided by the total amount of substance of the mixture (also equal to the ratio of the constituent partial pressure to the total pressure). The "dry mole fraction $\left(\chi_{s d}, \mathrm{~mol} \mathrm{~mol}^{-1}\right)$ " is the ratio of the amount of substance of $s$ to that of dry air. These variables are related by the ideal gas law and the Dalton law. Conversion factors are given in Table 3.

Amongst these variables, only the dry mole fraction is a conserved quantity of the substance in the presence of changes in temperature, pressure and $\mathrm{H}_{2} \mathrm{O}$ content (Kowalski and Serrano-Ortiz, 2007). Unfortunately, gas analysers based on optical spectroscopy techniques measure absorption, which is directly related to (molar) concentration - a metric that is not conserved in these conditions. Therefore, concentration variations may appear in the absence of production, absorption or transport of the component. For this reason, the turbulent flux, that is representative of the ecosystem source/sink intensity, is the covariance of the vertical wind velocity and the component dry mole fraction.

A number of disparate flux units are in use in the community that measures fluxes of $\mathrm{CH}_{4}$ and $\mathrm{N}_{2} \mathrm{O}$. Having started with manual static flux chambers that are often 
Table 2. Manufacturer-provided characteristics of commercially available fast-response gas analysers for $\mathrm{CH}_{4}$ and $\mathrm{N}_{2} \mathrm{O}$. $q$ is the flow rate through the instrument cell, $\lambda$ indicates the approximate wavelength (expressed as wave number) of the absorption features used, whilst $\tau$ is the time response of the instrument itself as stated by the manufacturer, if the pump recommended for fast-response instruments is used

\begin{tabular}{|c|c|c|c|c|c|c|c|c|}
\hline \multirow{3}{*}{ Manufacturer } & \multirow{3}{*}{ Model } & \multirow{2}{*}{$q$} & \multirow{2}{*}{$\lambda$} & \multirow{2}{*}{$\tau^{*}$} & \multicolumn{4}{|c|}{$10 \mathrm{~Hz} \mathrm{RMS}^{\dagger}$} \\
\hline & & & & & $\mathrm{CH}_{4}$ & $\mathrm{~N}_{2} \mathrm{O}$ & \multirow{2}{*}{$\begin{array}{c}\mathrm{H}_{2} \mathrm{O} \\
\left(\mu \mathrm{mol} \mathrm{mol}^{-1}\right)\end{array}$} & \multirow{2}{*}{$\begin{array}{l}\text { Other gases } \\
\left(\mathrm{nmol} \mathrm{mol}^{-1}\right)\end{array}$} \\
\hline & & (slpm) & $\left(\mathrm{cm}^{-1}\right)$ & (s) & \multicolumn{2}{|c|}{$\left(\mathrm{nmol} \mathrm{mol}{ }^{-1}\right)$} & & \\
\hline \multirow{4}{*}{ Aerodyne } & Mini QCL & & 2250 & 0.07 & & 0.09 & 30 & $\mathrm{CO}_{2}{ }^{\ddagger} 300$ \\
\hline & Mini QCL & & 1275 & 0.07 & 0.9 & 0.18 & 30 & \\
\hline & Mini QCL & & 2200 & 0.07 & & 0.09 & 30 & CO: 0.3 \\
\hline & Mini QCL & & 2227 & 0.07 & & 0.09 & 30 & CO: 3 \\
\hline Aerodyne & Dual QCL & & $\begin{array}{l}2989 \\
2227\end{array}$ & 0.07 & 0.6 & 0.09 & & $\begin{array}{c}\mathrm{CO}_{2}: 300 \\
\mathrm{C}_{2} \mathrm{H}_{6}: 0.15 \\
\mathrm{CO}: 3 \\
\mathrm{CO}_{2}: 300\end{array}$ \\
\hline Campbell & TGA200A & 3.5 & 2243 & 0.04 & & 1.8 & & $\mathrm{CO}_{2}^{\star}: 300$ \\
\hline \multirow{2}{*}{ Scientific } & TGA200A & 3.5 & 2209 & 0.04 & & 1.5 & & \\
\hline & TGA200A & 3.5 & 3018 & 0.04 & 7 & & & \\
\hline Li-COR & LI-7700 & $\mathrm{n} / \mathrm{a}$ & 6211 & $<0.025^{\S}$ & 5 to $10^{\|}$ & & & \\
\hline \multirow{3}{*}{ LGR Inc } & 911-0010 (FGGA-24EP) & & & 0.07 & 3 & - & 100 & $\mathrm{CO}_{2}: 630$ \\
\hline & $913-0014$ & & & 0.07 & - & 0.2 & 50 & CO: 0.3 \\
\hline & $913-1054$ & & & 0.07 & 3 & 0.9 & 50 & \\
\hline \multirow[b]{2}{*}{ Picarro } & 911-0001 (FMA) & & & & 3 & - & 100 & \\
\hline & $2311-\mathrm{f}^{\sharp}$ & $>5$ & $\begin{array}{l}1603 / \\
1651\end{array}$ & 0.08 & 3 & - & $\begin{array}{c}6+ \\
0.3 \%\end{array}$ & $\mathrm{CO}_{2}: 200$ \\
\hline
\end{tabular}

*Flow response time with recommended appropriate (external) high flow vacuum pump; †typically calculated as the Allan Deviation with $0.1 \mathrm{~s}$ averaging time; where only $1 \mathrm{~Hz}$ values were available, these have been multiplied by $\sqrt{ } 10$. $₫$ Scaled up from ${ }^{13} \mathrm{CO}_{2}$; ${ }^{\S}$ the effective ability to resolve eddies is limited by wind speed and spatial eddy averaging; $" 5 \mathrm{ppb}$ at $10 \mathrm{~Hz}$ when instrument is clean; $10 \mathrm{ppb}$ at $10 \mathrm{~Hz}$ when instrument is dirty (RSSI 20\%); flux uncertainty is dominated by additional uncertainty in the WPL terms; "precision is for 3-species mode $\left(\mathrm{CO}_{2} / \mathrm{CH}_{4} / \mathrm{H}_{2} \mathrm{O}\right)$ operation.

Table 3. Conversion factors between some variables describing the scalar intensity of an atmospheric constituent

\begin{tabular}{|c|c|c|c|}
\hline Conversion factor & $\begin{array}{c}\text { Dry mole fraction } \\
\left(\mathrm{nmol} \mathrm{mol}^{-1}\right) \\
\chi_{s d}=\end{array}$ & $\begin{array}{c}\text { Concentration } \\
\left(\mathrm{nmol} \mathrm{m}^{-3}\right) \\
c_{s}=\end{array}$ & $\begin{array}{l}\text { Mass concentration } \\
\left(\mathrm{ng} \mathrm{m}^{-3}\right) \\
\rho_{s}=\end{array}$ \\
\hline $\begin{array}{l}\text { Dry mole fraction } \\
\chi_{s d} \times\end{array}$ & 1 & $\frac{p_{a}-p_{v}}{R T_{a}}$ & $\frac{m_{s}\left(p_{a}-p_{v}\right)}{R T_{a}}$ \\
\hline $\begin{array}{l}\text { Concentration } \\
c_{s} \times\end{array}$ & $\frac{R T_{a}}{p_{a}-p_{v}}$ & 1 & $m_{s}$ \\
\hline $\begin{array}{l}\text { Mass concentration } \\
\rho_{s} \times\end{array}$ & $\frac{R T_{a}}{m_{s}\left(p_{a}-p_{v}\right)}$ & $\frac{1}{m_{s}}$ & 1 \\
\hline
\end{tabular}

The variable in the column header is obtained by multiplying the variable in the line header by the factor given in the table; $p_{a}$ : atmospheric pressure $(\mathrm{Pa}) ; p_{v}$ : water vapour pressure $(\mathrm{Pa})$; R: gas constant $\left(8.314 \mathrm{~J} \mathrm{~K}^{-1} \mathrm{~mol}^{-1}\right) ; T_{a}$ : air temperature $(\mathrm{K}) ; m_{s}$ : scalar molar mass $\left(\mathrm{kg} \mathrm{mol}^{-1}\right)$. 
closed for about one hour, hourly flux units are quite common. However, for consistency between compounds and to follow SI standards, it is recommended to use nmol m $\mathrm{m}^{-2} \mathrm{~s}^{-1}$ for individual flux values, whilst annual budgets should be expressed in $\mathrm{g} \mathrm{CH}_{4}-\mathrm{C} \mathrm{m}^{-2} \mathrm{y}^{-1}$ and $\mathrm{kg} \mathrm{N}_{2} \mathrm{O}-\mathrm{N} \mathrm{ha}^{-1} \mathrm{y}^{-1}$. The latter enables easy comparison of $\mathrm{CH}_{4}$ fluxes with those of $\mathrm{CO}_{2}$ and quantification of $\mathrm{N}_{2} \mathrm{O}$ losses in relation to fertiliser input and atmospheric $\mathrm{N}$ deposition, both of which are usually expressed in $\mathrm{kg} \mathrm{N} \mathrm{ha}^{-1} \mathrm{y}^{-1}$.

Criteria for analyser selection and minimum annual budgets to be resolved

The issue of analyser selection is closely linked to the question about the stations for which the $\mathrm{EC} \mathrm{CH}_{4}$ and $\mathrm{N}_{2} \mathrm{O}$ flux measurement is recommended, based on the relevance and contribution of $\mathrm{CH}_{4}$ and $\mathrm{N}_{2} \mathrm{O}$ fluxes to the site-based greenhouse gas balance. For ICOS ecosystem Class 1 Stations, flux measurements of $\mathrm{CH}_{4}$ and $\mathrm{N}_{2} \mathrm{O}$ by both $\mathrm{EC}$ and automated chamber methods are required, unless it is demonstrated (e.g. by means of short-term campaigns) that these fluxes are not relevant for the site. As an example, a station that does not measure $\mathrm{N}_{2} \mathrm{O}$ fluxes would be eligible of being a Class 1 Station, if it can be proven that $\mathrm{N}_{2} \mathrm{O}$ fluxes are negligibly small for that site, e.g. by means of shorter-term manual chamber campaigns. Up to now, "not relevant" and "negligibly small" were still to be defined. We recommend that for the application of EC methods to $\mathrm{CH}_{4}$ and $\mathrm{N}_{2} \mathrm{O}$ the following criteria should be considered:

1. The detection limit of current gas analysers: here the basis should not be the performance of the most sensitive analyser under laboratory conditions, but the reasonably maintainable performance of the latest generation of flux analysers that can be expected under field conditions. The quantification of the precision should include the additional uncertainty introduced by the conversion to dry mole fraction.

2. The relative contribution of the $\mathrm{CH}_{4}$ and $\mathrm{N}_{2} \mathrm{O}$ flux to the total atmospheric GHG budget at the site.

3. The relevance of the magnitude of the fluxes from the ecosystem type to the global terrestrial $\mathrm{CH}_{4}$ and $\mathrm{N}_{2} \mathrm{O}$ budgets.

4. Comparative merits with the alternative chamber method.

The random flux error and therefore the flux detection limit is determined by instrument noise (and its interplay with turbulence) as well as by random geophysical variability. Whilst for $\mathrm{CO}_{2}$ the latter dominates in most conditions, this is not necessarily true for $\mathrm{CH}_{4}$ and $\mathrm{N}_{2} \mathrm{O}$. Thus, the flux detection limit depends on the precision of the concentration measurement, but also on the turbulence and site characteristics. The random error due to instrument noise can be approximated as (Mauder et al., 2013):

$$
R E=\sqrt{\frac{\left(\sigma_{\mathrm{C}}^{\text {noise }}\right)^{2} \sigma_{w}^{2}}{N}},
$$

where: $\sigma_{c}^{\text {noise }}$ is the instrument noise, $\sigma_{w}$ is the standard deviation of the vertical wind component and $N$ is the number of (e.g. 10-Hz) data points the flux calculation is based on (typically 18000 for a 30-min averaging period of 10-Hz data).

For $\mathrm{N}_{2} \mathrm{O}$ it is estimated that an annual flux of $0.5 \mathrm{~kg}$ $\mathrm{N}_{2} \mathrm{O}-\mathrm{N} \mathrm{ha}^{-1} \mathrm{y}^{-1}$ is quantifiable by EC using the latest generation of QCL based instruments. Assuming a situation where $80 \%$ of the annual emission occurs during 2 weeks, the average background flux during the remainder of the year would then equate to $0.024 \mathrm{nmol} \mathrm{m}^{-2} \mathrm{~s}^{-1}$, whilst the average flux during the high emission period would be $2.4 \mathrm{nmol} \mathrm{m}^{-2} \mathrm{~s}^{-1}$.

This estimate comes from the first available long-term flux measurement datasets from managed crops and grassland measured with this technology (e.g. Huang et al., 2014; as well as unpublished datasets obtained by the authors; Merbold et al., 2014) and is also consistent with the detection limit reported during field deployments. Based on an intercomparison study carried out during the Integrated non- $\mathrm{CO}_{2}$ Greenhouse gas Observing System (InGOS) project, Nemitz et al. (2018) reported differences in standard deviations of flux values derived in the field were about twice the value reported by the manufacturers. A real-world precision of $1 \mathrm{nmol} \mathrm{mol}^{-1}$ is maintainable by several currently available $\mathrm{N}_{2} \mathrm{O}$ instruments (Rannik et al., 2015; Nemitz et al., 2019). Given a typical range of $u_{*}$ values of 0.15 to $1 \mathrm{~m} \mathrm{~s}^{-1}$ and a ratio of $\sigma_{w} / u_{*}=1.29$ under neutral conditions, this $u_{*}$ range equates to a limit of detection due to instrument noise $(L O D=3 \times$ relative error $(\mathrm{RE}))$ of 0.20 to 0.84 $\mathrm{nmol} \mathrm{m} \mathrm{m}^{-2} \mathrm{~s}^{-1}$. This is clearly adequate for quantifying the $\mathrm{N}_{2} \mathrm{O}$ flux estimated during high flux periods. In addition, if care is taken in the setup, operation and processing of the data, REs become smaller if small flux measurements are averaged according to time or another parameter, by $1 / J_{n}$, where $n$ is the number of 30-min fluxes that are being averaged (Langford et al., 2015). Thus, the detection limit of the estimated background flux is approached for averaging periods of 1.4 to 25.5 days, depending on $u_{*}$, and certainly for monthly values. To achieve this an RMS of $1 \mathrm{nmol} \mathrm{mol}^{-1}$ needs to be maintained under field conditions.

For $\mathrm{CH}_{4}$, fluxes tend to have a less episodic annual pattern than those of $\mathrm{N}_{2} \mathrm{O}$. To evaluate which magnitude may be relevant at the global scale, the average global wetland $\mathrm{CH}_{4}$ emission can, as an example, be estimated from the global $\mathrm{CH}_{4}$ emission $\left(200 \mathrm{Tg} \mathrm{CH}_{4} \mathrm{y}^{-1}\right.$; IPCC (2013)) and wetland area $\left(5 \times 10^{12} \mathrm{~m}^{2}\right.$; Matthews and Fung (1987)) as $34 \mathrm{~g}$ $\mathrm{CH}_{4}-\mathrm{C} \mathrm{y}^{-1}$ (equivalent to $90 \mathrm{nmol} \mathrm{m} \mathrm{m}^{-2} \mathrm{~s}^{-1}$ ). Nevertheless, a low flux that is still deemed relevant at the global scale is the winter emission background flux from northern wetlands, which is typically around $7 \mathrm{nmol} \mathrm{m}^{-2} \mathrm{~s}^{-1}$ (equivalent to $2.6 \mathrm{~g} \mathrm{CH}_{4}-\mathrm{C} \mathrm{m}^{-2} \mathrm{y}^{-1}$ ) (Rinne et al., 2007). To achieve a 30-min flux LOD of these lower values, the instrument 
precision needs to be in the range 8 to $35 \mathrm{ppb}$, depending on $u_{*}$. Indeed, a real-world precision of $10 \mathrm{ppb}$ is attainable by several instruments. Thus, EC measurements are deemed suitable to measure annual emission budgets of $2.5 \mathrm{~g} \mathrm{CH}_{4}-\mathrm{C} \mathrm{m}^{-2} \mathrm{y}^{-1}$ and for this real-world analyser a precision of at least $10 \mathrm{nmol} \mathrm{mol}^{-1}$ needs to be maintained.

\section{Other instrument criteria}

In addition to these criteria, the gas analyser must have an internal water measurement for water corrections to be applied accurately. Most commercially available closedpath instruments now correct for $\mathrm{H}_{2} \mathrm{O}$ and provide dry mole fraction of $\mathrm{CH}_{4}$ and $\mathrm{N}_{2} \mathrm{O}$. Some of the older instruments that do not report $\mathrm{H}_{2} \mathrm{O}$ can be upgraded at reasonable cost. The TGA200A of Campbell Scientific does not provide an internal $\mathrm{H}_{2} \mathrm{O}$ measurement and therefore does not meet the requirements of ICOS Class 1 stations. The instruments should be capable of measuring over the concentration ranges summarised in Table 4.

Table 4. Measured variables, their units, physical range and required precision

\begin{tabular}{lll}
\hline Variable (SI Unit) & Physical range & RMS at $10 \mathrm{~Hz}$ \\
\hline $\mathrm{CH}_{4}\left(\mathrm{nmol} \mathrm{CH}_{4} \mathrm{~mol}^{-1}\right)$ & & \\
$\begin{array}{l}\text { Dry } \\
\text { mole } \\
\text { fraction }\end{array}$ & $\begin{array}{l}\text { 1600-10000 } \\
\text { (up to } 500000 \quad\end{array}$ \\
$\begin{array}{l}\text { at landfill } \\
\text { sites) }\end{array}$ & $\leq 10$ \\
$\mathrm{~N}_{2} \mathrm{O}\left(\mathrm{nmol} \mathrm{N}_{2} \mathrm{O} \mathrm{mol}^{-1}\right)$ & & \\
$\begin{array}{l}\text { Dry } \\
\text { mole } \\
\text { fraction }\end{array}$ & $290-5000 \quad \leq 1$ \\
\hline
\end{tabular}

The analyser should further a priori be capable of providing high data capture of, e.g., $>90 \%$, and any data gaps should be uncorrelated with meteorology. Thus, the planned use of the analyser for calibrations, performance tests etc. should not exceed $10 \%$ of the time nor occur during potential high flux periods. As will become apparent later in this protocol, the data processing and quality control for small fluxes is greatly facilitated if the instruments also measure larger fluxes of another compound. Thus, in particular for $\mathrm{N}_{2} \mathrm{O}$, for which fluxes can be small for extensive periods, it helps greatly to use a combined $\mathrm{N}_{2} \mathrm{O}-\mathrm{CO}_{2}$ instrument. However, where $\mathrm{CO}$ or $\mathrm{CH}_{4}$ fluxes are consistently large, combined $\mathrm{N}_{2} \mathrm{O}-\mathrm{CO}$ and $\mathrm{N}_{2} \mathrm{O}-\mathrm{CH}_{4}$ analysers, respectively, can similarly facilitate the data analysis.

At the time of writing only closed-path analysers fulfil the requirements set out above.

\section{Instrument setup for closed-path analyser eddy covariance systems}

Closed-path sensors are currently the only choice for building a non- $\mathrm{CO}_{2}$ GHG EC system that fulfils the requirements set out in the previous section. Through the setup of the closed-path analyser, high-frequency concentration attenuation takes place. It is the goal of this section to describe a setup of such an EC system that minimises the high-frequency flux losses as efficiently as possible for long-term flux applications.

Although analysers listed in Table 2 are capable of measuring gas concentrations with a temporal resolution of up to $10 \mathrm{~Hz}$, several reasons like air mixing through the gas sampling system and/or the separation between sample air inlet and the centre of the sonic anemometer's transducer array usually lead to attenuation of high-frequency fluctuations and time delays between the concentration signal and the wind measurement. A robust setup seeks to minimise the flux loss, whilst, at the same time, trying to establish the predictable behaviour of the system that allows correction with automated standard methods (see below). For this, the spectral attenuation caused by the sampling system configuration needs to be determined and kept in an acceptable range under long-term use. A maximum of 30\% correction compared to a reference model spectrum under neutral conditions is acceptable. This requirement needs to be guaranteed through the interaction and relation of system parameters such as pump size, flow rate, tube diameter (which jointly dictate the Reynolds number), inlet mounting position, filter dimensions etc.

Relative position of the tube inlet and the sonic path

The current closed-path, non- $\mathrm{CO}_{2}$ GHG analysers are sensitive to temperature fluctuations in the environment and are relatively bulky. This is why, unlike $\mathrm{CO}_{2} / \mathrm{H}_{2} \mathrm{O}$ sensors, they can generally not be placed on a tower. Thus, compared with the recommended ICOS $\mathrm{CO}_{2} / \mathrm{H}_{2} \mathrm{O}$ analyser setup which is described in a companion paper of this issue, closed-path non- $\mathrm{CO}_{2}$ GHG EC systems have inevitably longer inlet tubes. Current closed-path laser devices have voluminous sample cells that require a large sampling flow, and the usually low pressure in the sample cell requires powerful pumps. Altogether, this makes the task of reducing the high-frequency damping of an EC system much more challenging compared with the $\mathrm{CO}_{2} / \mathrm{H}_{2} \mathrm{O}$ EC system.

The position of the inlet represents a compromise: it should be as close as possible to the sonic path while minimising perturbations of the micro-turbulence between the sonic transducers. The relative position also affects the system's time response. Different parameterisations of transfer functions suggest that the system cut-off frequency may depend on various factors such as lateral separation between sensors, atmospheric stability, wind velocity and direction that have been described by Moore (1986), Kristensen et al. (1997), and Horst and Lenschow (2009). 
If good practice is followed, inlet characteristics can be achieved that capture most of the frequencies that carry the vertical flux, given that a relatively small flux component is carried by frequencies $>5 \mathrm{~Hz}$ for most wind velocity conditions (Moore, 1986). The ICOS guidance is to share the position of the inlet of the IRGA, with the default sampling point being the end of the horizontal boom of the Gill HS ultrasonic anemometer as outlined in the protocol for the ICOS flux station setup of this issue. If the inlet flow for the $\mathrm{N}_{2} \mathrm{O} / \mathrm{CH}_{4}$ analyser(s) is particularly high (>20 lpm), it may be more appropriate to increase horizontal displacement by another $10 \mathrm{~cm}$ or so. The inlet should be kept as compact as possible.

\section{Features of the gas sampling system}

The sample air is transported through the gas sampling system to the analyser cell. Generally, a number of principles have to be considered to operate a system that ensures gas concentration measurements of highest possible quality. These principles - though being hardly compatible - are a minimisation of:

- the high-frequency attenuation of the concentration measurement,

- the cell contaminations with particles,

- pump-induced pressure fluctuations,

- air flow perturbation around the anemometer head caused by the tube,

- large temperature differences between the air sample and the instrument's optics that could lead to erroneous analyser readings,

- $\mathrm{H}_{2} \mathrm{O}$ effects on sample concentration,

- temperature fluctuations of the analyser.

To meet the constraints outlined above, adjustments to pump, tube, filter, temperature-controlled housing, etc. have to be made and are described in the following sections.

\section{Inlet dryer}

It is a requirement for the gas analyser to measure $\mathrm{H}_{2} \mathrm{O}$ internally so that accurate corrections can be performed. An additional inlet dryer adds complexity and can deteriorate the system response time, so is not generally recommended. However, where non- $\mathrm{CO}_{2}$ fluxes are very small and latent heat fluxes large, such dryers can be used as an option to improve the flux detection limit (see Results and Discussion below) and need not remove $100 \%$ of the $\mathrm{H}_{2} \mathrm{O}$ to improve the flux detection limit. In such situation, a high-flow Nafion dryer can be used, which can be pumped by the same vacuum pump used for the measurement cell. Here, the integrity of the dryer needs to be monitored continuously through the internal $\mathrm{H}_{2} \mathrm{O}$ measurement.

General layout, pump and system dimensioning

From upstream to downstream, the gas sampling system consists of a rain cap with bug screen, an overflow solenoid valve to provide a reference gas (reference gas overflow inlet, RGOI), a filter or set of filters, a sampling tube, the dryer (if present, see previous section), a flow and pressure sensor, the gas analyser, possibly another filter, and a pump. After passing the pump, the sample air is returned to the outside air through an exhaust (Fig. 1). Rain cap, filter and tube induce a pressure drop depending on their characteristics and on the flow rate. However, most analysers only operate over a limited pressure range. The user has to make sure that rain cap, filter, and tube fulfil the specifications given below and the given pressure regime. For current instruments, drying of the air sample is not required.

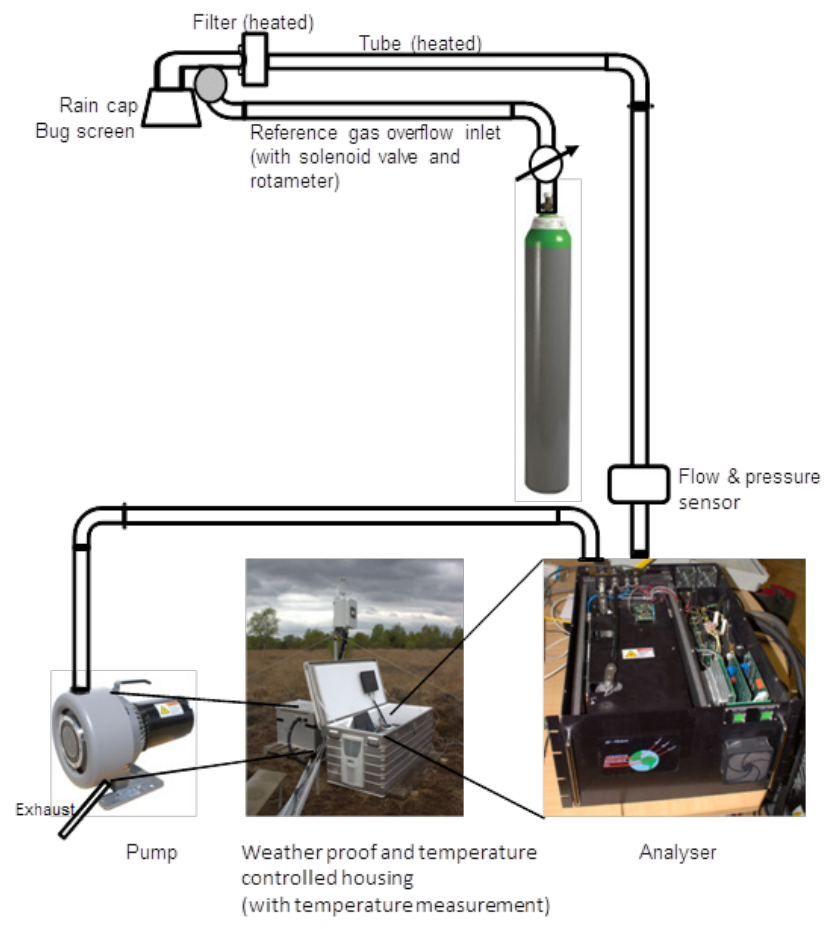

Fig. 1. Sketch of the gas sampling system.

Furthermore, dimensioning of the sampling system and pump has to meet the following specification:

- The gas filling the sampling cell under operation should at least be exchanged 10 times per seconds, i.e. the cell turn-over time $\left(\tau_{\text {cell }}\right)$ should be $<100 \mathrm{~ms}$.

- A filter and tube cut-off frequency should be as high as possible (ideally above $10 \mathrm{~Hz}$ ). This also implies that the flow must be turbulent in all sections of the inlet. The guiding principle here is that maximum flux attenuation under neutral conditions of the entire sampling system (incl. analyser) should not exceed $30 \%$.

Reference gas overflow inlet (RGOI)

A normally-closed solenoid valve (or similar) needs to be installed at/near the tube inlet for a reference gas, through which a reference gas can be injected into the inlet via a T-piece, at a flow just higher than the regular sample flow at regular intervals (see section on instrument calibration below). This reference gas should be of a concentration 
distinct of the ambient concentration, but well within the range of the analyser. This can either be an elevated mixture of $\mathrm{CH}_{4}$ and/or $\mathrm{N}_{2} \mathrm{O}$ in air or $\mathrm{N}_{2}$ (e.g. at roughly 2500 and $500 \mathrm{ppb}$, respectively) and, as long as it fulfils these requirements, the mixture does not need to be calibrated or certified. Alternatively, in many cases a cheap industrial compressed air cylinder can be found that contains slightly elevated concentrations. The flow through the solenoid inlet should be adjusted (e.g. via a rotameter) to be just (e.g. $10 \%$ ) above the highest flow rate expected through the inlet. Care needs to be taken that, when activated, the sample line pressure is close to normal to avoid pressure fluctuations in the analyser. The reference gas should be applied for 5-min, to assess the inlet response time and time-lag every three days (see below). It should further be activated for a 30-min period at least every month to assess the instrument stability in terms of instrumental noise and low-frequency drifts. For a system running at $15 \mathrm{lpm}$ with this scheme a $10 \mathrm{~m}^{3}$ cylinder will last for just over 8 months.

\section{Pump}

The pump must be strong enough to provide the designated flow rate in order to maintain at least 10 cell renewals per second. The cell turn-over time $\left(\tau_{\text {cell }}\right)$ for a given flow can be estimated as:

$$
\tau_{\text {cell }}=V_{\text {cell }} / q_{\text {inlet }} p_{\text {cell }} / p_{0,}
$$

where: $V_{\text {cell }}$ is the cell volume $\left(\mathrm{cm}^{3}\right), q_{\text {inlet }}$ is the inlet mass flow in standard $\mathrm{cm}^{3} \mathrm{~s}^{-1}$, and $p_{\text {cell }}$ and $p_{0}$ are cell and standard $(101.25 \mathrm{kPa})$ pressure, respectively. This $\tau_{\text {cell }}$ is equivalent to the e-folding time of the system and thus describes a $63 \%$ response. The $95 \%$ response time $\left(\tau_{95}\right)$ is three times longer. Pump capacity must significantly exceed the nominal flow rate selected for the system to lengthen pump longevity and to establish low pressures in the cell. If the cell volume is for example $0.5 \mathrm{~L}$ and the cell pressure $\sim 40$ Torr as is the case for Aerodyne's mini-QCL (Aerodyne Research Inc. Billerica, MA, USA), this implies that the flow rate has to be adjusted to at least 12-15 standard $\mathrm{L} \mathrm{min}^{-1}$.

Robustness and durability of the pump are fundamental. Brushless pumps have been identified as a suitable option for continuous operation due to their reliable endurance. At the time of writing, the model 'Agilent Varian TriScroll 600 Oil-Free Dry Scroll Vacuum Pump', the Edwards xi35i and the Busch (Fossa) FO0035 represent viable options and are widely used in the community. Screw pumps (e.g. Ebara) have started to be used, but information on longevity is more limited. If the pump is placed in a small box/ housing, it should further be ventilated to avoid overheating or condensation inside that box. On the contrary, the pumps also need to be protected from too low temperatures. Usually operating pumps heat themselves and their environment. But, in the absence of another source of heating, there is the potential danger of permanent pump damage should the pump stop for some reason.

\section{Monitoring of inlet flow (flow rate and pressure)}

Active flow control adds complexity to the system and the use of mass flow controllers (MFCs) introduce an additional pressure drop that would need to be compensated for through the use of an even larger pump unless a MFC with very low pressure drop is used. However, in order to provide quality control on how the physical time-lag may change with time, pressure and flow in the sampling line needs to be measured and digitally recorded with a low pressure drop flow meter, placed in the sampling line just upstream of the gas analyser. For this a model is needed that monitors flow, temperature and pressure to allow conversion from mass to volumetric flow. Suitable models include, e.g., the Mass Flowmeter 40xx and 41xx series (TSI Inc.). Data should be recorded digitally at $30 \mathrm{~s}$ resolution.

\section{Tube}

Tube length should be kept to a minimum, but is usually dictated by the vegetation type/height and the respective tower/cabinet configuration. Tube diameters should be chosen to optimise the interplay between pump size, filter, tube length and line pressure to assure the designated flow and cell renewal rate (Eq. (2)) at an inlet pressure the analyser can operate at, whilst maintaining turbulent flow. As a guide, the inner diameter of the tube should typically be in the range of 4 to $6 \mathrm{~mm}$, except for very long tubes (e.g. $>40 \mathrm{~m})$. Users are asked to thoroughly calculate the anticipated tube Reynolds number (Re) under the chosen system parameters to check whether the air flow inside all significant parts of the tube is turbulent $(\operatorname{Re}>2600)$; conditions along long tubes change considerably and the flow needs to be turbulent everywhere. Tube material should be as inert as possible with respect to $\mathrm{CH}_{4}$ and $\mathrm{N}_{2} \mathrm{O}$, thus it is recommended to use Dekabon/Synflex tubing. Turns and dead volumes tend to induce high-frequency losses and should be avoided. The entire inlet tube together with the filter should be heated to prevent condensation. This can be done either by lagging the tube together with some heating tape. If a dryer is used, the flow section downstream of the dryer does not need to be heated.

\section{Filter}

In principle, the same conditions apply as for the infrared gas analyser (IRGA) that measure $\mathrm{CO}_{2}$ and $\mathrm{H}_{2} \mathrm{O}$. As shown in Fig. 1, a filter should be placed in the sample tube 30 to $100 \mathrm{~cm}$ downstream of the bug screen, to avoid large particles penetrating into the gas sampling system whilst minimising flow distortions by the filter. Otherwise, it will be necessary to replace the inlet line more often. Additionally, it is necessary to heat the filter (with a heating power of $\sim 4 \mathrm{~W} \mathrm{~m}^{-2}$ ) by including it into the heating envelope, to prevent it from developing a high resistance in humid conditions. The filter must be changed regularly, depending on local environmental conditions. Digital 
monitoring of cell pressure (as is done by most commonly used analysers) as well as inlet pressure and flow rate help finding the right intervals for filter exchange.

It is recommended to use a Swagelok FW $2 \mu \mathrm{m}$ pore diameter filter. However, this may not be appropriate for all setups. Different analysers require different degrees of filtering: the Picarro analyser (Table 2) uses a small sample cell with a relatively low flow which gets dirty less easily compared with other analysers. The Aerodyne range of QCL based analysers are sensitive to contamination and here a second, $0.5 \mathrm{~mm}$ filter just before the instrument may be advisable. Because they work at relatively low cell pressure (typically $\sim 40$ Torr), they can cope with low pressure and restrictions in the inlet line relatively well. Automatic pressure control offered by some Aerodyne instruments should not be used.

Some early LGR analysers proved to be sensitive to contamination which caused problems at some stations. According to the manufacturer, more recent instruments should not suffer this problem and mirrors can be cleaned by the user as necessary. The LGR instruments can only control their cell pressure over a limited range and a manual valve is used to bring the pressure into the controllable range, which also dictates a minimum inlet pressure the instrument can cope with using the standard high-flow orifice, which is higher than for the Picarro and Aerodyne analysers. Therefore, a Swagelok FW $2 \mathrm{~mm}$ filter may not be appropriate. Low-pressure depth filters such as the Advantec PTFE Depth Filter PF020 boast a much-reduced pressure drop and increase service intervals. During operation, gradual clogging of the filter can result in changes in the inlet pressure which cause the analyser pressure to move out of the analyser-controllable range, requiring readjustment of the manual valve. This needs to be monitored carefully.

Rain cap and bug screen

Regarding rain cap and bug screen, the same conditions apply as for the setup of the $\mathrm{CO}_{2}$ infrared gas analyser described in the flux station setup paper of this issue. The installation is necessary at the tube inlet to avoid filter clogging by raindrops, small bugs or coarse dust particles. The size of the cap must be kept small $\left(<5 \mathrm{~cm}^{3}\right)$ to avoid interference with the natural micro-turbulence in the sonic anemometer path and avoid dead volume. The tube inside cap and bug screen should have the same diameter as the main tube. Turns and dead volume inside the rain cap should be kept to a minimum as they induce additional pressure drops and high-frequency losses. Both rain cap and bug screen need to be cleaned regularly to avoid reductions in the inlet flow (see below).

\section{Temperature-controlled housing}

The closed-path GHG analyser needs to be stored in a temperature-controlled housing. This can be a thermoinsulated box, a small trailer, a hut or any kind of robust housing that is able to prevent large temperature fluctuations, as some analysers are highly sensitive towards sudden temperature changes. Whilst the Picarro and LGR EP analysers have tighter control, the LGR non-EP series analysers and the Aerodyne QCL instruments require tighter control of the cabin temperature and fast changes in temperature should be avoided. It is mandatory that temperature changes in one half-hour must not exceed $2 \mathrm{~K}$ regardless of season and other site conditions. This tends to be the easier the larger the enclosure, but small enclosures may be required to minimise inlet line length and fetch obstruction, especially when measuring on short towers. In this case, it helps for the cooling air to be diffused around the enclosure rather than directed at the instruments, e.g. through the use of internal enclosure baffle. The enclosure temperature needs to be monitored and recorded at a time resolution of at least every $30 \mathrm{~s}$ and a measurement resolution of $0.1 \mathrm{~K}$.

\section{Calibration and maintenance of closed-path analyser eddy covariance systems}

The gas sampling system consists of several parts each requiring its own maintenance scheme. Maintenance of each separate item is particularly important since malfunction of either can lead to erroneous measurements. Maintenance of each sub-system is described in the following sections and the timing is compiled in Table 5.

\section{Pump}

Vacuum pumps run constantly in order to maintain low pressure in the measurement cell. When using scroll pumps under continuous usage, the Teflon gaskets inside the pump wear out following the manufacturers working hours. While some pumps have working hour counters, others do not. If such counter is not available, it is recommended to replace the gaskets every 14-16 months. This can either be done manually using a servicing kit or by sending the pump to the manufacturer. Following replacement of the gasket, it must be confirmed that the pump returned to similar performance as before. Regular changes of the gaskets avoid a contamination of the cell with Teflon particles following pump failure, which is a common scenario. Alternative a lengthy tube between analyser and pump also avoids back-flushing of debris.

Screw pumps do not require seals and this particular maintenance, but long-term experience is limited.

\section{Flow and pressure meter}

Flow meters should be checked for correct performance on a regular time schedule (every 6 months) against a primary gas flow calibrator (e.g. DryCal, Gilibrator) which itself is within its calibration interval, and also when changes 
Table 5. Calibration and maintenance schedule for closed-path sensor setups

\begin{tabular}{lll}
\hline Task & Interval & Comment \\
\hline Daily checks: & & Instrument specific (see text) \\
Monitor laser spectrometer performance & $\begin{array}{l}\text { Instruments specific; respond to unacceptable } \\
\text { reduction in ringdown time (LGR) or detector range }\end{array}$ & \\
& (Aerodyne); follow manufacturer's recommendations &
\end{tabular}

Weekly checks:

On Picarro analyser: check internal filter performance

Check inlet filter

Inspect rain cap \& bug screen

Empirical assessment of time-lag, response time and

Reference gas cylinder pressure

About annually:

Calibration for reported gases with certified standard

Calibration for $\mathrm{H}_{2} \mathrm{O}$ with dew point generator

Replacement of pump gasket

Service air conditioning of the enclosure

Calibration of flow meter

Maximum intervals for other maintenance:

Replacement of full inlet
Change if cavity pressure 0.1 Torr $<$ setpoint or valve position $<30,000$ units

Change if inlet pressure has dropped or instrument cavity gets contaminated

Clean if visibly dirty and at least every 6 months

Overflow inlet with reference gas for 5 min every 3 days and for 30 min every month

A $10 \mathrm{~m}^{3}$ cylinder should run out after about 8 months
Change inlet upstream of filter at the same time.

This can easily be automated

Annually mandatory

Annually mandatory

Typically 14-16 months, follow manufacturer guidelines

Follow manufacturer's guidelines

6 months, or when readings change unexpectedly

When visibly dirty or changing characteristics, at least every 6 years

in the measurement occur that cannot be associated with changes in inlet characteristics. Continuous operation of the flow controller is crucial to monitor filter, tube performance and flow rate of the gas under observation.

Tube

There is no recorded evidence that tube contamination is a major issue for measuring fluxes of $\mathrm{CH}_{4}$ and $\mathrm{N}_{2} \mathrm{O}$. The less the $\mathrm{H}_{2} \mathrm{O}$ fluctuates as it reaches the analyser, the smaller its effect on the $\mathrm{CH}_{4}$ and $\mathrm{N}_{2} \mathrm{O}$ measurement. Thus, the flux attenuation for $\mathrm{H}_{2} \mathrm{O}$ caused by increased adsorption/desorption reduces the magnitude of the GHG flux correction due to water vapour effects and is in principle helpful. Clearly, contamination to a degree that it can affect the instrument mirrors need to be avoided. Thus, it is recommended to renew the main inlet line at least every six years, but also when visibly dirty or when any of the quality checks indicate a change in performance. Reference gas measurements, flow rate measurements must be performed before and after the tube has been exchanged and noted. Check the system for leaks when the gas sampling set up is exchanged or modified by overflowing the system with zero air at the inlet.

By contrast, the inlet section upstream of the first filter should be replaced with each filter change.

Filter

The conditions apply as for the infrared gas analyser (IRGA) for measuring $\mathrm{CO}_{2}$ and $\mathrm{H}_{2} \mathrm{O}$. The installed Swagelok FW-2 $\mu \mathrm{m}$ pore diameter filter and additional elements can be cleaned numerous times. The recommended cleaning procedure is as follows:

- Use clean filtered compressed air (zero-grade air or ultra-pure nitrogen) to blow out the large particulate matter, around $300 \mathrm{kPa}$ of over-pressure, in the reverse flow direction.

- Place the filter in a sonic bath filled with chemistry grade glassware cleaner. Leave in the bath for about two hours. 
- Flush the filter with distilled water, first in the reverse flow direction and then in the flow direction.

- Use clean compressed air to blow out the large particulate matter, about $200 \mathrm{kPa}$, first in the reverse flow direction and then in the forward direction.

- Rinse again in the sonic bath filled with clean distilled water for one hour and then use clean filtered compressed air to blow out the clean filter, about $300 \mathrm{kPa}$, first in the reverse flow direction and then in the direction of flow. Allow the filter to dry for $24 \mathrm{~h}$ in a clean and dry location.

- Visually inspect the retainer screens on both sides of the filters inlet/outlet for corrosion. If corrosion/rust appears on the retainer screens, discard the filter.

- The filter should also be discarded if there is evidence that it is compromised (e.g. visible contamination of inlet line or degradation of measurement cell characteristics).

For the Picarro analysers, regular maintenance of the additional instrument-internal inlet filters should be performed to ensure adequate flow rates through the system. Filter cleaning becomes necessary when the Cavity pressure drops below 0.1 Torr of the setpoint value and the Inlet Valve Position drops significantly below 30000 digital units.

\section{Rain cap and bug screen}

Both rain cap and bug screen need to be cleaned regularly to minimise the potential for dirt to enter the sampling tubes and avoid reductions in pressure and flow rate in the sampling tube.

\section{Temperature controlled housing}

The air conditioning of the enclosure or cabin needs to be kept in good working conditions following the manufacturer's advice. The temperature sensor that monitors and records the housing temperature needs to be kept in good working order.

\section{Monitoring of the laser absorption spectrometer} performance

In order to operate a laser absorption spectrometer reliably, continuous monitoring of a few internal variables is essential. These include the mirror cleanliness, which can either be done via monitoring of the cavity ringdown time (e.g. LGR), the average detector range (e.g. Aerodyne) or the "baseline loss of the cavity" (Picarro), which is the inverse of the product of ringdown time and the speed of light. The cell pressure also needs to be monitored closely and action taken if it drifts. An overall monitoring of the instruments performance according to manufacturer's recommendations is recommended.

\section{Validation measurements / calibration}

Besides regular monitoring of the system performance and gas sampling sub-units, annual validation measurements of a specific reference gas and a zero reference are mandatory, together with calibration of the $\mathrm{H}_{2} \mathrm{O}$ measurement using a dew point generator. The way calibrations need to be applied to the data differs between manufacturers. The Picarro analysers apply a linear calibration internally which can be changed by the user, by updating a span and intercept value. Similarly, the Los Gatos Research instruments, with a performance specification of less than $+/-1 \%$ total uncertainty, allow the user the option to apply a 1-point calibration which will modify the internal (factory) calibration. The Aerodyne instruments report the concentration that is derived from first principles and do not apply any further calibration to the reported data, although the typical absolute values for $\mathrm{N}_{2} \mathrm{O}$ and $\mathrm{CH}_{4}$ concentration are within $2 \%$ of the actual values in the Aerodyne instruments, approaching the accuracy of the standards available. The water absolute values are typically within 3\% of absolute values. Dealing with all these variations of the various analysers requires the continuous submission of a span and offset correction to the ICOS Ecosystem Thematic Centre (ETC), which need to be applied in post-processing, based on the calibration results. If the internal calibration of the LGR and Picarro instruments is adjusted, the span and offset would be 1 and 0 , respectively.

Span validation measurements should be performed with a known reference gas (e.g. pressurized gas) at two concentrations (one near ambient and one higher). Thereby the pressurized gases have to be calibrated against a highprecision standard (e.g. WMO, NIST, WGAA etc.). The goal is to maintain working span gases that have $1 \%$ accuracy, or better, and are traceable to a known international standard. The high precision calibration gas certificate needs to be provided to the ETC and so do the results of the annual reference measurements.

A two-point calibration with a zero is not generally advised because absorption spectrometers are not normally optimised to detect zero concentration, and the spectral fit can be lost when no absorption peak is found. Where possible, however, the calibration of the zero can be checked with a zero gas which may be synthetic air minus the trace gas of interest, or pure $\mathrm{N}_{2}$. Another approach to receive a zero measurement can be achieved by pumping down the pressure in the sampling cell to measure "nothing" (e.g. Aerodyne).

Calibrations should be performed for all gases reported by the instrument that are submitted to the ICOS database or used in corrections (e.g. $\left.\mathrm{H}_{2} \mathrm{O}\right)$. Special care needs to be taken with calibrations of $\mathrm{CO}_{2}$ based on measurements of the ${ }^{13} \mathrm{CO}_{2}$ isotopologue; the isoptopic abundance of the standard, which may differ greatly from ambient air, needs to be known and taken into account (Brown et al., 2017; Tans et al., 2017).

For the $\mathrm{H}_{2} \mathrm{O}$ calibration, dewpoint generators generally control their own flow and cannot cope with pressure changes on the outlet. Thus, the gas analyser needs to sub-sample from the dewpoint generator outlet flow via a T-piece, which is open to ambient air. 
Based on the annual calibration, measurement drifts in the laser absorption spectrometer can be detected and corrected for. Internal instrument offsets may not be as critical for high-frequency flux measurements, but are problematic and are commonly corrected for internally (e.g. Aerodyne Research Inc.). In addition to the annual calibration, the instrument performance needs to be assessed regularly with the reference gas overflow inlet solenoid valve as detailed above (for 5 min every 3 days; for $30 \mathrm{~min}$, once a month).

\section{Quantification of storage flux}

So far, there is little evidence that the problem of the storage flux quantification for $\mathrm{CH}_{4}$ and $\mathrm{N}_{2} \mathrm{O}$ differs fundamentally from that for $\mathrm{CO}_{2}$.

Storage measurements for non- $\mathrm{CO}_{2}$ gases are mandatory for stations that measure these gases and where the EC system is placed at a height of $4 \mathrm{~m}$ or above. They can be either mandatory or only recommended for tower heights between 2 and $4 \mathrm{~m}$, depending on the relevance of fluxes (tested by estimating the difference between storage fluxes calculated with a single point at the EC level and those calculated with a concentration profile; for details see the ICOS protocol on storage term quantification of this issue). In addition to specifying the minimum number of sampling points according to the EC measurement height and their displacement, ICOS allows for three possible set-ups to sample the concentration profiles.

In the 'separate' scheme (named 'A' in the protocol), concentrations at each inlet (height) are continuously sampled by a dedicated gas analyser. In the 'sequential' scheme (' $\mathrm{B}$ ' in the protocol) a single gas analyser is used to measure the full profile system by the continuous and sequential sampling of each level. Gas concentrations from each inlet are averaged into ad-hoc mixing volumes before being measured. Measurements can be performed for a few minutes across the beginning and the end of the EC averaging period. The 'simultaneous' scheme (' $\mathrm{C}$ ' in the protocol) deploys one single gas analyser to continuously measure air from all the inlets after having been mixed together. Air from individual sampling lines flows into a single mixing volume causing a spatial integration of concentrations. The volume (flow rate) of air sampled from any given height needs to be proportional to the vertical extent of that given layer. Details and technical specification of each sampling scheme are provided in the ICOS protocol on storage term quantification of this issue and the ICOS Ecosystem Instructions. The high cost associated with analysers for $\mathrm{CH}_{4}$ and in particular $\mathrm{N}_{2} \mathrm{O}$ makes Scheme $\mathrm{A}$ rather unattractive. Scheme $\mathrm{B}$ and $\mathrm{C}$ are both potential options. The requirement for the analysers used to quantify storage is similar to that of the EC analysers and this in particular also relates to need for an internal $\mathrm{H}_{2} \mathrm{O}$ measurement. However, a response time of $10 \mathrm{~s}$ is sufficient, together with $10 \mathrm{~s}$ detection limits of $1 \mathrm{ppb}$. Because an increasingly larger number of analysers can meet these requirements, this paper does not attempt to provide a complete overview. Some photo-acoustic analyser (e.g. INNOVA Air Tech Instruments, Ballerup, DK) are known to have significant cross-interferences between compounds and these are difficult to eliminate completely (Neftel et al., 2006). Such instruments must be avoided to guarantee the most accurate measurement under all conditions.

In case the sequential sampling scheme is used, one of the inlets of the vertical profile should be placed at the EC system height so that potential sampling biases between the gradient and EC analysers can be corrected for.

\section{Data acquisition}

The compulsory output variables are described here for closed-path and in Appendix 1 for open-path analysers. The standard acquisition frequency is $10 \mathrm{~Hz}$ for EC concentration data and $1 \mathrm{~Hz}$ for other data. For closed-path analysers, the data that should be recorded at EC data frequency include the $\mathrm{CH}_{4}$ dry mole fraction (in nmol mol${ }^{-1}$ ) and/or the $\mathrm{N}_{2} \mathrm{O}$ dry mole fraction $\left(\mathrm{nmol} \mathrm{mol} \mathrm{l}^{-1}\right.$ ) as well as the $\mathrm{H}_{2} \mathrm{O}$ mole fraction $\left(\mathrm{mmol} \mathrm{mol}^{-1}\right)$, together with cell temperature $\left({ }^{\circ} \mathrm{C}\right)$ and cell pressure (Torr).

In addition, a data flag should be included that should differentiate between (i) valid EC data, (ii) valid gradient data, (iii) valid calibration data and (iv) invalid data (e.g. servicing, sensor obstruction). For the recording, the digital data stream from the analysers should be used and a highaccuracy time-stamp should be included that indicates when the measurements were taken. This time-stamp should be consistent with the one used for the recording of the sonic anemometer data to allow precise merging of the datasets during post-processing. If different data acquisition systems are used, these need to stay on the same time-stamp, e.g. using a precision timing protocol (IEEE, 2008). The state of the solenoid valve that forms part of the reference gas overflow inlet needs to be recorded as another flag.

The inlet flow $\left(1 \mathrm{~min}^{-1}\right)$ and pressure $[\mathrm{kPa}]$ should be recorded at a frequency of at least $1 \mathrm{~Hz}$. All relevant diagnostic analyser variables should be recorded and submitted to the ETC, but this can be recorded at a lower frequency and will depend on the instrument. The LGR analysers report various system health parameters and all measured variables that affect the measured gas concentration, as well as the the ringdown time (ms), which is an indicator of mirror reflectivity. If a significant change occurs in this ringdown time (for example, greater than $20 \%$ reduction), the precision of the instrument may be reduced.

The Aerodyne QCL instruments save diagnostics into a different $\left({ }^{*}\right.$.stc) file than the concentrations (*.str) and this includes important control indicators such as the range (the light level detected by the detector), internal valve states, laser temperature and voltage, as well as information on the spectral fit. The number of diagnostics that can be saved on Picarro analysers appears to have increased as the analysers and software have developed. The Picarro 
analyzer stores all relevant diagnostic data within the system file structure. Several important parameters for end users to record are: inlet valve position, outlet valve position, hot box temperature, warm box temperature, cavity temperature and cavity pressure.

It is good practice to duplicate data at the earliest possibility by storing at least two copies of all data (incl. metadata and log books) at two different locations.

\section{Additional measurements to evaluate fluxes of $\mathrm{CH}_{4}$ and $\mathrm{N}_{2} \mathrm{O}$}

There are more factors that control the exchange of $\mathrm{CH}_{4}$ and $\mathrm{N}_{2} \mathrm{O}$ between the surface and the atmosphere than for $\mathrm{CO}_{2}$. Measurements of these additional variables are required both to develop a better process-level understanding of the fluxes, but also to feed any process-oriented or stochastic models used for gap-filling (see below).

The emission of $\mathrm{CH}_{4}$ from anaerobic soil layers into the atmosphere can follow three different pathways: diffusion through the top-soil / water body, ebullition through a water body or plant-mediated transport through the aerenchyma of certain types of plants, by-passing the aerated top soil. The description of some basic variables affecting all these processes - and many of those related to $\mathrm{N}_{2} \mathrm{O}$ emissions too are covered in the ICOS protocols for $\mathrm{CO}_{2}$ of this issue, in particular by those for detailing (i) the description of site, management and lateral flux, (ii) ancillary vegetation measurements and (iii) soil meteorological measurements. Such variables include for instance soil temperature profiles, including soil surface temperature, soil moisture profiles, water table depth and snow depth, as well as livestock density, soil $\mathrm{pH}$ and soil type and bulk density. In addition, whilst water table depth is an easy-to-measure proxy for anaerobic conditions, a direct continuous measurement of redox potential and in particular of oxygen content would be a very useful additional direct measurement to have, bearing in mind that these parameters can be highly variable in space and time (Fiedler et al., 2007). Several $\mathrm{O}_{3}$ commercial sensors suitable for long-term operation are available.

In addition, it is mandatory at stations with significant $\mathrm{CH}_{4}$ emissions to estimate the fraction of open water surfaces in the EC footprint, e.g. by use of the daily images taken by the phenocams where they point into the main footprint direction (see ICOS protocol on phenology assimilation of this issue), supplemented with satellitederived estimates where available. These data are necessary because if $\mathrm{CH}_{4}$ is emitted through a water surface, the control factors are different from those affecting diffusion from a land surface. Based on the mandatory vegetation assessment following the instructions of the ICOS protocol for site characteristics, management and lateral fluxes contained in this issue, the surface fraction covered by plants with aerenchyma, as well as the height of these plants, should be derived, since both variables have a strong link to $\mathrm{CH}_{4}$ emissions via plant-mediated transport.
The respective plant survey must be repeated whenever visual inspection indicates significant changes in vegetation composition or structure. In terms of livestock, it is mandatory to report the number of animals per surface area and their species and age as well as the duration of the grazing season. Because of the movement of animals in relation to the flux footprint, ideally the position of the animals should be recorded, either by camera or individual GPS. It is further necessary to record the animals' age and type, so the analysis can distinguish between bulls, cows, heifers and calves for cattle and ewes and lambs of different ages for sheep, as they differ in food consumption and $\mathrm{CH}_{4}$ emissions. These differences are accounted for in most national greenhouse gas inventories through specific emission factors which need to be verified on the basis of ICOS flux data.

In oxygen-limited environments, microbial decomposition processes prefer alternative electron acceptors $\left(\mathrm{NO}_{3}{ }^{-}\right.$, $\mathrm{Mn}^{4+}, \mathrm{Fe}^{3+}$ and $\mathrm{SO}_{4}{ }^{2-}$ ) over carbon dioxide and therefore the presence of these ions reduces $\mathrm{CH}_{4}$ emissions (Laanbroek, 2010). They may derive from fertilisation, atmospheric deposition or through tidal inputs (Gauci et al., 2004; Gao et al., 2014). Thus measurements of the soil concentration of these ions as well as $\mathrm{NH}_{4}^{+}$provides very useful information for the interpretation of $\mathrm{CH}_{4}$ emissions. Measurements of soil $\mathrm{NO}_{3}{ }^{-}$and $\mathrm{NH}_{4}{ }^{+}$at annual time-scales is therefore mandatory at Class 1 sites where $\mathrm{CH}_{4}$ fluxes are measured, whilst measurements of the other ions is recommended.

For stations located near oil and gas pads and pipelines, it would be useful to record the ethane flux which provides information on $\mathrm{CH}_{4}$ emissions from the system leaks. Detailed information on soil microbial population and activity could be advantageous too, but it will not be mandatory to acquire such data.

The soil processes controlling $\mathrm{N}_{2} \mathrm{O}$ emissions are even more complex than those of $\mathrm{CH}_{4}$, and further additional sources have to be considered. Besides the standard soil environmental variables described in the ICOS protocol for soil meteorological measurements of this issue, which affect the microbial activities related to nitrification and denitrification it is mandatory at stations with $\mathrm{N}_{2} \mathrm{O}$ flux measurements to determine the extractable soil mineral nitrogen in terms of ammonium $\left(\mathrm{NH}_{4}^{+}\right)$and nitrate $\left(\mathrm{NO}_{3}{ }^{-}\right)$ and dissolved organic nitrogen (DON) regularly, certainly at Class 1 sites. For semi-natural vegetation annual sampling is sufficient, whilst for agricultural systems sampling of $\mathrm{NH}_{4}{ }^{+}$and $\mathrm{NO}_{3}{ }^{-}$should be conducted every 1-2 months and more frequently (i.e. daily/weekly) after management interventions whilst fluxes remain large and variable. The spatial sampling strategy should follow that for $\mathrm{C}$ concentrations. For cropland stations this should be done every month and additionally every two days after management activities (fertiliser application, ploughing, irrigation and other disturbances as reported according to the protocol for site characteristics, management, disturbance and lateral fluxes (this issue)), whereas at (semi-)natural sites 
it is sufficient to measure soil mineral nitrogen every six months. The station PIs are encouraged to collect as many of the ancillary parameters listed in the NitroEurope Sampling and Chemical Analysis Cookbook (NitroEurope, 2007) as possible in order to facilitate a robust interpretation of the measured turbulent fluxes. Particularly relevant for explaining the expected large variability of $\mathrm{N}_{2} \mathrm{O}$ fluxes are the parameters described in the following paragraph.

The nitrogen input through fertilizer application must be quantified for all fertilizing events. For mineral fertilisers, this information can be derived from the fertiliser's chemical composition that needs to be reported anyway according to the ICOS protocol that covers site management. In addition, also the $\mathrm{N}$ content of organic fertilisers (slurry, manure) must be reported, a measurement not currently covered by the other protocols. Ideally, the input of atmospheric $\mathrm{N}$ should also be estimated, at least where atmospheric $\mathrm{N}$ can reasonably be expected to make a significant or even the dominant contribution to the total $\mathrm{N}$ input. The quantity easiest to measure is the wet or bulk deposition. Where measurements are available from a nearby (within $100 \mathrm{~km}$ ) measurement station (e.g. from the EMEP programme), these should be submitted to the database if possible. For new measurements, monthly bulk deposition is probably more realistic to measure than event-based wet deposition. Dry deposition of relevant $\mathrm{N}$ compounds (normally gas-phase $\mathrm{NH}_{3}, \mathrm{HNO}_{3}$ and $\mathrm{NO}_{2}$ as well as aerosol $\mathrm{NH}_{4}^{+}$and $\mathrm{NO}_{3}{ }^{-}$) makes a significant contribution to total $\mathrm{N}$ deposition, especially to semi-natural vegetation in areas subject to high $\mathrm{NH}_{3}$ concentrations and their measurement is encouraged. A first estimate can be derived from measured air concentrations using inferential modelling approaches (Flechard et al., 2010).

\section{Data processing and uncertainty estimation}

Overall, data processing of $\mathrm{EC}$ data for $\mathrm{CH}_{4}$ and $\mathrm{N}_{2} \mathrm{O}$ follows the practices developed for $\mathrm{CO}_{2}$. This is described in the eddy-covariance data processing protocol (ECDPP) contained in this issue, together, together with graphical illustrations of the overall work flow. However, there are some important additional considerations. Firstly, the use of closed-path analysers for these non- $\mathrm{CO}_{2}$ compounds is likely to result in longer time-lags than for the ICOS $\mathrm{CO}_{2}$ IRGA setup, and these need to be determined accurately. Secondly, small fluxes need to be dealt with very carefully. For $\mathrm{CO}_{2}$ both day- and night-time fluxes tend to be above the detection limit, with small fluxes mainly occurring when the net flux changes sign. Notable exceptions include measurements over snow and ice as well as water bodies, where $\mathrm{CO}_{2}$ fluxes can be small for extended periods. As a consequence, the random error of the $\mathrm{CO}_{2}$ flux measurement is almost always dominated by the uncertainty in single-point measurements capturing the geospatial variability in turbulence. By contrast, fluxes of $\mathrm{CH}_{4}$ and, in particular, of $\mathrm{N}_{2} \mathrm{O}$ can be small over extended periods even over surfaces were annual fluxes are consid- ered important. In addition, reflecting the much smaller concentrations, instrument noise makes an important contribution to the random error. There is significant potential for the systematic removal of small fluxes to bias overall results. Also, gap-filling strategies are not straightforward (see below). Therefore, the following peculiarities need to be considered:

- All fluxes should be reported together with their random error. In particular, fluxes below the detection limit should be included in the reported data, together with the random error, and flagged.

- The processing should not introduce a systematic bias on small fluxes which, individually, are below the detection limit.

- For flux measurements near or below the detection limit, it is difficult to estimate certain parameters required during the processing from the flux data themselves. This includes instrument response time, time-lags and degree of stationarity. This may be the case over extensive periods of time. Processing of these data needs to follow a distinct protocol, where other, independent, means are used to provide accurate estimates for these parameters.

The following additional requirements are designed to address these peculiarities.

\section{Raw data filtering based on diagnostics / data ranges}

Some sensors stop measuring during certain phases of data processing and storage. Affected periods must be identified and the raw data flagged and excluded from the flux calculation. In addition, most analysers provide diagnostic values of the signal absorption from which the mixing ratios are derived. These should be recorded at the frequency at which they are provided by the instrument (see above). Signal deterioration is typically linked to the mirrors in the optical cell getting increasingly contaminated, but can also indicate ageing of the laser or detector. Follow the manufacturer's instructions and criteria to judge data validity and flag a 30-min flux averaging period as unreliable if it includes questionable data. For example:

1. In the LGR off-axis analysers, a $20 \%$ decrease in the mirror ring-down time can indicate a loss of sensitivity; the cell pressure should be regulated stably at an instrument specific set point (depending on the model, somewhere between 40 and 140 Torr).

2. Although the Picarro fast-response $\mathrm{CO}_{2} / \mathrm{CH}_{4} / \mathrm{H}_{2} \mathrm{O}$ analyser derives concentrations from the relative ring-down times at different wavelengths, it does not provide a direct output of the ring-down time. It does, however, report the baseline loss of the cavity, which is the reciprocal of the product of the ringdown time and the speed of light, which can be used as an indicator of mirror reflectivity. However, due to the use of a nanometre-scale particle filter in the Picarro instruments, contamination is unlikely. 
3. For the Aerodyne analysers, the acceptable range (provided in $\mathrm{mV}$ ) depends on the individual laser. Here a more robust filter criterion is the instrument noise.

Data outside the ranges set out in Table 4 should be flagged as being unreasonable and excluded from the data processing.

Despiking, detrending and calculation of the background signal

The advice on despiking and detrending fundamentally follows the procedure for $\mathrm{CO}_{2}$. For ICOS ecosystem flux data a relatively new method is designated which derives from the assessment of a value against the median absolute deviation (MAD) over the (30-min) flux averaging period. A value is considered a spike if it deviates by more than $10.38 \times$ MAD from its median evaluated over the averaging period. Because for non- $\mathrm{CO}_{2}$ GHGs transient extreme concentration values, e.g., due to animal emissions or ebullition may be real contributors to the flux, it is recommended that, unlike in for the processing of the $\mathrm{CO}_{2}$ fluxes, despiking is only applied to the wind data, but not to the concentration data.

The ECDPP provides a choice of two methods for estimating the background signal: block-averaging (BA) and linear detrending (LD). Either method removes lowfrequency contributions that need to be compensated for, the correction being smaller for BA than LD. For this reason BA is preferred over LD. However, because spectroscopic analysers are known to gradually change characteristics, the raw data need to be inspected regularly for artefacts such as regular patterns, one known example being unacceptable oscillations in response to fluctuations in instrument or ambient temperature. To assess the instrument stability regularly and to allow for automated detection of low-frequency modulations, the overflow valve should be activated to provide a constant reference gas for a 30-minute period every week and the Allan variance should be calculated for these data.

Where slow-response changes are identified to cause near-linear drifts over a time-period of 30-min, LD of the concentration time-series may be the processing option of choice. Where medium frequency patterns (several minutes) are identified their cause (pressure fluctuations, poor tuning of the optics or moving fringes that respond to excessive temperature variations) needs to be rectified. Such data need to be processed using a relatively short (e.g. 5 to $10 \mathrm{~min}$ ) centred running mean average as demonstrated by Mammarella et al. (2010), resulting in large low-frequency loss corrections.

\section{Time lag compensation}

Time-lags can range from $<1 \mathrm{~s}$ for open-path analysers to tens of seconds for closed-path analysers, e.g. where instruments have to be placed in air-conditioned environments at the bottom of forest towers. It is always good practice to try to minimise time-lags, but, in selecting inlet line diameters and pump speeds, the allowed inlet pressure range of the instrument may become a limiting factor (see above).

In any case, the time lag needs to be quantified accurately. If the wrong time-lag is used, fluxes are systematically biased. For $\mathrm{CO}_{2}$ closed-path measurements, the ECDPP recommends identifying recommend identifying the timelag at which the cross-correlation between $w$ and $c$ shows a maximum of the absolute value, i.e. by identifying the position of the peak in the cross-correlation function within a pre-determined window of physically possible time-lags (covariance maximisation method). However, it has been demonstrated that, when processing EC data with low signal to noise ratio, the cross-correlation function is noisier, and here searching for the absolute maximum systematically biases the flux towards larger absolute flux values (Langford et al., 2015). This remains true even if the window of allowed fluxes is small. The high bias that is introduced is correlated with turbulence and can be larger than the low bias introduced by using a somewhat incorrect time-lag determined by independent means. In these situations, the time-lag must be identified as accurately as possible through an independent means. Several approaches are possible:

a) If the same instrument measures the flux of another (reference) compound, which shows a flux clearly above the detection limit, and which is shown to have similar adsorption / desorption characteristics in the inlet line as the target compound (avoid $\mathrm{H}_{2} \mathrm{O}$ !), the time lag for that compound can be applied to the first compound. For example, some $\mathrm{N}_{2} \mathrm{O}$ sensors also measure $\mathrm{CO}_{2}$ or $\mathrm{CO}$, and in the case of combined $\mathrm{CH}_{4} / \mathrm{N}_{2} \mathrm{O}$ analysers, one compound may show a clear time lag whilst the other may not. In particular, the combined $\mathrm{N}_{2} \mathrm{O} / \mathrm{CO}_{2}$ analyser may be a particularly good choice for stations where $\mathrm{CH}_{4}$ fluxes have been demonstrated not to be important.

b) It is possible to derive a relationship between the time-lag and the volumetric flow rate in the inlet tube from those periods when fluxes are large and to use this relationship to estimate the time-lag for the periods when they are small. This is the reason why inlet flow and pressure need to be monitored.

c) From the data taken with the reference gas overflow inlet (RGOI) the time-lag can be established experimentally as the time-delay between switching the solenoid valve and the detection of the associated step change in concentration. This needs to be corrected further for each flux averaging period, for the additional time-lag at the inlet and the theoretical lag associated with the horizontal sensor displacement as a function of wind speed and direction.

Approach (c) requires further testing to judge its robustness in routine and automated application; thus, for the time being, the following multi-step process for selecting the time-lag is recommended: 
1. Calculate the time-lag from the despiked and detrended raw data using the covariance maximisation method for a (relatively relaxed) window of the expected time-lag range. A typical starting window could range from 0.5 $\mathrm{x} \tau_{\text {expected }}$ to $2 \mathrm{x} \tau_{\text {expected, }}$, where $\tau_{\text {expected }}$ is the expected time lag that is calculated from the physical properties of the inlet system (inlet volume and flow rate).

2. Calculate an initial flux limit of detection $(L O D)$ as 3 times the standard error evaluated with Eq. (1). For this an actual estimate of the instrument noise should be used, based on Eq. (3) below.

3. Use the values from those fluxes where the calculated flux (using the covariance maximisation) was above an initial estimate of the $L O D$ and the returned time-lag was not one of the limits of the time-lag window, assess both the frequency distribution and time-series of these time-lags.

4. For the remaining data, select one of the following options (in decreasing preference):

5. If a valid time lag is available from another (reference) gas from the same analyser with similar adsorption / desorption characteristics (not $\mathrm{H}_{2} \mathrm{O}$ !), apply that timelag to the target compound. Similar time-lags are usually found for $\mathrm{CH}_{4}, \mathrm{~N}_{2} \mathrm{O}, \mathrm{CO}_{2}$ and $\mathrm{CO}$.

6. If valid time-lags have been identified for other flux measurement periods within 2 days of the target time and if there is no evidence of systematic diurnal variability, derive the time-lag by interpolation.

7. If a recent experimental measurement of the time-lag using the overflow delivery setup is available, apply this.

8. Use the theoretically derived time-lag $\tau_{\text {expected }}$.

As a note of caution, the clock producing the timestep on the Aerodyne instrument was found to drift over a 24-h period (i.e. between synchronisations with a suitable time server) by $<1 \mathrm{~s}$ on recent and several tens of second on older versions of the Aerodyne WinTEL software that runs the Aerodyne QCL based analysers. An update to the most recent software version is therefore strongly recommended. A relative drift between the time-stamps of concentration and wind data needs to be eliminated when imposing an external time-lag.

\section{Quantification of random error}

Recent instrument intercomparison campaigns, using the latest generation of fast-response optical spectrometers for $\mathrm{CH}_{4}$ and $\mathrm{N}_{2} \mathrm{O}$ have revealed that instrument noise is highly variable with time (Peltola et al., 2013, 2014; Rannik et al., 2015; Nemitz et al., 2019). It is therefore important to quantify the instrument error regularly and monitor its evolution with time, to ensure that it is within the limits set out above and to spot deterioration of the instrument.

\section{Quantification of random instrument noise}

The main challenges of measuring $\mathrm{CH}_{4}$ and $\mathrm{N}_{2} \mathrm{O}$ compared to $\mathrm{CO}_{2}$ come from lower signal-to-noise ratio (SNR) due to low fluxes and high instrumental noise. Thus, in order to evaluate the reliability of the data, the instrumental noise needs to be estimated. We define the instrumental noise as the $1-\sigma$ random uncertainty of the $10 \mathrm{~Hz} \mathrm{CH}_{4}$ or $\mathrm{N}_{2} \mathrm{O}$ data. Truly random noise can be estimated readily from the measurements for each 30-min averaging period following the method proposed by Lenschow et al. (2000) (see also Mauder et al. (2013), Peltola et al. (2014) and Langford et al. (2015)). The method relies heavily on the property of random variation that it correlates only with itself and thus, by definition, it contributes to the autocovariance of $\mathrm{CH}_{4}$ or $\mathrm{N}_{2} \mathrm{O}$ time series only at lag 0 . Therefore, the instrumental noise $\left(\sigma_{\mathrm{C}}^{\text {noise }}\right)$ can be estimated as

$$
\left(\sigma_{C}^{\text {noise }}\right)^{2}=f_{c^{\prime} c^{\prime}}(0)-f_{c^{\prime} c^{\prime}}(p \rightarrow 0),
$$

where: $f_{c^{\prime} c^{\prime}}(p)$ is the auto-covariance function at time lag $p$, $f_{c^{\prime} c^{\prime}}(p \rightarrow 0)$ is an extrapolation of the auto-covariance function to lag zero, and $\sigma_{\mathrm{C}}^{\text {noise }}$ is the instrumental noise in ppb. In essence, with this method the variance of $30-\min \mathrm{CH}_{4}$ or $\mathrm{N}_{2} \mathrm{O}$ time series (i.e. $f_{c^{\prime} c^{\prime}}(0)$ ) is divided into two parts: the variance reflecting turbulent mixing processes $\left(f_{c^{\prime} c^{\prime}}(p \rightarrow 0)\right)$ and the variance caused by instrumental noise $\left(\left(\sigma_{\mathrm{C}}^{\text {noise }}\right)^{2}\right)$. A practical solution for estimating $f_{c^{\prime} c^{\prime}}(p \rightarrow 0)$ is the extrapolation of autocovariance values at lags $1 \leq p \leq 5$ to lag 0 . The contribution of this noise to the uncertainty of the covariance can be estimated from $\sigma_{\mathrm{C}}^{\text {noise }}$ according to Eq. (1) (Mauder et al., 2013; Peltola et al., 2014; Langford et al., 2015). This analysis can be implemented in standard data processing routines and should be performed for each 30-min measurement period to track the random noise level of the analysers, which are known to be variable.

\section{Quantification of total instrument noise}

This method only identifies the true random noise as it assumes that correlations between the signals between adjacent (or more distant) data points are due to the structure introduced by turbulence. Optical spectroscopic measurements are often subject to optical effects (e.g. fringes) that change slowly, e.g. in the response of the temperature control of the instrument or wider environment, and can introduce structured noise (Mammarella et al., 2010). This can sometimes be visually seen in the raw data (see above), but it can only be quantified experimentally. We therefore recommend the use of the RGOI for automated measurement of a constant reference gas for $5 \mathrm{~min}$ every three days and for $30 \mathrm{~min}$, every month, at changing times of the day (temperature variations of the environment are likely to be largest during midday) to track overall system performance. The time when reference gas is delivered must be clearly marked by a flag in the recorded time series, which should be saved at the acquisition frequency $($ e.g. $10 \mathrm{~Hz})$. The 
concentration time-series acquired during RGOI activation, and in particular the 30-min weekly time-series, should then be used to perform the Allan variance analysis and to assess the system performance (Mammarella et al., 2010).

\section{Quantification of total random flux error}

Two independent approaches for calculating the total random flux error (i.e. due to instrument noise and stochastic turbulence) are appropriate for the type of instrumentation we are dealing with (Rannik et al. (2016) for a review of all available methods). The first approach, following Finkelstein and Sims (2001) is the one proposed for the other EC fluxes according to the ECDPP of this issue. It is based on the analysis of the auto-covariance function of the instantaneous flux $\left(\varphi=w^{\prime} c^{\prime}=(w-\bar{w})(c-\bar{c})\right)$, normalised by its variance. From this the variance of the covariance (i.e. the relative flux error) can be calculated as:

$$
\sigma_{F}^{2}=\frac{1}{N}\left(\sum_{p=-m}^{m} f_{w, w}(p) f_{c, c}(p)+\sum_{p=-m}^{m} f_{w, c}(p) f_{c, w}(p)\right) .
$$

Here, $f_{w^{\prime} w^{\prime}}$ and $f_{w, c}$ are auto-covariance and cross-covariance terms for atmospheric fluxes, which can be estimated for lag $h$ as:

$$
\begin{aligned}
& f_{w, w}(h)=f_{w, w}(-h)=\frac{1}{N} \sum_{t=1}^{n-h}(w(t)-\bar{w})(w(t+h)-\bar{w}), \\
& f_{w, c}(h)=f_{c, w}(-h)=\frac{1}{N} \sum_{t=1}^{n-h}(w(t)-\bar{w})(c(t+h)-\bar{c}) .
\end{aligned}
$$

Furthermore represents the number of samples large enough to capture the integral timescale (ITS), which can be calculated as:

$$
m=I T S f_{a},
$$

where: $f_{\mathrm{a}}$ is the acquisition frequency. Care needs to be taken of how to estimate the ITS. Often the ITS is derived from the position of the first zero-crossing of the cross-covariance function. However, for concentration time-series subject to large analyser noise, the cross-covariance function can be very noisy and zero-crossings are likely to occur before the ITS is reached. Here, for sake of simplicity, a more conservative approach is used and $m$ is chosen as $m=200 f_{a}$, as proposed by Rannik et al. (2016). It should be noted that Eq. (4) should not be sensitive to the choice of $m$ as long as it is sufficiently large and an overestimate of $m$ is therefore preferable.

The other approach to quantifying the total random flux error is based on the calculation of the root mean square error (RMSE) of the cross-covariance function well away (the minimum distance is again the ITS) from the position of the true time-lag. This follows the modification of Langford et al. (2015) to the approach suggested by Wienhold et al. (1995).

Note that in both cases the errors are calculated on the raw data. Any scaling and spectral correction that is applied to the fluxes after the calculation of the covariances should also be applied to the errors.

\section{Spectral corrections}

Similarly to $\mathrm{CO}_{2}$, turbulent $\mathrm{CH}_{4}$ and $\mathrm{N}_{2} \mathrm{O}$ measurements have to be corrected for spectral attenuation to calculate unbiased fluxes. The EC system acts like a filter in both high and low-frequency ranges. The analytical correction is based on the calculation of different transfer functions (i.e. signal filters) in the frequency domain representing the dampening at both low and high frequencies, characterised by a specific time constant (or response time) or cut-off frequency. The individual contributions from components of the EC system to high-frequency attenuation add up to an integral frequency response at the EC system scale. Given an optimal set-up of the closed-path EC system, the damping of concentration fluctuations in the tube and the gas analyser are clearly the dominating sources for low-pass filtering.

For the estimation of the flux correction factor $F_{\mathrm{a}}$ for a scalar $(s)$ both the co-spectra and the power spectra can be used (Aubinet et al., 2012), an example for using co-spectra being:

$$
F_{a} \approx \frac{\int_{f_{\min }}^{f_{\max }} T F(f) C o_{w s}(f) d f}{\int_{f_{\min }}^{f_{\max }} C o_{w s}(f) d f},
$$

where: $f$ is the natural frequency (i.e. not normalised with the wind speed and measurement height), $C o_{w s}(f)$ is the sitespecific co-spectral model describing the un-attenuated cospectral density of the scalar flux $\overline{w^{\prime} s^{\prime}}$. The $T F=T F_{H} T F_{L}$ is the total transfer function formed as the product of a high pass $\left(T F_{H}\right)$ and low pass $\left(T F_{L}\right)$ transfer function for the scalar measurement. If $T F$ is appropriately determined, this approach estimates an integral transfer function for the whole system, i.e. it includes sensor separation. The disadvantage of this approach is that it relies on the correct determination of the lag time and that the spectral response of the analyser is calculated from a co-spectrum while the wind speed signal does not contain any information on the damping. A more straightforward approach is calculating the sensor separation analytically (Moore, 1986) and the time constant of the analyser from the comparison of the power spectrum of the gas concentration with a reference spectrum, i.e. temperature (see below).

For the correction of variances, the same approach is used based on the power spectra. As the default $T F$ model, we suggest using the first order infinite impulse response filter (Ibrom et al., 2007; Fratini et al., 2012). Note that the spectral transfer function for co-spectra is equal to the square root of that for the power spectra.

\section{Estimation of the site-specific co-spectral model}

The ECDPP identifies the experimental method as the most appropriate approach for correcting gas fluxes measured with closed-path analysers. 
Good power spectra and co-spectra are those measured when fluxes were large and conditions reasonably turbulent:

$$
\begin{aligned}
& H>20 \mathrm{~W} \mathrm{~m}^{-2} \\
& u_{*}>0.2 \mathrm{~m} \mathrm{~s}^{-1}
\end{aligned}
$$

where: $H$ is the sensible heat flux. Assuming that the normalized co-spectrum of all scalars has the same functional form (scalar similarity), the site-specific co-spectral and power spectral models can be estimated using the measured co-spectra of sonic temperature flux or the power spectra of the sonic temperature.

Several analytical formulations exist for the scalar cospectrum model, and here we suggest the ones proposed by Horst (1997), which are based on Kansas co-spectra (Kaimal et al., 1972). In unstable and near-neutral stratification, the $\overline{w^{\prime} \theta^{\prime}}$ co-spectra are clustered in a narrow band (Kaimal and Finnigan, 1994) and the near-neutral formulation of Kaimal et al. (1972) is suitable:

$$
\frac{f C o_{w \theta}(f)}{w^{\prime} \theta^{\prime}}=\left\{\begin{array}{ll}
\left.\frac{\beta_{1} n / n_{0}}{\left(1+\beta_{1} n / n_{0}\right.}\right)^{7 / 4} & \text { for } n \leq 1 \\
\frac{\beta_{3} n / n_{0}}{\left(1+\beta_{4} n / n_{0}\right)^{7 / 3}} & \text { for } n \geq 1
\end{array}\right. \text {, }
$$

where: $\beta_{1}$ to $\beta_{4}$ are the empirical fitting parameters, $n=f(z-d) / U$ is the dimensionless frequency, $z$ the EC measurement level, $d$ the displacement height, $U$ the mean wind speed, and $n_{0}$ is the frequency at which the frequency weighted logarithmic co-spectrum $f \mathrm{Co}_{w \theta}(f)$ attains its maximum value.

For stable stratification, the temperature flux co-spectrum is described by:

$$
\frac{f \operatorname{Co}_{u s}(f)}{\overline{w^{\prime} \theta^{\prime}}}=\frac{\beta_{5} n / n_{0}}{1+\beta_{6}\left(n / n_{0}\right)^{2.1}},
$$

where: again $\beta_{5}$ and $\beta_{6}$ are empirical regression parameters (Horst, 1997).

The peak frequency $n_{0}$ should be broadly constant in unstable stratification, and increases with stability in stable stratification, according to the following equation:

$$
\begin{gathered}
n_{0}=\alpha_{1} \quad \text { for } \zeta \leq 0 \\
n_{0}=\alpha_{1}\left[1+\alpha_{2} \zeta^{\alpha 3}\right] \text { for } \zeta>0
\end{gathered},
$$

where: $L$ is the Obukhov length, and empirical regression parameters.

\section{Estimation of the spectral transfer function}

The spectral transfer function can be derived from purely theoretical considerations (analytical method), i.e. as a convolution of all single transfer functions (Moore, 1986). This requires, however, precise knowledge about all contributions to the low-pass filter characteristics of the EC systems, which are difficult to attain. Therefore, for the GHG flux measurement the empirical method is recommended, where a type of the spectral filter function is prescribed, e.g. a Lorentzian for a first order infinite impulse filter (IIR), and its parameters (e.g. the cut- off frequency) fitted to the filtered and unfiltered power spectrum. For this to be successful, the power spectra need to be normalised and either restricted to the spectral domain where noise can be neglected or the noise must be subtracted from the high-frequency end (for details see Ibrom et al., 2007). The normalisation needs to make sure that the two spectra overlap in the low-frequency domain, where the low-pass filtering is not important. Which frequency domain this is, needs to be carefully examined in an iterative process.

In order to reduce the random uncertainty, the non-linear fit is applied to ensemble averaged power spectra over a period of two weeks of suitably high fluxes. If a continuous period of high enough fluxes does not exist, the time period must be prolonged accordingly. From this database, spectra are bin averaged from those samples that exceed certain flux levels, i.e. at high signal to noise ratios. The recommended conditions are $H>20 \mathrm{~W} \mathrm{~m}^{-2}, u_{*}>0.2 \mathrm{~m} \mathrm{~s}^{-1}, F_{\mathrm{CH}_{4}}>$ $7 \mathrm{nmol} \mathrm{m}^{-2} \mathrm{~s}^{-1}$, and $F_{\mathrm{N}_{2} \mathrm{O}}>1 \mathrm{nmol} \mathrm{m}^{-2} \mathrm{~s}^{-1}$.

If power spectra are used to estimate the $T F$, the flux loss due to the separation between the gas inlet and the sonic anemometer, affecting the cospectral density at high frequency, is not included with this method, then a correction for this effect is done according to Horst and Lenschow (2009), as described in the ECDPP. In an optimal EC set-up the uncertainty introduced by this correction is not critical.

\section{High pass transfer function}

The high pass transfer function depends on the method used to extract the turbulent fluctuation from the measured signals. The analytical forms of $T F_{H}$ can be found in Rannik and Vesala (1999).

After all parameters have been determined, the spectral integrations are performed in order to estimate the correction factor from Eq. (5) for fluxes and a similar equation for variances. For these integrations the stability parameter and the horizontal wind speed are needed to estimate the model co-spectra and power spectra in non-normalised form (i.e. with natural frequency), because both the low-pass and the high-pass filter effects depend on natural frequency as measured by the analyser.

Correction for dilution/expansion and spectroscopic effects in closed-path systems

One of the key advantages of closed-path instruments is that they minimize the need for density corrections by measuring the number density of the target species at a stable temperature $\left(T_{\text {cell }}\right)$ and pressure $\left(P_{\text {cell }}\right)$ within the optical cavity. Since the total number density in the cavity can be derived from $P$ and $T$ using the ideal gas law, these instruments are able to report the mole fraction of the target species by dividing its spectroscopically measured number density by the total number density. Therefore, in the 
absence of $\mathrm{H}_{2} \mathrm{O}$, dry air mole fraction is directly measured without the application of any density corrections during post-processing.

The removal of $\mathrm{H}_{2} \mathrm{O}$ from the sample stream can be accomplished using dryers based on Nafion gas exchangers. This approach has been used but does, of course, add cost, complexity and additional flux loss, and is only recommended as an additional measure, where fluxes are so small that uncertainties in the $\mathrm{H}_{2} \mathrm{O}$ correction become a key limitation.

The mandatory internal $\mathrm{H}_{2} \mathrm{O}$ measurement in the analyser allows a mathematical correction to be applied to convert the measured total mole fraction to dry air mole fraction even in the presence of variable $\mathrm{H}_{2} \mathrm{O}$ concentration. The $\mathrm{H}_{2} \mathrm{O}$ correction is not simply a dilution correction. The presence of $\mathrm{H}_{2} \mathrm{O}$ modifies the spectral line shape of the target species. The correction of the gas concentration measurement must account both for the dilution by $\mathrm{H}_{2} \mathrm{O}$ and for enhanced pressure broadening due to the presence of $\mathrm{H}_{2} \mathrm{O}$ (Rella et al., 2013). The Aerodyne and LGR instruments accomplish this by actually modifying the pressure broadening coefficient used in the spectral fit according to the amount of water present. This correction is robust and pressure independent. Therefore, it is unaffected by any pressure fluctuation or drifts. It is also possible to make empirical analytical corrections to account for the pressure broadening. Some instruments use this approach which implies that the correction factors are derived for a given $P_{\text {cell }}$ and are not expected to be accurate if $P_{\text {cell }}$ drifts.

The accuracy of these $\mathrm{H}_{2} \mathrm{O}$ corrections over time depends on the calibration for $\mathrm{H}_{2} \mathrm{O}$ remaining very stable. Unfortunately, it is difficult to confirm this in the field since $\mathrm{H}_{2} \mathrm{O}$ calibrations are inherently difficult. Therefore, there remains a possibility that small drifts in the $\mathrm{H}_{2} \mathrm{O}$ calibration could lead to imperfect corrections and ultimately to small, false fluxes for the target species which mirror the true water flux. We estimate that this is not likely to be a problem for moderate to large fluxes of $\mathrm{CH}_{4}$ and $\mathrm{N}_{2} \mathrm{O}$ as long as the $\mathrm{H}_{2} \mathrm{O}$ calibration span does not drift by more than 1 or $2 \%$ from the true value. However, even this level of calibration drift could be significant when measuring very low background fluxes over long time periods. We advise taking care when reporting very small fluxes using the mathematical $\mathrm{H}_{2} \mathrm{O}$ correction method. One should take measures to verify that the $\mathrm{H}_{2} \mathrm{O}$ correction is working at the required degree of accuracy.

This requires the annual calibration of the $\mathrm{H}_{2} \mathrm{O}$ signal, using a dew point generator (see above). An alternative when measuring small fluxes over long periods of time is to use the aforementioned Nafion dryer in addition to the mathematical $\mathrm{H}_{2} \mathrm{O}$ correction.

\section{Filtering and gap-filling}

Calculation of QA/QC parameters and flag definitions

Data filtering needs to be applied both on a point-bypoint data on the raw data prior to processing and on the processed fluxes.

\section{Filtering of raw data quality}

The flagging for raw data quality should follow the system developed for the fluxes of $\mathrm{CO}_{2}$ and $\mathrm{H}_{2} \mathrm{O}$, with the following modifications:

1. Raw data points should be removed if they fall outside the physically meaningful range outlined in Table 4.

2. The data flagging needs to account for the time the $\mathrm{CH}_{4} /$ $\mathrm{N}_{2} \mathrm{O}$ analysers are used for the inlet response tests.

3. Instrument diagnostics as appropriate for the various instruments.

4. Data need to be flagged if the wind direction includes obstructed wind sectors.

For each flux measurement, the overall random uncertainty and the random uncertainty due to instrument noise should be reported. In addition, a flag should indicate if a flux is below the $3 \mathrm{~s}$ detection limit and some analysis steps and calculation of QA/QC criteria should be performed conditionally according to that flag.

Stationarity. For fluxes below or even for small fluxes above the detection limit, the normal test for stationarity is not applicable and an assessment of stationarity is therefore problematic. In general, the stationarity should be calculated and reported in analogy with $\mathrm{CO}_{2}$ using the approach of Foken and Wichura (1996), but as with the time-lag procedure, it is suggested to distinguish in its interpretation between small fluxes well above and near the detection limit. For fluxes $\angle L O D=3 \sigma_{F}$ and also for small $\mathrm{N}_{2} \mathrm{O}$ fluxes (e.g. $|F|<0.5 \mathrm{nmol} \mathrm{m}^{-2} \mathrm{~s}^{-1}$ ), the stationarity flag for $\mathrm{CH}_{4}$ or $\mathrm{N}_{2} \mathrm{O}$ should be set to the one derived for $\mathrm{CO}_{2}$. For fluxes $>L O D$, the stationarity test may have some significance. In the specific case of grazed grasslands, movements of cattle in and out of the main footprint area will lead to strong $\mathrm{CH}_{4}$ flux variations within one half-hour. The application of the stationarity test will potentially remove cases with high cattle contributions, as well as ebullition events in the case of wetland studies. It should therefore be avoided. Whether a stationarity criterion is applied in the filtering of the data will depend on the use. Care needs to be taken to erroneously remove all small fluxes when taking averages as this can greatly bias long-term budgets.

Integral-turbulence characteristics test (ITC). This test can be applied to the wind components as described in the ECDPP. It is not recommended to be applied to $\mathrm{CO}_{2}$ concentration and the argument to not apply it to $\mathrm{CH}_{4}$ and $\mathrm{N}_{2} \mathrm{O}$ concentration time-series is even stronger, given the often much smaller fluxes than observed for $\mathrm{CO}_{2}$. 
Overall quality flags should be combined as for $\mathrm{CO}_{2}$ and $\mathrm{H}_{2} \mathrm{O}$ fluxes. The overall quality flag should reflect the highest flag found in any one of the individual tests. However, a separate flag should mark fluxes that are below the detection limit.

Low turbulence friction velocity $\left(u_{*}\right)$ thresholds for non- $\mathrm{CO}_{2} \mathrm{GHG}$ fluxes

At low turbulence, advection can considerably contribute to the total atmospheric flux, which is not accounted for in regular EC data processing. For this reason for $\mathrm{CO}_{2}$ it is suggested to filter flux data based on a friction velocity $\left(u_{*}\right)$ threshold value, beyond which the flux does not depend on $u_{*}$ anymore (Goulden et al., 1996; Aubinet et al., 2000). In this section we recommend how to filter time series of non$\mathrm{CO}_{2} \mathrm{GHG}$ turbulent flux data.

There are two aspects that are specific to non- $\mathrm{CO}_{2} \mathrm{GHG}$ fluxes:

1. For $\mathrm{N}_{2} \mathrm{O}$ and in particular for $\mathrm{CH}_{4}$ there are situations in which a direct or indirect relationship between the $u_{*}$ and the actual surface flux cannot be ruled out. For example, in wetlands the flux into the atmospheric boundary layer can be triggered by turbulence and relatively low fluxes at low turbulence can therefore be real (Sachs et al., 2008; Herbst et al., 2011). In other words, it is not only the loss through horizontal advection that is increased, but the source strength at the surface is also reduced.

2. $\mathrm{CH}_{4}$ and $\mathrm{N}_{2} \mathrm{O}$ fluxes can often not be accurately measured at 30-min, time scale (see above).

Both factors mean that for these gases a $u_{*}$ threshold can often only be estimated with large uncertainty. By contrast, for $\mathrm{CO}_{2}$ it is well documented that under low-turbulent conditions advection results in an underestimation of the flux, and the controls of (night-time) fluxes are well established. Assumed turbulent flux similarity and a similar distribution of sources within the ecosystem (from soil or vegetation), different gases behave similarly in the atmospheric boundary layer. Consequently, $u_{*}$ thresholds can be detected with any gas, e.g. one with a high flux that is measurable at the 30 -minute time scale and for which actual emissions are not reduced at low turbulence.

Because under low turbulent conditions the flux is known to be subject to a methodological systematic bias towards lower values, it is recommended to apply the same $u_{*}$ threshold established for $\mathrm{CO}_{2}$ also to $\mathrm{CH}_{4}$ and $\mathrm{N}_{2} \mathrm{O}$. During the period of low turbulence, emission is likely to result in an accumulation near the surface. On re-establishment of turbulence, this accumulation is gradually vented past the measurement height, resulting in a non-zero storage flux. Only at stations where the storage flux is quantified, this phenomenon is accounted for.

It should be borne in mind that the $u_{*}$ filter may result in the removal of fluxes that were physically repressed by low turbulence, thus introducing a positive bias in the filtered dataset; i.e. for wetland stations, the application of the $u_{*}$ filter to $\mathrm{CH}_{4}$ fluxes also removes measurements, when the flux through the water column, the water surface, or the aerenchyma of, e.g. rice plants, may well be hampered by lack of turbulence.

If, however, the gas is not inert, e.g. it is subject to oxidation by methanotrophs or conversion to $\mathrm{N}_{2}$, the limited turbulence might indirectly lead to increased reaction rates, e.g., simply because the gas is longer accessible to micro-organisms. These effects will be lost, if they coincide with periods that are filtered out when applying the $u_{*}$ filter. The relevance of these effects can only be investigated with methods other than turbulent flux measurements, and such effects are thus not considered in the following recommendations:

1. Perform $u_{*}$ filtering on the basis of a $u_{*}$ threshold from $\mathrm{CO}_{2}$, for which it can be estimated, to characterise site-specific conditions of limiting turbulence. In periods where possible, compare the $u_{*}$ threshold value with similar analyses with the gas of interest to demonstrate the similarity between the proxy and the considered gas.

2. Remove 30-min, flux data of $\mathrm{CH}_{4}$ and $\mathrm{N}_{2} \mathrm{O}$ at $u_{*}$ lower than the threshold and flag subsequent 30 -min period if storage correction is not available.

It is worth pointing out, that a systematic underestimation of night-time emissions for $\mathrm{CH}_{4}$ and $\mathrm{N}_{2} \mathrm{O}$ would have a much smaller relative effect on the annual budget than what tends to be the case for $\mathrm{CO}_{2}$ over terrestrial ecosystems, where the net flux is a fine balance between night-time respiration and day-time net photosynthesis.

\section{Gap-filling}

At present we can neither recommend a mechanistic nor a statistical modelling approach that could generically be used for gap-filling of $\mathrm{CH}_{4}$ fluxes across all ICOS ecosystem stations, but it is anticipated that the ICOS database will allow us to make progress in developing procedures as long as a comprehensive set of ancillary measurements of driving parameters is available. For the time being, the recommendations are:

- Fluxes that are below the detection limit but passed other QA/QC criteria are included in the calculation of annual budgets rather than gap-filled. The unpracticalities of removing these values are highlighted in Langford et al. (2015), as the flux detection limit is not only dependent on the signal-to-noise ratio of the scalar measurement but also varies with wind speed and atmospheric stability.

- Short data gaps, of up to three half-hourly values are gap-filled by applying a linear interpolation between the values adjacent to the missing value(s) as suggested by Falge et al. (2001) but mainly used for meteorological data.

- If gaps are between three and six hours, the mean diurnal variation method can be applied by replacing respective missing half-hour values with the arithmetic mean for the 
time period of the adjacent days, given the gap-filled values fit seemingly into the data and are representative of the conditions in the gap or the trend observed that day.

- For larger gaps of more than six hours it is recommendable to utilise ANNs as they have proven to be most flexible and reliable gap-filling method. Though no standard input selection is currently presented, it is advisable to select an assembly of representative $\mathrm{CH}_{4}$ flux drivers as input variables.

- Where fluxes do not follow any obvious pattern at all, gaps can alternatively be filled with the running average in a weekly time window, centred on the data gap (again including fluxes below the detection limit).

ICOS requires standardisation; thus, site-specific, subseasonal dependent separation and look-up tables are not are not a practical way forward and difficult to implement across all ICOS ecosystem stations. Similar can be said about applying the mean diurnal variation (MDV) method because its application depends on the gap-length and time of year. While there is currently no "one-fits-all" method, the ICOS database opens and paves the way for the development of sophisticated gap-filling methods integrating a wide range of drivers and environmental conditions/ properties. That said, to-date ANNs are the most flexible gap-filling method for missing $\mathrm{CH}_{4}$ values, applicable across a wide range of gap length (Moffat et al., 2007), a large variety of ecosystems and implementable in ICOS.

As with $\mathrm{CH}_{4}$, at this point in time, it is impossible to recommend one single state-of-the-art methodology that can universally be applied to any $\mathrm{N}_{2} \mathrm{O}$ flux dataset for data gap-filling. This is particularly due to the fact that each ecosystem is characterised by different drivers and emission patterns and by the complexity of underlying processes. Still, standardization and traceability of gap-filling approaches for $\mathrm{N}_{2} \mathrm{O}$ flux data are needed.

We recommend as the first and most easy-to-apply approach for filling gaps in $\mathrm{N}_{2} \mathrm{O}$ flux data to average the available 30 -min data to daily integrals (averages). However, prior to doing so, we suggest to linearly interpolate 30-min flux data if gaps are equal to or shorter than $2 \mathrm{~h}$. Daily integrals should only be calculated if at least 30 of 48 possible half-hourly flux values are available. The remaining days of data are filled with a moving average. However, the window size and averaging period need to be carefully determined to avoid moving across $\mathrm{N}_{2} \mathrm{O}$-emission regime shifts. The window length and position must thus consider potential changes in the magnitude of the $\mathrm{N}_{2} \mathrm{O}$ flux that are, e.g., triggered by management events or shifts in weather and soil physical conditions (e.g. rewetting phases or freeze-thaw events). $\mathrm{N}_{2} \mathrm{O}$ flux measurements are only mandatory at stations with significant $\mathrm{N}_{2} \mathrm{O}$ emissions (threshold $0.5 \mathrm{~kg} \mathrm{~N}_{2} \mathrm{O}-\mathrm{N} \mathrm{ha}^{-1} \mathrm{y}^{-1}$ ) where the observed ecosystem will most likely experience a variety of management activities such as ploughing, fertilization, or harvest. Therefore, we recommend averaging only for time periods within manage- ment phases with similar emission rates. Otherwise, there is a great risk to fill data gaps following specific management activities with flux averages from a totally different management period and thus bias the calculated annual sums. The uncertainty in determining the exact length of such phases must be included in the uncertainty assessment by running the gap-filling with different but equally valid options. We further recommend determining background emissions during periods without management and potential emission peaks, e.g. freeze-thaw periods.

The next step will be to test more sophisticated gap-filling approaches, like the ANN that has been proven suitable for $\mathrm{CH}_{4}$ fluxes. More annual $\mathrm{N}_{2} \mathrm{O}$ flux datasets become available from ICOS ecosystem stations and beyond will support increasingly reliable empirical relationships at the site level that can be used to fill data gaps in future and improve our understanding of determinants of the $\mathrm{N}_{2} \mathrm{O}$ exchange between ecosystems and the atmosphere. To foster this development, a whole range of ancillary measurements is needed (see above).

\section{RESULTS AND DISCUSSION}

\section{Measurement approaches}

The latest generation of closed-path EC sensors for $\mathrm{CH}_{4}$ and $\mathrm{N}_{2} \mathrm{O}$ no longer needs large amounts of liquid nitrogen and has therefore become much more realistically deployable for long-term observations. The best instruments available are now capable of measuring relatively small fluxes by EC, but, especially for $\mathrm{N}_{2} \mathrm{O}$, fluxes can be below the detection limit for lengthy periods of time even at sites where the annual $\mathrm{N}_{2} \mathrm{O}$ flux makes a significant contribution to the greenhouse gas balance. Methodologically, the same analyser can resolve even smaller fluxes if used with a flux chamber, than in an EC setup. Fluxes of $\mathrm{CH}_{4}$ and $\mathrm{N}_{2} \mathrm{O}$ can be highly variable spatially, however, and it has been estimated that many tens of flux chambers would be required to provide a robust representation of the field-scale emission (Levy et al., 2017). Whilst such intensive study is possible with manual chambers for short periods of time, this level of replication is not achievable with automated chamber systems. In addition, the episodic nature of fluxes of either compound can result in emission spikes being missed by non-continuous measurement approaches (Flechard et al., 2007). Nevertheless, chamber approaches can shed additional light on the variability and thus processes driving small fluxes and, in tall canopies such as forests, they provide a means to distinguish between soil fluxes and total-ecosystem fluxes. The ICOS network therefore applies a dual strategy to the measurement of $\mathrm{CH}_{4}$ and $\mathrm{N}_{2} \mathrm{O}$, applying both EC and automated chamber approaches ( $c f$. ICOS protocol on chamber measurements contained in this issue).

A range of alternative micrometeorological flux measurement approaches has been applied to $\mathrm{CH}_{4}$ and $\mathrm{N}_{2} \mathrm{O}$, including the aerodynamic gradient method, the modified 
Bowen ratio method and relaxed eddy accumulation. The main advantage of these methods over EC, i.e. the relaxation of the requirement of fast-response, does not apply to compounds for which fast-response analysers are readily available. By contrast, these approaches not only require the same sort of precision in resolving concentration differences as EC, they are also all (semi-)empirical at some level and do, for this reason, not fulfil ICOS requirements.

Open-path analysers currently on the market for $\mathrm{CH}_{4}$ do not meet the necessary requirements set out above as they, by default, cannot provide full data coverage (due to the need to exclude measurements for a few hours after precipitation events) and also rely on the $\mathrm{H}_{2} \mathrm{O}$ correction based on an external instrument. The currently commercially available analyser (LI-COR LI-7700) does not achieve the precision set out above once the uncertainty introduced by the correction for fluctuations in density (WPL correction) is taken into account (Table 2). However, open-path GHG analysers also have certain advantages over closed-path instruments, such as (i) potentially a better high-frequency response in the absence of intake tube, depending on the averaging volume; (ii) operation at ambient pressure and related low-power demand; (iii) simple infrastructure, without the need for climate control, enclosure, or pump, (iv) low power demands, and (v) long-term stability of the laser-based sensor. These sum up into an ability to place the flux station in a remote location, in the centre of the ecosystem of interest, regardless mains power availability. These analysers may therefore be useful for measurements, e.g., at ICOS Associated Stations, but only if fluxes are large and heat fluxes, and thus the WPL correction term, remain relatively small. Thus, although not suitable for measurements at Class 1 Stations, recommendations for the setup, operation and processing of open-path analyser data are included in the Appendix 1 to this paper.

\section{Sites at which eddy-covariance flux measurements are} compulsory for ICOS ecosystem Class 1 stations

Fluxes of $\mathrm{N}_{2} \mathrm{O}$ need to be measured by EC if annual fluxes are expected to exceed $0.5 \mathrm{~kg} \mathrm{~N}_{2} \mathrm{O}-\mathrm{N} \mathrm{ha}^{-1} \mathrm{y}^{-1}$. This would be expected to be the case for fertilized vegetation (agricultural and forest), grazed pastures and quite possibly for semi-natural vegetation that receives large amounts of atmospheric $\mathrm{N}$ deposition ( $>50 \mathrm{~kg} \mathrm{~N} \mathrm{ha}^{-1} \mathrm{y}^{-1}$ ), as well as for some sites undergoing land-use change that received larger amounts of $\mathrm{N}$ in the past. Similarly, enhanced $\mathrm{N}_{2} \mathrm{O}$ emissions have been reported from high latitude ecosystems undergoing fast warming causing rapid changes in a systems moisture and temperature regime (Martikainen et al., 1993; Marushchak et al., 2011; Voigt et al., 2017). Similarly, it is expected that all wetlands (possibly with the exception of some saline or brackish tidal wetlands; cf. Poffenbarger et al. (2011)), water bodies and fields subject to grazing by ruminants fall into the category of sites at which the annual $\mathrm{CH}_{4}$ flux exceeds $2.5 \mathrm{~g} \mathrm{CH}_{4}-\mathrm{C} \mathrm{m}^{-2} \mathrm{y}^{-1}$ and therefore needs to be measured by EC. However, these are only guidelines and fluxes of either compound cannot be estimated with certainty without actual measurements.

The flux measurements can only be omitted if it can be demonstrated that annual fluxes are below these thresholds. The temptation is to do this without much capital investment, through manual chamber measurements. It should be noted, however, that short-term manual chamber campaigns would need to be designed carefully to capture short-term emission pulses during key periods, which, in particular for $\mathrm{N}_{2} \mathrm{O}$, may dominate the annual budget (Butterbach-Bahl et al., 2013). An annual measurement period using either auto-chambers (with high temporal coverage) and/or EC would be more convincing.

For ICOS ecosystem Class 2 Stations the EC flux measurements of $\mathrm{CH}_{4}$ and $\mathrm{N}_{2} \mathrm{O}$ are not a mandatory requirement. However, for voluntary flux measurements at Class 2 Stations to be acceptable for the ICOS database, the EC flux measurements need to be carried out according to the guidelines for Class 1 Stations. A full set of the additional measurements, although desirable, is not compulsory for Class 2 Stations.

\section{Uncertainties specific to flux measurements of $\mathrm{CH}_{4}$ and $\mathrm{N}_{2} \mathrm{O}$}

Water corrections

Because fluxes of $\mathrm{CH}_{4}$ and $\mathrm{N}_{2} \mathrm{O}$ tend to be much smaller than those of $\mathrm{CO}_{2}$, the correction for $\mathrm{H}_{2} \mathrm{O}$ dilution needs to be applied much more carefully. External measurements of $\mathrm{H}_{2} \mathrm{O}$ fluctuations cannot be used to correct for spectroscopic and dilution effect, not least because $\mathrm{H}_{2} \mathrm{O}$ arrives in the measurement cell with a different time lag to $\mathrm{CH}_{4}$ and $\mathrm{N}_{2} \mathrm{O}$, and with a deteriorated time response (Ibrom et al., 2007; Peltola et al., 2014). Thus, the instruments need to have an internal $\mathrm{H}_{2} \mathrm{O}$ measurement and the quality of the correction depends on the accuracy of this internal $\mathrm{H}_{2} \mathrm{O}$ measurement. As an example, the Aerodyne and LGR analysers apply the $\mathrm{H}_{2} \mathrm{O}$ corrections to $\mathrm{N}_{2} \mathrm{O}$ and $\mathrm{CH}_{4}$ fluxes based on the uncalibrated $\mathrm{H}_{2} \mathrm{O}$ value. Typically, these concentrations are within $3 \%$ of the actual value. Although a revised correction could be applied in post-processing, this accuracy is difficult to improve upon with calibrators based on dew point generators. This results in $\mathrm{H}_{2} \mathrm{O}$ related uncertainties in the $\mathrm{N}_{2} \mathrm{O}$ dry mixing ratio of $65 \mathrm{ppt}$ and $6.5 \mathrm{ppt}$ at $1 \%$ and $0.1 \% \mathrm{H}_{2} \mathrm{O}$, respectively, as the long as the $\mathrm{H}_{2} \mathrm{O}$ fit is not lost. (This could occur at very low $\mathrm{H}_{2} \mathrm{O}$ concentrations and could result in the analyser reporting erroneous results even if $\mathrm{H}_{2} \mathrm{O}$ concentrations increase again.) Although small, such uncertainties could induce a significant systematic bias if fluxes are very small.

In most instances, inlet dryers are not generally recommended as they add avoidable complexity to the system, such as potential for failure, additional volume, and potentially flux loss associated with laminar flow sections. However, where fluxes are small and $\mathrm{H}_{2} \mathrm{O}$ fluxes large, 
an optional dryer can help avoid biases. Even a dryer that does not remove $100 \%$ of the $\mathrm{H}_{2} \mathrm{O}$ can reduce the water correction and associated uncertainty as long as this is still applied, based on internally measured $\mathrm{H}_{2} \mathrm{O}$.

The situation is very different in the case of the LI-7700 open-path analyser. As an example, LI-7700 specifications $\left(5 \mathrm{ppb}\right.$ at $10 \mathrm{~Hz}$ ) are stated in Table 2 for measuring $\mathrm{CH}_{4}$ in dry air at constant $T$ and $P$ with RSSI near $80 \%$ (clean instrument). In addition, an instrument must also have a noise of less than $10 \mathrm{ppb}$ at $10 \mathrm{~Hz}$ when RSSI is near $20 \%$ (dirty instrument). Using Eq. (1) with $u_{*}=0.6 \mathrm{~m} \mathrm{~s}^{-1}$ gives an $\mathrm{RE}$ of $1.25 \mathrm{nmol} \mathrm{m}^{-2} \mathrm{~s}^{-1}$ when the instrument is clean, and $2.5 \mathrm{nmol} \mathrm{m}^{-2} \mathrm{~s}^{-1}$ when it is dirty. This represents instrumental error in the covariance of $w^{\prime}$ and open-path $\mathrm{CH}_{4}^{\prime}$.

By comparison, even in low energy flux environments with small $H$ and $L E$ density terms, such as northern wetlands during cool periods, the flux uncertainty due to WPL terms can be significant, e.g. $1.3 \mathrm{nmol} \mathrm{m}^{-2} \mathrm{~s}^{-1}$, assuming $10 \%$ uncertainty on WPL terms computed using $H=50 \mathrm{~W} \mathrm{~m}^{-2}$ and $L E=50 \mathrm{~W} \mathrm{~m}^{-2}$. Since the covariance and the WPL terms are additive, their errors will combine in quadrature, giving a flux uncertainty of about $1.8 \mathrm{nmol} \mathrm{m}^{-2} \mathrm{~s}^{-1}$ when the instrument is clean and $2.8 \mathrm{nmol} \mathrm{m}^{-2} \mathrm{~s}^{-1}$ when it is dirty.

For a more extreme case of warm mid-summer mid-day conditions $\left(10 \%\right.$ uncertainty on $600 \mathrm{~W} \mathrm{~m}^{-2}, 200 \mathrm{~W} \mathrm{~m}^{-2} \mathrm{H}$, $400 \mathrm{~W} \mathrm{~m}^{-2} L E$ ), these numbers become $6.3 \mathrm{nmol} \mathrm{m}^{-2} \mathrm{~s}^{-1}$ for a clean instrument, and $6.6 \mathrm{nmol} \mathrm{m} \mathrm{m}^{-2} \mathrm{~s}^{-1}$ for a dirty one. Although such conditions occur a small percentage of the time in $\mathrm{CH}_{4}$-producing wetlands, the open-path $\mathrm{CH}_{4}$ flux uncertainty during these times would be heavily dominated by the WPL terms. Further increases in $H$ during midday, which are normal for dry environments in conjunction with typically smaller $\mathrm{CH}_{4}$ fluxes, can make uncertainties in the WPL terms dominate the instrument-related uncertainties by as much as 10:1 and this is the reason why the openpath sensor, in addition to not being able to measure after rain events, does not achieve the effective precision set out above.

\section{Dealing with small fluxes}

Optical absorption spectrometers can change their characteristics in response to the cleanliness of the optics, the response of the optics to temperature fluctuations, and the goodness of the spectral fits. For this reason, the instruments' noise levels should be continuously tracked in time, and this paper describes two parallel approaches for doing this. The reference gas overflow inlet allows the instrument noise level to be assessed experimentally on a regular basis by inspecting the Allen Variance of a time series taken from a bottled reference gas. When measuring longer time-series this approach also provides information on the instrument stability (Werle et al., 1993). In parallel, the noise level can be quantified continuously from the normal measurement data by analysis of the autocovariance function, following Eq. (3) (Mauder et al., 2013). This works well as long as the instrument noise adds significantly to the total time-series variance. It is important that the users respond to deterioration in performance promptly.

The potential need for deriving small fluxes over lengthy periods of time without introducing a systematic bias, challenges various aspects of the common EC approach and this protocol has been developed to provide the most robust approach:

1. Time-lag estimation by maximisation of the cross-correlation function is no longer applicable (e.g. Langford et al., 2015).

2. Spectral approaches for high- and low-frequency loss corrections become uncertain.

3. Uncertainty in assessing $u_{*}$ thresholds.

4. Quality tests such as for stationarity become meaningless.

The approaches described here could, however, also benefit the measurement of a number EC applications such as the measurement of other compounds that show small fluxes and are measured with relatively high noise (e.g. aerosols and some volatile organic compounds). Even the processing of $\mathrm{CO}_{2}$ fluxes may benefit from some of the considerations of this paper in situations where fluxes are typically small, e.g. above water.

Many of the uncertainties associated with small fluxes can be avoided if another compound is measured within the same instrument that shows larger fluxes and behaves similarly during transport in the inlet tube.

\section{Methodological uncertainties and future research}

This is the first comprehensive attempt at standardising EC flux measurements of $\mathrm{CH}_{4}$ and $\mathrm{N}_{2} \mathrm{O}$ across a large network. As the latest generation of analysers has only been available for a few years and long-term datasets are only now starting to become more commonplace, experience in how best to automate the processing of data and calculation of gap-filled annual budgets is at relative infancy, compared with the processing of annual fluxes of $\mathrm{CO}_{2}$ and $\mathrm{H}_{2} \mathrm{O}$. There are therefore a number of areas where only preliminary guidelines can be developed and further research is required.

\section{Storage flux quantification}

In some situations, fluxes of $\mathrm{CH}_{4}$ and $\mathrm{N}_{2} \mathrm{O}$ can be more heterogeneous in both space and time than fluxes of $\mathrm{CO}_{2}$. This might mean that more vertical sampling points are required to estimate the storage flux sufficiently accurately, and that vertical gradients at the measurement point could become non-representative of the flux footprint.

However, there are too little quantitative estimates to tailor the optimal sampling strategy to account for these problems. For $\mathrm{CH}_{4}$, Peltola et al. (2015) reported storage change fluxes measured on tall and short towers in a temperate grassland in The Netherlands. Measured values were in the range of -11 to $15 \mathrm{nmol} \mathrm{m}^{-2} \mathrm{~s}^{-1}$ (25th and 75th 
percentiles) at the level of $60 \mathrm{~m}$, and -2 to $2 \mathrm{nmol} \mathrm{m}^{-2} \mathrm{~s}^{-1}$ for a $6 \mathrm{~m}$ short tower. For $\mathrm{N}_{2} \mathrm{O}$ storage change fluxes do not appear to have been quantified in the literature. For the time being, in the absence of compound-specific evidence, the storage flux quantification for $\mathrm{CH}_{4}$ and $\mathrm{N}_{2} \mathrm{O}$ should follow that of $\mathrm{CO}_{2}$ as laid out in the ICOS protocol for storage flux quantification of this issue.

\section{Despiking}

Current recommendations for despiking follow those for $\mathrm{CO}_{2}$ : whilst the wind data should be despiked, the concentration data should not. However, there is currently limited experience in despiking concentration time series of $\mathrm{CH}_{4}$ and $\mathrm{N}_{2} \mathrm{O}$. In particular, the MAD based despiking approach has not yet been evaluated for $\mathrm{CH}_{4}$ and $\mathrm{N}_{2} \mathrm{O}$ concentration data, for which rapid changes may be genuine: for $\mathrm{N}_{2} \mathrm{O}$ rapid releases of the gas due to rain events may occur. For $\mathrm{CH}_{4}$ over porous surfaces, such as landfills, both precipitation and changes in pressure could lead to a very rapid release of the gas. For $\mathrm{CH}_{4}$ over-grazed grasslands, the erratic presence of cattle in the footprint zone will lead to rapid fluctuations in the measured concentration (Felber et al., 2015). For these cases, the performance of the despiking routine will need to be assessed carefully in the future, as a multiplier of 10.38 may be too conservative.

\section{Dealing with low turbulence conditions}

More research is required to investigate which emission processes, in particular for $\mathrm{CH}_{4}$ whether and under what conditions the true surface flux may indeed be suppressed under low turbulence conditions, leading to a mechanistic dependence of the surface flux on $u_{*}$. Approaches to investigate associated processes might include measurements of water emissions using floating chambers with various degrees of artificially generated turbulence and/or waves. If substantiated, taking a suppression into account would result in reduced emission estimates compared with a blanket application of a $u_{*}$ filter. The results would not only be important to decide whether $u_{*}$ filtering biases fluxes, but also as input to advanced gap filling strategies (see below).

Gap-filling and calculation of annual budgets

Various gap-filling procedures have been developed for $\mathrm{CO}_{2}$ and other gases, ranging from interpolation, simple and ensemble mean diurnal averaging in gliding time windows, artificial neural networks (Papale and Valentini, 2003), nonlinear regression approaches (Lasslop et al., 2010; Wu et al., 2013) and process modelling. The difference to the non- $\mathrm{CO}_{2}$ GHGs is that (a) such clear and robust relationships between the fluxes and drivers (meteorological and soil conditions) have not yet been established, that (b) these drivers appear to differ greatly between ecosystems and seasons, (c) their simulation with process-based models is only possible with comparably large uncertainties and (d) fluxes can be small over extended periods with large relative uncertainty making it harder to train gap filling techniques. Studies by Falge et al. (2001) and Moffat et al. (2007) have summarised and compared a variety of gap-filling methods for $\mathrm{CO}_{2}$. Whilst some of these are also applicable to $\mathrm{CH}_{4}$ and $\mathrm{N}_{2} \mathrm{O}$, systematic and comprehensive comparison studies for these gases are still lacking. As a consequence, there is currently still no consensus on gap-filling techniques for these gases, and methods applied are still dependent on site and auxiliary data availability. Standardisation of the gap-filling method is a requirement under ICOS and for this a consensus has to be found on main drivers and their compulsory measurements across all ecosystem stations. There is also significant uncertainty about how to treat the spatial variability of fluxes (as demonstrated with chamber measurements) and their driving parameters. For $\mathrm{CH}_{4}$ this includes the hummocks and hollows in wetlands and the associated variability in water table depth and plant species composition. This complexity also extends to animal movement at pasture/grazed stations (Felber et al., 2015). In contrast to $\mathrm{CH}_{4}$ exchange, which is driven by two antagonistic biological processes, $\mathrm{N}_{2} \mathrm{O}$ exchange is influenced by multiple biological and chemical processes in the soil (Butterbach-Bahl et al., 2013). With this multitude of processes involved the suite of drivers explaining $\mathrm{N}_{2} \mathrm{O}$ emissions becomes very large. In addition, potential $\mathrm{N}_{2} \mathrm{O}$ uptake is even more difficult to quantify, since the uptake rates are commonly small but persistent in some ecosystems while often being overlaid by $\mathrm{N}_{2} \mathrm{O}$ emissions, i.e. hardly visible in net exchange measurements.

For $\mathrm{CH}_{4}$, several studies (Kroon et al., 2010; Herbst et al., 2011; Dengel et al., 2013; and references therein) have highlighted the wide range of applied $\mathrm{CH}_{4}$ gap-filling methods using a variety of site specific available environmental data. The only comparison of different $\mathrm{N}_{2} \mathrm{O}$ flux gap-filling approaches (Mishurov and Kiely, 2011) focused primarily on chamber $\mathrm{N}_{2} \mathrm{O}$ flux measurements and has involved only some of the basic available techniques. For $\mathrm{N}_{2} \mathrm{O}$, approaches include setting missing values to zero (Eugster et al., 2007), calculating daily averages (Imer et al., 2013), using linear interpolation (Mishurov and Kiely, 2011), fitting non-linear functions to emission peaks as well as simple (Kroon et al., 2010; Leppelt et al., 2014) and more complex biogeochemical process-based modelling approaches. $\mathrm{N}_{2} \mathrm{O}$ flux data often comprise high-emission pulses and long phases with low background fluxes. The strong focus on growing season flux estimates (e.g. in crops and fertilised grasslands) leads easily to large biases when trying to estimate annual $\mathrm{N}_{2} \mathrm{O}$ emissions (Rees et al., 2013; Skiba et al., 2013). Gap-filling with chamber flux data is difficult as these might not cover the spatial variability and are often only taken sporadically. Especially non-growing season fluxes of $\mathrm{N}_{2} \mathrm{O}$ during freeze-thaw events have been shown to considerably bias annual estimates (Butterbach-Bahl et al., 2013). Whilst these events should be covered by 
continuous EC flux measurements, they are rare and it has so far proved difficult to train gap-filling algorithms to capture such $\mathrm{N}_{2} \mathrm{O}$ flux bursts.

One method applied in $\mathrm{CO}_{2}$ flux gap-filling studies is the use of look-up tables (Baldocchi et al., 2001; Falge et al., 2001), a method that is very site and time of year dependent. The generation of site-specific look-up tables of average fluxes for binned conditions can work in some situations. Utilising this method to replace missing non$\mathrm{CO}_{2}$ GHG flux values is not straightforward due to the nature and high variability of non- $\mathrm{CO}_{2} \mathrm{GHG}$ fluxes, but it has been used for $\mathrm{N}_{2} \mathrm{O}$ (Merbold et al., 2014). A further obstacle introduced by this method, highlighted in Falge et al. (2001), are gaps in look-up tables themselves requiring additional gap-filling and so further attention. A more common and practical routine is the mean diurnal variation (MDV) method. This method, highlighted in Baldocchi et al. (2001) and Falge et al. (2001) replaces the missing halfhour value with the mean for the time period of the adjacent days. Falge et al. (2001)) applied an averaging window size of 4-14 days. A too short time frame introduces errors as demonstrated by Moncrieff et al. (1996). Is the averaging period too long, then low-frequency noise on the average is introduced, incorporating seasonal trends as has been observed by Baldocchi et al. (2001). Regarding $\mathrm{CH}_{4}$ fluxes these seasonal trends become very relevant during both shoulder seasons. A similar approach is the application of the MDV method where estimated averages are replaced with weighted averages or the respective median.

High resolution (30-min or hourly) flux values are noisy and often characterised by sporadic emission events rather than by distinctive diurnal variation. Such data prove to be far too complex for such simple interpolation, non-linear regression applications, look-up table approaches or MDV. More promising in this respect may be the gap filling with a highly flexible Artificial Neural Networks (ANN) approach, which has performed well for $\mathrm{CH}_{4}$ across a variety of high latitude wetlands (Dengel et al., 2013). Gap-filling with ANNs has both advantages but also disadvantages: on the one hand, it has a "black box" image, i.e. limited transparency of the results and the way they were generated. On the other hand, the network has the capability to train itself using given input data (environmental variables) and the corresponding flux values, which then is being tested on a new set of environmental variables from the same data pool (excluding data used for training) in order to predict the corresponding GHG fluxes. Its output and the surprisingly high performance (e.g. high $\mathrm{r}^{2}$ and RMSE values achieved by Moffat et al., 2007; and Dengel et al., 2013) prove its applicability.

In order to standardise the ANN method needs to be tested across many different ecosystems, similar to the approach suggested by Dengel et al. (2013), who used the same environmental variables, number of neurons and neu- ron layers in order to find a suitable universal ANN setup. As such it is expected that the ICOS database will make a major contribution to developing more generic gap-filling algorithms, e.g. based on ANN and developing statistical modelling approaches. For the training and application of sophisticated gap-filling algorithms like ANN and look-up tables and process models, the additional ancillary data outline above are crucial.

\section{CONCLUSIONS}

1. The EC flux measurement of $\mathrm{CH}_{4}$ and $\mathrm{N}_{2} \mathrm{O}$ is subject to several complexities that are additional to those for $\mathrm{CO}_{2}$, which need to be dealt most accurately: (i) best precision can currently be achieved with closed-path systems, but these are subject to the typical complexities of inlet damping; (ii) fluxes are often small over extensive periods of time, resulting in problems for the determination of timelags, time-response and some quality assessments; (iii) the LI-7700 open-path analyser for $\mathrm{CH}_{4}$, which is only justifiable for certain lower-quality sites, is subject to large WPL corrections that need careful optimisation.

2. Based on (a) what fluxes are relevant for the terrestrial greenhouse gas balance and (b) currently measurable by $\mathrm{EC}$, at ICOS ecosystem Class 1 Stations, $\mathrm{N}_{2} \mathrm{O}$ fluxes should be measured if their annual flux is expected to exceed 0.5 $\mathrm{kg} \mathrm{N}_{2} \mathrm{O}-\mathrm{N} \mathrm{ha}^{-1} \mathrm{y}^{-1}$, including, e.g., fertilised land, grazed pastures as well as some sites undergoing land-use change and/or receiving large inputs of atmospheric $\mathrm{N}$.

3. Similarly, $\mathrm{CH}_{4}$ fluxes should be measured if annual fluxes are thought to exceed $2.5 \mathrm{~g} \mathrm{CH}_{4}-\mathrm{C} \mathrm{m}^{-2} \mathrm{y}^{-1}$, which includes, e.g., wetlands, water bodies and fields grazed by ruminants.

4. For Class 1 Stations, analysers need to be selected, housed and maintained at all times to achieve a real-world precision of $1 \mathrm{nmol} \mathrm{mol}^{-1}$ dry mixing ratio for $\mathrm{N}_{2} \mathrm{O}$ and 10 nmol mol${ }^{-1}$ for $\mathrm{CH}_{4} .90 \%$ data capture should be achievable.

5. For stations where $\mathrm{N}_{2} \mathrm{O}$ fluxes are relevant but small, it is strongly advised to use an instrument which can also measure $\mathrm{CO}_{2}$ (or $\mathrm{CH}_{4}$ if these fluxes are large). This simplifies the data processing and quality control because lag times and spectral corrections can be derived for the stronger $\mathrm{CO}_{2}\left(\right.$ or $\left.\mathrm{CH}_{4}\right)$ flux signal and transferred to $\mathrm{N}_{2} \mathrm{O}$.

6. Because spectroscopic instruments as used for $\mathrm{CH}_{4}$ and $\mathrm{N}_{2} \mathrm{O}$ can change characteristics during operation, the performance needs to be monitored continuously and carefully, by: (i) continuous recording of the instrument status, (ii) continuous calculation of the instrument noise and (iii) periodic measurement of a reference gas and calculation of the Allan variance for these data.

7. Small fluxes, even below the detection limit, should not be removed from the dataset, as long as they are calculated with the methods set out in this protocol. They should be reported together with their random uncertainty and it should be left to the user of the data to decide when to include these fluxes in their interpretation. 
8. More work is required, in particular to (i) assess and improve despiking routines for episodic $\mathrm{CH}_{4}$ and $\mathrm{N}_{2} \mathrm{O}$ fluxes and (ii) to improve gap filling approaches based on process models and statistical approaches, (iii) to assess the applicability of low-turbulence $u_{*}$ filtering, and (iv) to assess the robustness of automation of these analysis guidelines.

9. Standardisation of instrumentation, its operation, data processing and measurement of supporting data will allow large consistent datasets to be compiled which are expected to provide the basis for improving the process understanding of non- $\mathrm{CO}_{2}$ greenhouse gas exchange and refine measurement strategies further.

\section{ACKNOWLEDGEMENTS}

This protocol and the meetings of the associated working group was funded through the European Commission through the projects InGOS ("Integrated non- $\mathrm{CO}_{2}$ Greenhouse gas Observation System"; FP7 grant 284274 (20112015) and RINGO ("Readiness of ICOS for Necessities of integrated Global Observations"; H2020 grant 730944, since 2016), with national contributions from the UK NERC grants "Greenhouse Gas Network" (2017-2018) and UK-ScaPE (grant NE/R016429/1) (from 2018) delivering National Capability, operated by CEH. Lutz Merbold and Lukas Hörtnagl acknowledge funds received under the Swiss National Science Foundation-funded project ICOS-CH (grant agreement: 20FI21_128992; July 2013 to June 2017) and of ETH Zurich (0-23184-15; June 2015 to Dec. 2017). Ivan Mammarella and Olli Peltola acknowledge funds received under the Academy of Finland-funded projects ICOS-Finland (281255) and Centre of Excellence (272041) (2014-2019). Mika Aurela and Annalea Lohila also acknowledge funds received under the Academy of Finland-funded project Centre of Excellence (272041; 2014 to 2019) and funding from Ministry of Transport and Communications (since 2010). The authors acknowledge fruitful discussions in the wider ICOS Working Group on non- $\mathrm{CO}_{2}$ eddy-covariance flux measurements and in particular comments on the manuscript from Christof Ammann, Nicola Arriga, Doug Baer, Daniela Franz, Steve Sargent, Renato Winkler and Georg Wohlfahrt.

Conflict of interest: The Authors declare no conflict of interest.

\section{REFERENCES}

Alberto M.C.R., Wassmann R., Buresh R.J., Quilty J.R., Correa T.Q., Sandro J.M., and Centeno C.A.R., 2014. Measuring methane flux from irrigated rice fields by eddy covariance method using open-path gas analyzer. Field Crops Research, 160, 12-21.

Aubinet M., Grelle A., Ibrom A., Rannik U., Moncrieff J., Foken T., ... Vesala T., 2000. Estimates of the annual net carbon and water exchange of forests: The EUROFLUX methodology, in: Advances in Ecological Research, 30, Advances in Ecological Research, 113-175.
Aubinet M., Vesala T., and Papale D., 2012. Eddy covariance: a practical guide to measurement and data analysis, Springer Science and Business Media, Dordrecht, The Netherlands.

Baldocchi D., Detto M., Sonnentag O., Verfaillie J., Teh Y.A., Silver W., and Kelly N.M., 2012. The challenges of measuring methane fluxes and concentrations over a peatland pasture. Agric. Forest Meteorol., 153, 177-187.

Baldocchi D., Falge E., Gu L.H., Olson R., Hollinger D., Running S., ... Wofsky S., 2001. FLUXNET: A new tool to study the temperal and spatial variability of ecosystem-scale carobn dioxide, water vapor, and energy flux densities. Bull. American Meteorol. Soc., 82, 2415-2434.

Bhattacharyya P., Neogi S., Roy K.S., Dash P.K., Nayak A.K., and Mohapatra T., 2014. Tropical low land rice ecosystem is a net carbon sink. Agriculture, Ecosystems Environ., 189, 127-135.

Brown M.G., Humphreys E.R., Moore T.R., Roulet N.T., and Lafleur P.M., 2014. Evidence for a nonmonotonic relationship between ecosystem-scale peatland methane emissions and water table depth. J. Geophysical Res.: Biogeosciences, 119, 826-835.

Brown S.E., Sargent S., and Wagner-Riddle C., 2017. Evaluation of a lower-powered analyser and sampling system for eddy-covariance measurements of nitrous oxide fluxes. Atmos. Meas. Tech. Discuss., 2017, 1-28.

Butterbach-Bahl K., Baggs E.M., Dannenmann M., Kiese R., and Zechmeister-Boltenstern S., 2013. Nitrous oxide emissions from soils: how well do we understand the processes and their controls? Philosophical Trans. Royal Society B-Biological Sciences, 368.

Christensen S., Ambus P., Arah J.R.M., Clayton H., Galle B., Griffith D.W.T., . . . Wienhold F.G., 1996. Nitrous oxide emission from an agricultural field: Comparison between measurements by flux chamber and micrometerological techniques. Atmospheric Environment, 30, 4183-4190.

Chu H., Chen J., Gottgens J.F., Ouyang Z., John R., Czajkowski K., and Becker R., 2014. Net ecosystem methane and carbon dioxide exchanges in a Lake Erie coastal marsh and a nearby cropland. J. Geophysical Research: Biogeosciences, 119, 722-740.

Coates T.W., Benvenutti M.A., Flesch T.K., Charmley E., McGinn S.M., and Chen D., 2018. Applicability of eddy covariance to estimate methane emissions from grazing cattle. J. Environmental Quality, 47, 54-61.

Cowan N.J., Levy P.E., Famulari D., Anderson M., Drewer J., Carozzi M., .. . Skiba U.M., 2016. The influence of tillage on $\mathrm{N}_{2} \mathrm{O}$ fluxes from an intensively managed grazed grassland in Scotland. Biogeosciences, 13, 4811-4821.

Dengel S., Levy P.E., Grace J., Jones S.K., and Skiba U.M., 2011. Methane emissions from sheep pasture, measured with an open-path eddy covariance system. Global Change Biology, 17, 3524-3533.

Dengel S., Zona D., Sachs T., Aurela M., Jammet M., Parmentier F.J.W., . . . Vesala T., 2013. Testing the applicability of neural networks as a gap-filling method using $\mathrm{CH}_{4}$ flux data from high latitude wetlands. Biogeosciences, $10,8185-8200$

Desai A.R., Xu K., Tian H., Weishampel P., Thom J., Baumann D., ... Kolka R., 2015. Landscape-level terrestrial methane flux observed from a very tall tower. Agricultural and Forest Meteorology, 201, 61-75. 
Detto M., Verfaillie J., Anderson F., Xu L., and Baldocchi D., 2011. Comparing laser-based open- and closed-path gas analyzers to measure methane fluxes using the eddy covariance method. Agricultural and Forest Meteorology, 151, 1312-1324.

Di Marco C., Skiba U., Weston K., Hargreaves K., and Fowler D., 2004. Field scale $\mathrm{N}_{2} \mathrm{O}$ flux measurements from grassland using eddy covariance. Water Air and Soil Pollution Focus, 4, 143-149.

Erkkilä K.M., Mammarella I., Bastviken D., Biermann T., Heiskanen J.J., Lindroth A., . . O Ojala A., 2017. Methane and carbon dioxide fluxes over a lake: comparison between eddy covariance, floating chambers and boundary layer method. Biogeosciences Discuss., 2017, 1-29.

Eugster W., DelSontro T., and Sobek S., 2011. Eddy covariance flux measurements confirm extreme $\mathrm{CH}_{4}$ emissions from a Swiss hydropower reservoir and resolve their short-term variability. Biogeosciences, 8, 2815-2831.

Eugster W., and Merbold L., 2015. Eddy covariance for quantifying trace gas fluxes from soils. Soil, 1, 187-205.

Eugster W. and Plüss P., 2010. A fault-tolerant eddy covariance system for measuring $\mathrm{CH}_{4}$ fluxes. Agricultural and Forest Meteorology, 150, 841-851.

Eugster W., Zeyer K., Zeeman M., Michna P., Zingg A., Buchmann N., and Emmenegger L., 2007. Methodical study of nitrous oxide eddy covariance measurements using quantum cascade laser spectrometery over a Swiss forest. Biogeosciences, 4, 927-939.

Falge E., Baldocchi D., Olson R., Anthoni P., Aubinet M., Bernhofer C., ... Wofsy S., 2001. Gap filling strategies for defensible annual sums of net ecosystem exchange. Agricultural and Forest Meteorology, 107, 43-69.

Famulari D., Nemitz E., Di Marco C., Phillips G.J., Thomas R., House E., and Fowler D., 2010. Eddy-covariance measurements of nitrous oxide fluxes above a city. Agricultural and Forest Meteorology, 150, 786-793.

Fan S.M., Wofsy S.C., Bakwin P.S., Jacob D.J., Anderson S.M., Kebabian P.L., . . . Fitzjarrald D.R., 1992. Micrometeorological measurements of $\mathrm{CH}_{4}$ and $\mathrm{CO}_{2}$ exchange between the atmosphere and sub-arctic Tundra. J. Geophysical Research-Atmospheres, 97, 16627-16643.

Felber R., Münger A., Neftel A., and Ammann C., 2015. Eddy covariance methane flux measurements over a grazed pasture: effect of cows as moving point sources. Biogeosciences, 12, 3925-3940.

Fiedler S., Vepraskas M.J., and Richardson J.L., 2007. Soil redox potential: importance, field measurements, and observations. Advances in Agronomy, 94, 1-54.

Finkelstein P.L., and Sims P.F., 2001. Sampling error in eddy correlation flux measurements. Journal of Geophysical Research: Atmospheres, 106, 3503-3509.

Flechard C.R., Ambus P., Skiba U., Rees R.M., Hensen A., van Amstel A., . . . Grosz B., 2007. Effects of climate and management intensity on nitrous oxide emissions in grassland systems across Europe. Agriculture, Ecosystems Environment, 121, 135-152.

Flechard C.R., Nemitz E., Smith R.I., Fowler D., Vermeulen A.T., Bleeker A., .. . Sutton M.A., 2010. Dry deposition of reactive nitrogen to European ecosystems: a comparison of inferential models across the NitroEurope network. Atmos. Chem. Phys. Discuss., 10, 29291-29348.
Foken T. and Wichura B., 1996. Tools for quality assessment of surface-based flux measurements. Agricultural and Forest Meteorology, 78, 83-105.

Forbrich I., Kutzbach L., Wille C., Becker T., Wu J., and Wilmking M., 2011. Cross-evaluation of measurements of peatland methane emissions on microform and ecosystem scales using high-resolution landcover classification and source weight modelling. Agricultural and Forest Meteorology, 151, 864-874.

Franz D., Koebsch F., Larmanou E., Augustin J., and Sachs T., 2016. High net $\mathrm{CO}_{2}$ and $\mathrm{CH}_{4}$ release at a eutrophic shallow lake on a formerly drained fen. Biogeosciences, 13, 3051-3070.

Fratini G., Ibrom A., Arriga N., Burba G., and Papale D., 2012. Relative humidity effects on water vapour fluxes measured with closed-path eddy-covariance systems with short sampling lines. Agricultural and Forest Meteorology, 165, 53-63.

Gao Y., Chen H., and Zeng X., 2014. Effects of nitrogen and sulfur deposition on $\mathrm{CH}_{4}$ and $\mathrm{N}_{2} \mathrm{O}$ fluxes in high-altitude peatland soil under different water tables in the Tibetan Plateau. Soil Science and Plant Nutrition, 60, 404-410.

Gauci V., Matthews E., Dise N., Walter B., Koch D., Granberg G., and Vile M., 2004. Sulfur pollution suppression of the wetland methane source in the 20th and 21st centuries. Proc. National Academy of Sciences of the United States of America, 101, 12583.

Gažovič M., Kutzbach L., Schreiber P., Wille C., and Wilmking M., 2010. Diurnal dynamics of $\mathrm{CH}_{4}$ from a boreal peatland during snowmelt. Tellus B, 62, 133-139.

Ge H.-X., Zhang H.-S., Zhang H., Cai X.-H., Song Y., and Kang L., 2018. The characteristics of methane flux from an irrigated rice farm in East China measured using the eddy covariance method. Agricultural and Forest Meteorology, 249, 228-238.

Gioli B., Toscano P., Lugato E., Matese A., Miglietta F., Zaldei A., and Vaccari F.P., 2012. Methane and carbon dioxide fluxes and source partitioning in urban areas: The case study of Florence, Italy. Environ. Pollution, 164, 125-131.

Goulden M.L., Munger J.W., Fan S.-M., Daube B.C., and Wofsy S.C., 1996. Measurements of carbon sequestration by long-term eddy covariance: methods and a critical evaluation of accuracy. Global Change Biology, 2, 169-182.

Groffman P.M., Butterbach-Bahl K., Fulweiler R.W., Gold A.J., Morse J.L., Stander E.K., . . . Vidon P., 2009. Challenges to incorporating spatially and temporally explicit phenomena (hotspots and hot moments) in denitrification models. Biogeochemistry, 93, 49-77.

Hargreaves K.J., and Fowler D., 1998. Quantifying the effects of water table and soil temperature on the emission of methane from peat wetland at the field scale. Atmospheric Environment, 32, 3275-3282.

Hargreaves K.J., Fowler D., Pitcairn C.E.R., and Aurela M., 2001. Annual methane emission from Finnish mires estimated from eddy covariance campaign measurements. Theoretical Applied Climatology, 70, 203-213.

Hargreaves K.J., Wienhold F.G., Klemedtsson L., Arah J.R.M., Beverland I.J., Fowler D., . . . Harris G.W., 1996. Measurement of nitrous oxide emission from agricultural land using micrometeorological methods. Atmospheric Environment, 30, 1563-1571. 
Haszpra L., Hidy D., Taligás T., and Barcza Z., 2018. First results of tall tower based nitrous oxide flux monitoring over an agricultural region in Central Europe. Atmospheric Environment, 176, 240-251.

Hatala J.A., Detto M., and Baldocchi D.D., 2012a. Gross ecosystem photosynthesis causes a diurnal pattern in methane emission from rice. Geophysical Research Letters, 39.

Hatala J.A., Detto M., Sonnentag O., Deverel S.J., Verfaillie J., and Baldocchi D.D., 2012b. Greenhouse gas $\left(\mathrm{CO}_{2}\right.$, $\mathrm{CH}_{4}, \mathrm{H}_{2} \mathrm{O}$ ) fluxes from drained and flooded agricultural peatlands in the Sacramento-San Joaquin Delta. Agriculture, Ecosystems \& Environment, 150, 1-18.

Helfter C., Tremper A.H., Halios C.H., Kotthaus S., Bjorkegren A., Grimmond C.S.B., . . . Nemitz E., 2016. Spatial and temporal variability of urban fluxes of methane, carbon monoxide and carbon dioxide above London, UK. Atmos. Chem. Phys. Discuss., 2016, 1-31.

Hendriks D.M.D., van Huissteden J., and Dolman A.J., 2010. Multi-technique assessment of spatial and temporal variability of methane fluxes in a peat meadow. Agricultural and Forest Meteorology, 150, 757-774.

Herbst M., Friborg T., Ringgaard R., and Soegaard H., 2011. Interpreting the variations in atmospheric methane fluxes observed above a restored wetland. Agricultural and Forest Meteorology, 151, 841-853.

Herbst M., Friborg T., Schelde K., Jensen R., Ringgaard R., Vasquez V., . . . Soegaard H., 2013. Climate and site management as driving factors for the atmospheric greenhouse gas exchange of a restored wetland. Biogeosciences, $10,39-52$.

Hommeltenberg J., Mauder M., Drösler M., Heidbach K., Werle P., and Schmid H.P., 2014. Ecosystem scale methane fluxes in a natural temperate bog-pine forest in southern Germany. Agricultural and Forest Meteorology, 198-199, 273-284.

Horst T.W., 1997. A simple formula for attenuation of eddy fluxes measured with first-order-response scalar sensors. Boundary-Layer Meteorology, 82, 219-233.

Horst T.W. and Lenschow D.H., 2009. Attenuation of Scalar Fluxes Measured with Spatially-displaced Sensors. Boundary-Layer Meteorology, 130, 275-300.

Hörtnagl L., Barthel M., Buchmann N., Eugster W., Butterbach-Bahl K., Díaz-Pinés E., . . . Merbold L., 2018. Greenhouse gas fluxes over managed grasslands in Central Europe. Global Change Biology, 24, 1843-1872.

Hörtnagl L., and Wohlfahrt G., 2014. Methane and nitrous oxide exchange over a managed hay meadow. Biogeosciences, 11, 7219-7236.

Hsieh C.-I., Leahy P., Kiely G., and Li C., 2005. The Effect of Future Climate Perturbations on $\mathrm{N}_{2} \mathrm{O}$ Emissions from a Fertilized Humid Grassland. Nutrient Cycling in Agroecosystems, 73, 15-23.

Huang H., Wang J., Hui D., Miller D.R., Bhattarai S., Dennis S., . . . Reddy K.C., 2014. Nitrous oxide emissions from a commercial cornfield (Zea mays) measured using the eddy covariance technique. Atmos. Chem. Phys., 14, 12839-12854.

Ibrom A., Dellwik E., Flyvbjerg H., Jensen N.O., and Pilegaard K., 2007. Strong low-pass filtering effects on water vapour flux measurements with closed-path eddy correlation systems. Agricultural and Forest Meteorology, 147, 140-156.
IEEE, 2008. IEEE Standard for a precision clock synchronization protocol for networked measurement and control systems, edited by: 1588-2002), I. S.-R. o. I. S., IEEE, 300 pp.

Imer D., Merbold L., Eugster W., and Buchmann N., 2013. Temporal and spatial variations of soil $\mathrm{CO}_{2}, \mathrm{CH}_{4}$ and $\mathrm{N}_{2} \mathrm{O}$ fluxes at three differently managed grasslands. Biogeosciences, 10, 5931-5945.

IPCC, 2013. Climate Change 2013 - The physical science basis. Working Group I Contri bution to the Fifth Assessment Report of the Intergovernmental Panel on Climate Change, Cambridge University Press, Cambridge.

ISO, 2009. ISO 80000-9. Quantitities and units - Part 9: Physical chemistry and molecular physics, International Standard, ISO copyright office, Geneva, Switzerland.

Jammet M., Crill P., Dengel S., and Friborg T., 2015. Large methane emissions from a subarctic lake during spring thaw: Mechanisms and landscape significance. J. Geophysical Research: Biogeosciences, 120, 2289-2305.

Jammet M., Dengel S., Kettner E., Parmentier F.J.W., Wik M., Crill P., and Friborg T., 2017. Year-round $\mathrm{CH}_{4}$ and $\mathrm{CO}_{2}$ flux dynamics in two contrasting freshwater ecosystems of the subarctic. Biogeosciences Discuss., 2017, 1-49.

Jarvi L., Nordbo A., Rannik Ü., Haapanala S., Riikonen A., Mammarella I., . . . Vesala T., 2014. Urban nitrous-oxide fluxes measured using the eddy-covariance technique in Helsinki, Finland. Boreal Environ. Res., 19, 108-121.

Jha C.S., Rodda S.R., Thumaty K.C., Raha A.K., and Dadhwal V.K., 2014. Eddy-covariance based methane flux in Sundarbans mangroves, India. J. Earth Syst. Sci., 5, 1089-1096.

Jones S.K., Famulari D., Di Marco C.F., Nemitz E., Skiba U.M., Rees R.M., and Sutton M.A., 2011. Nitrous oxide emissions from managed grassland: a comparison of eddy covariance and static chamber measurements. Atmos. Meas. Tech., 4, 2179-2194.

Kaimal J.C., and Finnigan J.J., 1994. Atmospheric boundary layer flows, Oxford University Press, New York.

Kaimal J.C., Wyngaard J.C., Izumi Y., and Cote O.R., 1972. Spectral characteristics of surface-layer turbulence. Quart. J. Roy. Meteorol. Soc., 98, 563-589.

Kim D.-G., Mishurov M., and Kiely G., 2010. Effect of increased $\mathrm{N}$ use and dry periods on $\mathrm{N}_{2} \mathrm{O}$ emission from a fertilized grassland. Nutrient Cycling in Agroecosys., 88, 397-410.

Knox S.H., Matthes J.H., Sturtevant C., Oikawa P.Y., Verfaillie J., and Baldocchi D., 2016. Biophysical controls on interannual variability in ecosystem-scale $\mathrm{CO}_{2}$ and $\mathrm{CH}_{4}$ exchange in a California rice paddy. J. Geophysical Research: Biogeosciences, 121, 978-1001.

Knox S.H., Sturtevant C., Matthes J.H., Koteen L., Verfaillie J., and Baldocchi D., 2015. Agricultural peatland restoration: effects of land-use change on greenhouse gas $\left(\mathrm{CO}_{2}\right.$ and $\mathrm{CH}_{4}$ ) fluxes in the Sacramento-San Joaquin Delta. Global Change Biology, 21, 750-765.

Koebsch F., Jurasinski G., Koch M., Hofmann J., and Glatzel S., 2015. Controls for multi-scale temporal variation in ecosystem methane exchange during the growing season of a permanently inundated fen. Agricultural and Forest Meteorology, 204, 94-105.

Kormann R., Muller H., and Werle P., 2001. Eddy flux measurements of methane over the fen „Murnauer Moos“, 11 degrees 11 , E, 47 degrees 39 , N, using a fast tunable diode laser spectrometer. Atmospheric Environ., 35, 2533-2544. 
Kowalski A. and Serrano-Ortiz P., 2007. On the relationship between the eddy covariance, the turbulent flux, and surface exchange for a trace gas such as $\mathrm{CO}_{2}$. Boundary-Layer Meteorology, 124, 129-141.

Kristensen L., Mann J., Oncley S.P., and Wyngaard J.C., 1997. How close is close enough when measuring scalar fluxes with displaced sensors? J. Atmospheric and Oceanic Technology, 14, 814-821.

Kroon P.S., Schrier-Uijl A.P., Hensen A., Veenendaal E.M., and Jonker H.J.J., 2010. Annual balances of $\mathrm{CH}_{4}$ and $\mathrm{N}_{2} \mathrm{O}$ from a managed fen meadow using eddy covariance flux measurements. European J. Soil Sci., 61, 773-784.

Laanbroek H.J., 2010. Methane emission from natural wetlands: interplay between emergent macrophytes and soil microbial processes. A mini-review. Annals of Botany, 105, 141-153.

Langford B., Acton J., Ammann C., Valach A., and Nemitz E., 2015. Eddy-covariance data with low signal-to-noise ratio: time-lag determination, uncertainties and limit of detection. Atmos. Meas. Tech., 8, 4197-4213.

Lasslop G., Reichstein M., Papale D., Richardson A.D., Arneth A., Barr A., . . . Wohlfahrt G., 2010. Separation of net ecosystem exchange into assimilation and respiration using a light response curve approach: critical issues and global evaluation. Global Change Biology, 16, 187-208.

Laurila T., Tuovinen J.P., Lohila A., Hatakka J., Aurela M., Thum M., ... Vesala T., 2005. Measuring methane emissions from a landfill using a cost-effective micrometeorological method. Geophysical Research Letters, 32, L19808.

Leahy P., Kiely G., and Scanlon T.M., 2004. Managed grasslands: A greenhouse gas sink or source? Geophysical Research Letters, 31.

Lee S.C., Christen A., Black A.T., Johnson M.S., Jassal R.S., Ketler R., . . . Merkens M., 2017. Annual greenhouse gas budget for a bog ecosystem undergoing restoration by rewetting. Biogeosciences, 14, 2799-2814.

Lenschow D.H., Wulfmeyer V., and Senff C., 2000. Measuring Second- through Fourth-Order Moments in Noisy Data. J. Atmospheric and Oceanic Technology, 17, 1330-1347.

Leppelt T., Dechow R., Gebbert S., Freibauer A., Lohila A., Augustin J., . . . Strömgren M., 2014. Nitrous oxide emission budgets and land-use-driven hotspots for organic soils in Europe. Biogeosciences, 11, 6595-6612.

Levy P.E., Cowan N., van Oijen M., Famulari D., Drewer J., and Skiba U., 2017. Estimation of cumulative fluxes of nitrous oxide: uncertainty in temporal upscaling and emission factors. European J. Soil Sci., 68, 400-411.

Li H., Dai S., Ouyang Z., Xie X., Guo H., Gu C., . . Z Zhao B., 2018. Multi-scale temporal variation of methane flux and its controls in a subtropical tidal salt marsh in eastern China. Biogeochemistry, 137, 163-179.

Lohila A., Aalto T., Aurela M., Hatakka J., Tuovinen J.-P., Kilkki J., . . . Laurila T., 2016. Large contribution of boreal upland forest soils to a catchment-scale $\mathrm{CH}_{4}$ balance in a wet year. Geophysical Research Letters, 43, 2946-2953.

Lohila A., Laurila T., Tuovinen J.-P., Aurela M., Hatakka J., Thum T., ... Vesala T., 2007. Micrometeorological measurements of methane and carbon dioxide fluxes at a municipal landfill. Environmental Sci. Technol., 41, 2717-2722.

Long K.D., Flanagan L.B., and Cai T., 2010. Diurnal and seasonal variation in methane emissions in a northern Canadian peatland measured by eddy covariance. Global Change Biology, 16, 2420-2435.
Mammarella I., Werle P., Pihlatie M., Eugster W., Haapanala S., Kiese R., . . . Vesala T., 2010. A case study of eddy covariance flux of $\mathrm{N}_{2} \mathrm{O}$ measured within forest ecosystems: quality control and flux error analysis. Biogeosciences, 7, 427-440.

Mammarella I., Peltola O., Nordbo A., Järvi L., and Rannik Ü., 2016. Quantifying the uncertainty of eddy covariance fluxes due to the use of different software packages and combinations of processing steps in two contrasting ecosystems. Atmos. Meas. Tech., 9, 4915-4933.

Martikainen P.J., Nykänen H., Crill P., and Silvola J., 1993. Effect of a lowered water table on nitrous oxide fluxes from northern peatlands. Nature, 366, 51-53.

Marushchak M.E., Friborg T., Biasi C., Herbst M., Johansson T., Kiepe I., . . . Shurpali N.J., 2016. Methane dynamics in the subarctic tundra: combining stable isotope analyses, plot- and ecosystem-scale flux measurements. Biogeosci., 13, 597-608.

Marushchak M.E., PitkÄMÄKi A., Koponen H., Biasi C., SeppÄLÄ M., and Martikainen P.J., 2011. Hot spots for nitrous oxide emissions found in different types of permafrost peatlands. Global Change Biology, 17, 2601-2614.

Matthews E. and Fung I., 1987. Methane emission from natural wetlands: Global distribution, area, and environmental characteristics of sources. Global Biogeochemical Cycles, 1, 61-86.

Matzner E. and Borken W., 2008. Do freeze-thaw events enhance $\mathrm{C}$ and $\mathrm{N}$ losses from soils of different ecosystems? A review. European J. Soil Sci., 59, 274-284.

Mauder M., Cuntz M., Drüe C., Graf A., Rebmann C., Schmid H.P., ... Steinbrecher R., 2013. A strategy for quality and uncertainty assessment of long-term eddy-covariance measurements. Agricultural and Forest Meteorology, 169, 122-135

McDermitt D., Burba G., Xu L., Anderson T., Komissarov A., Riensche B., . . . Hastings S., 2011. A new low-power, open-path instrument for measuring methane flux by eddy covariance. Appl. Phys. B, 102, 391-405.

Meijide A., Manca G., Goded I., Magliulo V., di Tommasi P., Seufert G., and Cescatti A., 2011. Seasonal trends and environmental controls of methane emissions in a rice paddy field in Northern Italy. Biogeosciences, 8, 3809-3821.

Merbold L., Steinlin C., and Hagedorn F., 2013. Winter greenhouse gas fluxes $\left(\mathrm{CO}_{2}, \mathrm{CH}_{4}\right.$ and $\left.\mathrm{N}_{2} \mathrm{O}\right)$ from a subalpine grassland. Biogeosciences, 10, 3185-3203.

Merbold L., Eugster W., Stieger J., Zahniser M., Nelson D., and Buchmann N., 2014. Greenhouse gas budget $\left(\mathrm{CO}_{2}\right.$, $\mathrm{CH}_{4}$ and $\mathrm{N}_{2} \mathrm{O}$ ) of intensively managed grassland following restoration. Global Change Biology, 20, 1913-1928.

Mishurov M., and Kiely G., 2010. Nitrous oxide flux dynamics of grassland undergoing afforestation. Agric, Ecosystems and Environment, 139, 59-65.

Mishurov M. and Kiely G., 2011. Gap-filling techniques for the annual sums of nitrous oxide fluxes. Agricultural and Forest Meteorology, 151, 1763-1767.

Moffat A.M., Papale D., Reichstein M., Hollinger D.Y., Richardson A.D., Barr A.G., . . . Stauch V.J., 2007. Comprehensive comparison of gap-filling techniques for eddy covariance net carbon fluxes. Agricultural and Forest Meteorology, 147, 209-232.

Molodovskaya M., Singurindy O., Richards B.K., Warland J., Johnson M.S., and Steenhuis T.S., 2012. Temporal variability of nitrous oxide from fertilized croplands: hot moment analysis. Soil Sci. Soc. Am. J., 76, 1728-1740. 
Moncrieff J.B., Malhi Y., and Leuning R., 1996. The propagation of errors in long-term measurements of land-atmosphere fluxes of carbon and water. Global Change Biol., 2, 231-240.

Moncrieff J.B., Massheder J.M., de Bruin H., Elbers J., Friborg T., Heusinkveld B., ... Verhoef A., 1997. A system to measure surface fluxes of momentum, sensible heat, water vapour and carbon dioxide. J. Hydrology, 189, 589-611.

Moore C.J., 1986. Frequency-response corrections for eddy-correlation systems. Boundary-Layer Meteorology, 37, 17-35.

Nadeau D.F., Rousseau A.N., Coursolle C., Margolis H.A., and Parlange M.B., 2013. Summer methane fluxes from a boreal bog in northern Quebec, Canada, using eddy covariance measurements. Atmospheric Environment, 81, 464-474.

Neftel A., Ammann C., Fischer C., Spirig C., Conen F., Emmenegger L., ... Wahlen S., 2010. $\mathrm{N}_{2} \mathrm{O}$ exchange over managed grassland: Application of a quantum cascade laser spectrometer for micrometeorological flux measurements. Agricultural and Forest Meteorology, 150, 775-785.

Neftel A., Fischer C., and Flechard C., 2006. Measurements of greenhouse gas fluxes from agriculture. International Congress Series, 1293, 3-12.

Neftel A., Flechard C., Ammann C., Conen F., Emmenegger L., and Zeyer K., 2007. Experimental assessment of $\mathrm{N}_{2} \mathrm{O}$ background fluxes in grassland systems. Tellus B, 59, 470-482.

Nemitz E., Famulari D., Ibrom A., Lohila A., Mammarella I., Hensen A., .. . Helfter C., 2019. Performance assessment of six nitrous oxide fast-response sensors for eddy-covariance flux measurements over a managed pasture. Atmospheric Measurement Techniques Discussions, [in preparation].

Nicolini G., Castaldi S., Fratini G., and Valentini R., 2013. A literature overview of micrometeorological $\mathrm{CH}_{4}$ and $\mathrm{N}_{2} \mathrm{O}$ flux measurements in terrestrial ecosystems. Atmospheric Environment, 81, 311-319.

NEU A1.3 Sampling \& chemical analysis cookbook, Version 1.3: http://www.nitroeurope.eu/sites/nitroeurope.eu/files/neu data/Component $2 /$ The\%20NEU\%20cookbook_june07. doc, access: 05/02/2018, 2007.

Olson D.M., Griffis T.J., Noormets A., Kolka R., and Chen J., 2013. Interannual, seasonal, and retrospective analysis of the methane and carbon dioxide budgets of a temperate peatland. J. Geophysical Research: Biogeosciences, 118, 226-238.

Papale D. and Valentini R., 2003. A new assessment of European forests carbon exchanges by eddy fluxes and artificial neural network spatialization. Global Change Biology, 9, 525-535.

Parmentier F.J.W., van Huissteden J., van der Molen M.K., Schaepman-Strub G., Karsanaev S.A., Maximov T.C., and Dolman A.J., 2011. Spatial and temporal dynamics in eddy covariance observations of methane fluxes at a tundra site in northeastern Siberia. J. Geophysical Research: Biogeosciences, 116, n/a-n/a.

Pattey E., Blackburn L.G., Strachan I.B., Desjardins R., and Dow D., 2008. Spring thaw and growing season $\mathrm{N}_{2} \mathrm{O}$ emissions from a field planted with edible peas and a cover crop. Canadian J. Soil Science, 88, 241-249.

Pattey E., Strachan I.B., Desjardins R.L., Edwards G.C., Dow D., and MacPherson J.I., 2006. Application of a tunable diode laser to the measurement of $\mathrm{CH}_{4}$ and $\mathrm{N}_{2} \mathrm{O}$ fluxes from field to landscape scale using several micrometeorological techniques. Agricultural and Forest Meteorology, 136, 222-236.

Pawlak W., and Fortuniak K., 2016. Eddy covariance measurements of the net turbulent methane flux in the city centre - results of 2-year campaign in Łódź, Poland. Atmos. Chem. Phys., 16, 8281-8294.

Peltola O., Hensen A., Belelli Marchesini L., Helfter C., Bosveld F.C., van den Bulk W.C.M., .. . Mammarella I., 2015. Studying the spatial variability of methane flux with five eddy covariance towers of varying height. Agricultural and Forest Meteorology, 214-215, 456-472.

Peltola O., Hensen A., Helfter C., Belelli Marchesini L., Bosveld F.C., van den Bulk W.C.M., ... Mammarella I., 2014. Evaluating the performance of commonly used gas analysers for methane eddy covariance flux measurements: the InGOS inter-comparison field experiment. Biogeosciences, 11, 3163-3186.

Peltola O., Mammarella I., Haapanala S., Burba G., and Vesala T., 2013. Field intercomparison of four methane gas analyzers suitable for eddy covariance flux measurements. Biogeosciences, 10, 3749-3765.

Pihlatie M.K., Kiese R., Brüggemann N., Butterbach-Bahl K., Kieloaho A.J., Laurila T., .. . Vesala T., 2010. Greenhouse gas fluxes in a drained peatland forest during spring frostthaw event. Biogeosciences, 7, 1715-1727.

Pihlatie M., Rinne J., Ambus P., Pilegaard K., Dorsey J.R., Rannik U., . . . Vesala T., 2005. Nitrous oxide emissions from a beech forest floor measured by eddy covariance and soil enclosure techniques. Biogeosciences, 2, 377-387.

Podgrajsek E., Sahlée E., Bastviken D., Holst J., Lindroth A., Tranvik L., and Rutgersson A., 2014. Comparison of floating chamber and eddy covariance measurements of lake greenhouse gas fluxes. Biogeosciences, 11, 4225-4233.

Podgrajsek E., Sahlée E., Bastviken D., Natchimuthu S., Kljun N., Chmiel H.E., .. . Rutgersson A., 2016. Methane fluxes from a small boreal lake measured with the eddy covariance method. Limnology and Oceanography, 61, S41-S50.

Poffenbarger H.J., Needelman B.A., and Megonigal J.P., 2011. Salinity influence on methane emissions from tidal marshes. Wetlands, 31, 831-842, 10.1007/s13157-011-0197-0

Prajapati P. and Santos E.A., 2017. Measurements of methane emissions from a beef cattle feedlot using the eddy covariance technique. Agricultural and Forest Meteorology, 232, 349-358.

Pypker T.G., Moore P.A., Waddington J.M., Hribljan J.A., and Chimner R.C., 2013. Shifting environmental controls on $\mathrm{CH}_{4}$ fluxes in a sub-boreal peatland. Biogeosciences, 10, 7971-7981.

Rannik Ü., Haapanala S., Shurpali N.J., Mammarella I., Lind S., Hyvönen N., . . . Vesala T., 2015. Intercomparison of fast response commercial gas analysers for nitrous oxide flux measurements under field conditions. Biogeosciences, 12, 415-432.

Rannik Ü., Peltola O., and Mammarella I., 2016. Random uncertainties of flux measurements by the eddy covariance technique. Atmos. Meas. Tech. Discuss., 2016, 1-31.

Rannik Ü. and Vesala T., 1999. Autoregressive filtering versus linear detrending in estimation of fluxes by the eddy covariance method. Boundary-Layer Meteorology, 91, 259-280. 
Rees R.M., Augustin J., Alberti G., Ball B.C., Boeckx P., Cantarel A., ... Wuta M., 2013. Nitrous oxide emissions from European agriculture an analysis of variability and drivers of emissions from field experiments. Biogeosciences, 10, 2671-2682.

Rella C.W., Chen H., Andrews A.E., Filges A., Gerbig C., Hatakka J., ... Zellweger C., 2013. High accuracy measurements of dry mole fractions of carbon dioxide and methane in humid air. Atmos. Meas. Tech., 6, 837-860.

Rinne J., Pihlatie M., Lohila A., Thum T., Aurela M., Tuovinen J.-P., ... Vesala T., 2005. Nitrous Oxide Emissions from a Municipal Landfill. Environmental Science \& Technology, 39, 7790-7793.

Rinne J., Riutta T., Pihlatie M., Aurela M., Haapanala S., Tuovinen J.-P., . . . Vesala T., 2007. Annual cycle of methane emission from a boreal fen measured by the eddy covariance technique. Tellus B, 59, 449-457.

Rinne J., Tuittila E.-S., Peltola O., Li X., Raivonen M., Alekseychik P., .. . Vesala T., 2018. Temporal Variation of Ecosystem Scale Methane Emission From a Boreal Fen in Relation to Temperature, Water Table Position, and Carbon Dioxide Fluxes. Global Biogeochemical Cycles, 32, 1087-1106.

Sachs T., Wille C., Boike J., and Kutzbach L., 2008. Environmental controls on ecosystem-scale $\mathrm{CH}_{4}$ emission from polygonal tundra in the Lena River Delta, Siberia. Journal of Geophysical Research: Biogeosciences, 113, $\mathrm{n} / \mathrm{a}-\mathrm{n} / \mathrm{a}$.

Sayres D.S., Dobosy R., Healy C., Dumas E., Kochendorfer J., Munster J., . . . Anderson J.G., 2017. Arctic regional methane fluxes by ecotope as derived using eddy covariance from a low-flying aircraft. Atmos. Chem. Phys., 17, 8619-8633.

Scanlon T.M. and Kiely G., 2003. Ecosystem-scale measurements of nitrous oxide fluxes for an intensely grazed, fertilized grassland. Geophysical Research Letters, 30, n/a-n/a.

Schrier-Uijl A.P., Kroon P.S., Hensen A., Leffelaar P.A., Berendse F., and Veenendaal E.M., 2010. Comparison of chamber and eddy covariance-based $\mathrm{CO}_{2}$ and $\mathrm{CH}_{4}$ emission estimates in a heterogeneous grass ecosystem on peat. Agricultural and Forest Meteorology, 150, 825-831.

Schroth M.H., Eugster W., Gómez K.E., Gonzalez-Gil G., Niklaus P.A., and Oester P., 2012. Above- and belowground methane fluxes and methanotrophic activity in a landfill-cover soil. Waste Management, 32, 879-889.

Schubert C.J., Diem T., and Eugster W., 2012. Methane Emissions from a Small Wind Shielded Lake Determined by Eddy Covariance, Flux Chambers, Anchored Funnels, and Boundary Model Calculations: A Comparison. Environmental Science \& Technology, 46, 4515-4522.

Shoemaker J.K., Keenan T.F., Hollinger D.Y., and Richardson A.D., 2014. Forest ecosystem changes from annual methane source to sink depending on late summer water balance. Geophysical Research Letters, 41, 673-679.

Shurpali N.J., Rannik Ü., Jokinen S., Lind S., Biasi C., Mammarella I., . . . Martikainen P.J., 2016. Neglecting diurnal variations leads to uncertainties in terrestrial nitrous oxide emissions. Scientific Reports, 6, 25739.

Skiba U., Hargreaves K.J., Beverland I.J., ONeill D.H., Fowler D., and Moncrieff J.B., 1996. Measurement of field scale $\mathrm{N}_{2} \mathrm{O}$ emission fluxes from a wheat crop using micrometeorological techniques. Plant and Soil, 181, 139-144.
Skiba U., Jones S.K., Drewer J., Helfter C., Anderson M., Dinsmore K., . . . Sutton M.A., 2013. Comparison of soil greenhouse gas fluxes from extensive and intensive grazing in a temperate maritime climate. Biogeosciences, 10, 1231-1241.

Smeets C.J.P.P., Holzinger R., Vigano I., Goldstein A.H., and Röckmann T., 2009. Eddy covariance methane measurements at a Ponderosa pine plantation in California. Atmos. Chem. Phys., 9, 8365-8375.

Strack M., Keith A.M., and Xu B., 2014. Growing season carbon dioxide and methane exchange at a restored peatland on the Western Boreal Plain. Ecological Engineering, 64, 231-239.

Sun L., Song C., Miao Y., Qiao T., and Gong C., 2013. Temporal and spatial variability of methane emissions in a northern temperate marsh. Atmospheric Environment, 81, 356-363.

Tang A.C.I., Stoy P.C., Hirata R., Musin K.K., Aeries E.B., Wenceslaus J., and Melling L., 2018. Eddy Covariance Measurements of Methane Flux at a Tropical Peat Forest in Sarawak, Malaysian Borneo. Geophysical Research Letters, 45, 4390-4399.

Tans P.P., Crotwell A.M., and Thoning K.W., 2017. Abundances of isotopologues and calibration of $\mathrm{CO}_{2}$ greenhouse gas measurements. Atmos. Meas. Tech., 10, 2669-2685.

Tseng K.-H., Tsai J.-L., Alagesan A., Tsuang B.-J., Yao M.-H., and Kuo P.-H., 2010. Determination of methane and carbon dioxide fluxes during the rice maturity period in Taiwan by combining profile and eddy covariance measurements. Agricultural and Forest Meteorology, 150, 852-859.

Voigt C., Lamprecht R.E., Marushchak M.E., Lind S.E., Novakovskiy A., Aurela M., .. . Biasi C., 2017. Warming of subarctic tundra increases emissions of all three important greenhouse gases - carbon dioxide, methane, and nitrous oxide. Global Change Biology, 23, 3121-3138.

Wagner-Riddle C., Congreves K.A., Abalos D., Berg A.A., Brown S.E., Ambadan J.T., ... Tenuta M., 2017. Globally important nitrous oxide emissions from croplands induced by freeze-thaw cycles. Nature Geoscience, 10, 279.

Wang J.M., Murphy J.G., Geddes J.A., Winsborough C.L., Basiliko N., and Thomas S.C., 2013a. Methane fluxes measured by eddy covariance and static chamber techniques at a temperate forest in central Ontario, Canada. Biogeosciences, 10, 4371-4382.

Wang K., Zheng X., Pihlatie M., Vesala T., Liu C., Haapanala S., .. . Liu H., 2013b. Comparison between static chamber and tunable diode laser-based eddy covariance techniques for measuring nitrous oxide fluxes from a cotton field. Agricultural and Forest Meteorology, 171-172, 9-19.

Wang M., Wu J., Luan J., Lafleur P., Chen H., and Zhu X., 2017. Near-zero methane emission from an abandoned boreal peatland pasture based on eddy covariance measurements. PLOS ONE, 12, e0189692.

Webb E.K., Pearman G.I., and Leuning R., 1980. Correction of flux measurements for density effects due to heat and water vapour transfer. Quarterly J. Royal Meteorological Society, 106, 85-100.

Werle P., and Kormann R., 2001. Fast chemical sensor for eddy-correlation measurements of methane emissions from rice paddy fields. Applied Optics, 40, 846-858. 
Werle P., Mücke R., and Slemr F., 1993. The limits of signal averaging in atmospheric trace-gas monitoring by tunable diode-laser absorption spectroscopy (TDLAS). Appl. Phys. B, 57, 131-139.

Wienhold F.G., Welling M., and Harris G.W., 1995. Micrometeorological measurement and source region analysis of nitrous oxide fluxes from an agricultural soil. Atmospheric Environment, 29, 2219-2227.

Wille C., Kutzbach L., Sachs T., Wagner D., and Pfeiffer E.-M., 2008. Methane emission from Siberian arctic polygonal tundra: eddy covariance measurements and modeling. Global Change Biology, 14, 1395-1408.

Wolf B., Merbold L., Decock C., Tuzson B., Harris E., Six J., . .. Mohn J., 2015. First on-line isotopic characterization of $\mathrm{N}_{2} \mathrm{O}$ above intensively managed grassland. Biogeosciences, 12, 2517-2531.

Wu J., Larsen K.S., van der Linden L., Beier C., Pilegaard K., and Ibrom A., 2013. Synthesis on the carbon budget and cycling in a Danish, temperate deciduous forest. Agricultural and Forest Meteorology, 181, 94-107.

Xu L., Lin X., Amen J., Welding K., and McDermitt D., 2014. Impact of changes in barometric pressure on landfill methane emission. Global Biogeochemical Cycles, 28, 679-695.

Yu L., Wang H., Wang G., Song W., Huang Y., Li S.-G., . . He J.-S., 2013. A comparison of methane emission measure- ments using eddy covariance and manual and automated chamber-based techniques in Tibetan Plateau alpine wetland. Environmental Pollution, 181, 81-90.

Zenone T., Zona D., Gelfand I., Gielen B., Camino-Serrano M., and Ceulemans R., 2016. $\mathrm{CO}_{2}$ uptake is offset by $\mathrm{CH}_{4}$ and $\mathrm{N}_{2} \mathrm{O}$ emissions in a poplar short-rotation coppice. GCB Bioenergy, 8, 524-538.

Zona D., Gioli B., Commane R., Lindaas J., Wofsy S.C., Miller C.E., .. . Oechel W.C., 2016. Cold season emissions dominate the Arctic tundra methane budget. Proceedings of the National Academy of Sciences, 113, 40-45.

Zona D., Janssens I.A., Aubinet M., Gioli B., Vicca S., Fichot R., and Ceulemans R., 2013a. Fluxes of the greenhouse gases $\left(\mathrm{CO}_{2}, \mathrm{CH}_{4}\right.$ and $\left.\mathrm{N}_{2} \mathrm{O}\right)$ above a short-rotation poplar plantation after conversion from agricultural land. Agricultural and Forest Meteorology, 169, 100-110.

Zona D., Janssens I.A., Gioli B., Jungkunst H.F., Serrano M.C., and Ceulemans R., 2013b. $\mathrm{N}_{2} \mathrm{O}$ fluxes of a bio-energy poplar plantation during a two years rotation period. GCB Bioenergy, 5, 536-547.

Zona D., Oechel W.C., Kochendorfer J., Paw U K.T., Salyuk A.N., Olivas P.C., . . Lipson D.A., 2009. Methane fluxes during the initiation of a large-scale water table manipulation experiment in the Alaskan Arctic tundra. Global Biogeochemical Cycles, 23, n/a-n/a. 
Appendix 1: Setup, operation and data processing for the LI-7700 open-path methane analyser

This appendix provides information on the best practice of instrument set-up, and maintenance of the LI-7700 open-path $\mathrm{CH}_{4}$ analyser, together with guidelines for data acquisition and processing. As mentioned in the main text, this analyser does not fulfil the requirements for ICOS ecosystem Class 1 Stations, but may in certain situations be a useful instrument for flux measurements at remote and low-power installations at ICOS Associated Stations.

\section{Measured entity}

Both closed- and open-path gas analysers fundamentally measure the amount of gas in the volume, e.g. gas density, and not the dry mole fraction required for ecosystem flux calculations. Tightly temperature- and pressure-controlled closed-path analysers, which also measure fast high-resolution water vapour concentrations, can instantaneously convert the density to the dry mole fraction. By contrast, the open-path analysers cannot do such a conversion on the fly, so fluxes computed from these devices need to be corrected for the effects of temperature- and pressure-related expansions and contractions, and for the dilution effects. In laser-based openpath instruments, spectroscopic effects of the temperature, pressure and water vapour should also be considered in addition to the density and dilution effects (McDermitt et al., 2011).

Instrument setup for open-path analyser eddy covariance systems

As discussed before, open-path measurements of $\mathrm{CH}_{4}$ are often subject to large WPL correction (Webb et al., 1980) terms (Chamberlain et al., 2017). The minimum detectable flux is mostly determined by the uncertainty associated with computing relatively large WPL terms (Mammarella et al., 2016). The 10-20\% error bars (coefficient of variation, $\mathrm{CV}$ ), typically associated with measurements of sensible $(H)$ and latent heat $(L E)$ flux and carried over into WPL terms, may cross zero when applied to relatively small $\mathrm{CH}_{4}$ fluxes (Chamberlain et al., 2017). This dominates the effective detection limit, and as a result, very small fluxes may be difficult to resolve at statistically significant levels and, as with the open-path analysers for $\mathrm{CO}_{2} / \mathrm{H}_{2} \mathrm{O}$, can even change the sign of the flux (e.g. Peltola et al., 2013).

As a result, these measurements should have a specific strategy for handling the density terms and spectroscopic corrections, and related steps in setup, operation and processing. The key aspects of such a strategy include:

1. Careful measurement of WPL terms, and especially $H$ and $L E$ : relatively small errors in $H$ and $L E$ may result in relatively large errors in the open-path $\mathrm{CH}_{4}$ flux. The error in the WPL terms should be minimised to 5$10 \%$ or less in order to resolve smaller $\mathrm{CH}_{4}$ fluxes. This can be achieved by careful setup, operation and processing of all relevant components. Since the raw $\overline{w^{\prime} \mathrm{CH}_{4}^{\prime}}$ covariance is usually measured with error bars $<10 \%$, the smaller the error bars associated with all the parameters going into the WPL terms, the smaller the $\mathrm{CH}_{4}$ fluxes that can be resolved.

2. The necessity to combine spectroscopic corrections with the WPL terms: fluctuations in temperature, pressure and $\mathrm{H}_{2} \mathrm{O}$ content do not only cause density effects (Ideal Gas and Dalton's Laws), but also influence the absorption line being measured.

Open-path $\mathrm{CH}_{4}$ flux measurements are also subject to normal requirements of all open-path measurements. The key requirements include:

1. Installation optimised to provide minimal wind flow distortion to the sonic anemometer, while providing maximum data coverage from the most probable wind directions. This is a well-established and somewhat obvious requirement, since all flux calculations heavily rely on the proper derivation of instantaneous $w$ ' from undistorted 3-dimensional wind flow data.

2. The necessity to measure fast $\mathrm{H}_{2} \mathrm{O}$ concentrations in close proximity to the $\mathrm{CH}_{4}$ concentration measurements. This is required for the latent heat flux portion of WPL terms and for the spectroscopic $\mathrm{H}_{2} \mathrm{O}$ correction. 
3. The necessity to keep the instrument clean, so signal strength remains well above the minimum threshold. This is required mainly to maintain low noise in the fast data, but also to minimize drift in mean concentrations, thus minimizing data gaps.

If these aspects are neglected, the uncertainties in flux measurements may exceed the flux values themselves rendering measurements unreliable, or data coverage may be sporadic.

Recommendations in the following sections address these requirements in terms of instrument setup, configuration and maintenance. At the time of writing, there is only one commercially available open-path highspeed analyser for $\mathrm{CH}_{4}$ flux measurements, the LI-COR LI-7700. Therefore, some recommendations may be analyser-specific in order to assure maximum performance of that analyser. Some recommendations may change if other open-path analysers for $\mathrm{CH}_{4}$ flux measurements become available in the future.

Mounting the open-path gas analyser

Position with respect to the anemometer

- Set in a vertical orientation as per instruction manual; do not mount at an angle; this helps keep the top mirror clean

- Setup hardware should be assembled in a way to minimize wind-related vibration; this helps keep measurement noise to a minimum

- Centres of analyser and anemometer should ideally be matched vertically and the horizontal separation of the $\mathrm{CH}_{4}$ analyser and sonic anemometer should be about $10-30 \mathrm{~cm}$ between edges of the instruments. At heights above $10 \mathrm{~m}$, the analyser can be placed below the anemometer such that horizontal separation is zero and vertical separation is significant

- Use Kristensen et al. (1997) for rules of thumb for each specific site.

\section{Orientation}

- To decide on the best orientation, examine a wind rose from the stations or from nearby airport or weather station.

- If the wind rose at the station shows multiple different wind directions, then the $\mathrm{CH}_{4}$ analyser and other bulky structures (including the tower itself) should be positioned in the least prevalent wind direction relative to the sonic anemometer.

- When the wind rose at the station shows one prevalent wind direction, then the $\mathrm{CH}_{4}$ analyser and sonic anemometer should be positioned perpendicular to the main wind flow.

- The $\mathrm{CH}_{4}$ analyser and sonic anemometer should be set away from any obstructions; see ICOS protocol for station setup in this issue for similar guidance.

- All associated boxes and enclosures should be positioned below and away from fast instruments, using the full length of the $5 \mathrm{~m}$ cable if possible.

- Any other bulky objects should be placed with the goal to minimize flow distortion to fast instruments.

\section{Other mounting}

- The cover from the temperature probe needs to be removed; this will minimise corrosion of the temperature probe and will reduce the need to replace it.

- The instrument should be rotated such that the temperature probe is positioned away from prevailing wind; this will help minimize condensation or rain water dropping from the probe onto mirrors.

- Use of the radiation shield provided with the instrument will help minimise condensation on the top mirror.

- It is advised to use the newer version of the radiation shield that extends $2 \mathrm{~cm}$ below the top mirror, which is available from the manufacturer free of charge. This helps keep the top mirror clean and extends the maintenance intervals. 
Additional measurements:

- High-speed $\mathrm{H}_{2} \mathrm{O}$ measurements should be located in close proximity to the sonic anemometer and highspeed $\mathrm{CH}_{4}$ measurements to measure over substantially the same footprint.

- Water flux measurements must be of high quality to minimize uncertainty in the WPL and spectroscopic terms and allow for the highest accuracy in the $\mathrm{CH}_{4}$ flux.

- Water flux measurements should be high-frequency (using open-path or short-tube closed-path analysers).

- Long-tube closed-path $\mathrm{H}_{2} \mathrm{O}$ analysers should be avoided, as these lead to substantial losses in $\mathrm{H}_{2} \mathrm{O}$ frequency response requiring large flux corrections which again introduce uncertainties; inlet tubes should be $1 \mathrm{~m}$ or less. The standard EC setup as described in the ICOS station setup protocol of this issue is designed to minimise flux losses for $\mathrm{H}_{2} \mathrm{O}$.

Calibration and maintenance of open-path analyser (LI-7700)

Keeping the mirrors clean is the most important consideration for making precise and accurate $\mathrm{CH}_{4}$ concentration measurements with open-path analysers. Mirror contamination leads to reduced signal strength, which causes the signal to appear noisier. Generally, for the LI-7700 the mean concentration is not affected until relative signal strength (RSSI) drops below $20 \%$, or even lower, and noise will be constrained when RSSI is above $25 \%$. Instrument calibration drift is small, so annual validation/calibration checks are generally adequate.

\section{Calibration}

- Clean the mirrors before checking calibration

- Zero and span should be checked in the laboratory approximately once per year (LI-7700); field calibration checks are prone to errors and are not recommended

- Zero-gas can be $\mathrm{CH}_{4}$-free synthetic air or $\mathrm{N}_{2}$; the LI-7700 is not known to be sensitive to VOCs

- A single span gas can be used; it should be 2 to $10 \mathrm{ppm}$ in air; do not use $\mathrm{CH}_{4}$ in $\mathrm{N}_{2}$ for a calibration check as this will affect pressure broadening and produce erroneous results.

- Factory calibration consists of setting zero using ultra-pure $\mathrm{CH}_{4}$-free air and span at 2 ppm $\mathrm{CH}_{4}$ in air and then checking readings over a wide range of $\mathrm{CH}_{4}$ concentrations (zero to $40 \mathrm{ppm}$ ) and temperatures (about $21^{\circ} \mathrm{C}$ to $\left.45^{\circ} \mathrm{C}\right)$.

\section{Maintenance}

Activate self-cleaning tools and tune them to the specific site conditions to maximize data coverage and to minimize power consumption due to mirror spinning, heating and washer pump:

- To avoid condensation heat top mirror 0.5 to $1{ }^{\circ} \mathrm{C}$ above ambient temperature (5\% to $20 \%$ of full power) and heat bottom mirror with about $10 \%$ of full power

- After gaining some experience with condensations timing at the specific site, adjust the heater settings depending on local conditions

- To avoid contamination build-up on the lower mirror, activate and program spinning or spinning/washing cycles

- Spinning the lower mirror every 10-15 seconds at the end of each hour may help keep the mirror clean and extend the periods between manual cleaning

- Schedule the fluid washer to activate when RSSI is $25 \%$ or lower

- Spinning and activating the fluid washer can be scheduled independently when using GUI version 1.0.5 and firmware version 1.0.19 or higher

- After gaining some experience with contamination frequency and levels at the specific site, adjust the spinning and washing settings depending on local conditions 
- If after cleaning, RSSI does not recover to $40 \%$ or higher, consider cleaning the mirrors manually

- Remove data during cleaning cycles; this is automated in EddyPro

- Flag or delete data collected when RSSI is less than $20 \%$

Periodically check the software indicator for the $R H$ status in the head; the desiccant in the head should be changed if $R H$ reaches $30 \%$. At remote infrequently visited stations, it is possible to extend washer fluid volume using an external tank. Consult the manufacturer for technical details. The open-path $\mathrm{CH}_{4}$ analyser can also be made suitable for flux measurements in winter.

Data acquisition

For the LI-7700 open-path analyser, the system must be set to record high-speed $\mathrm{CH}_{4}$ density. Do not use highspeed $\mathrm{CH}_{4}$ mole fraction to compute the flux; the mole fraction output is provided only for calibration and validation procedures as per manufacturer's guidelines in the manual. Care needs to be taken to record mole fractions at sufficient resolution. If using a custom data collection scheme, avoid truncating the $\mathrm{CH}_{4}$ density value as happened in some previous studies (Peltola et al., 2014); save at least 6 decimals.

For the LI-7700 open-path analyser, the list of variables that should be saved at $10 \mathrm{~Hz}$ is given as per Table A1.

Table A1. List of variables to recorded for the LI-7700 open-path $\mathrm{CH}_{4}$ analyser

\begin{tabular}{ll}
\hline Variable & Explanation \\
\hline $\mathrm{CH}_{4}$ density $\left(\mathrm{mmol} \mathrm{mol}^{-3}\right)$ & $\begin{array}{l}\text { the one used for computing fluxes, needs } 6 \text { or more decimals to prevent } \\
\text { truncation }\end{array}$ \\
$\mathrm{CH}_{4}$ mole fraction $\left(\mu \mathrm{mol} \mathrm{mol}^{-3}\right)$ & $\begin{array}{l}\text { for calibrations/validations } \\
\text { near the top of the path, for calibrations/validations and other non-flux } \\
\text { references and computations } \\
\text { Temperature }\left({ }^{\circ} \mathrm{C}\right)\end{array}$ \\
near the bottom of the path, for calibrations/validations and other non-flux \\
references and computations \\
threshold for automated and manual cleaning, and QC
\end{tabular}

Quantification of random flux error for open-path analysers

As explained above, the open-path fluxes are calculated from values reported as fast densities that have yet to be corrected for $\mathrm{H}_{2} \mathrm{O}$ dilution or thermal expansion effects. A point-by-point conversion to dry mole fraction is not advisable because fast temperature and $\mathrm{H}_{2} \mathrm{O}$ concentrations integrated over the same sampling volume are not available. Instead, the corrections for density fluctuations are applied to raw frequency-corrected fluxes based on $H$ and $L E$ using the formulation of Webb et al. (1980). However, the density corrections have significant random errors of their own, which need to be added to the random errors of the flux covariance through error propagation. Thus, the error analysis described above for the closed-path systems should be applied to the temperature and $\mathrm{H}_{2} \mathrm{O}$ terms of the WPL density correction as well as to the $\mathrm{CH}_{4}$ time series.

High-pass transfer function

For $\mathrm{CH}_{4}$ fluxes measured by open-path analysers, it is recommended to apply the analytical method, as it is done for momentum and sensible heat fluxes after Moncrieff et al. (1997). The total transfer function is calculated as a superposition of specific transfer functions representing different causes of flux loss. For the sensor separation effect, the formulation proposed by Horst and Lenschow (2009) should be used. 
Correction for dilution/expansion and spectroscopic effects in open-path systems

As described above, the open-path measurements of $\mathrm{CH}_{4}$ and other gases with fluxes relatively small in comparison to their typical atmospheric concentrations are subject to large WPL terms. As a result, uncertainties in WPL terms dominate the instrument-related uncertainties in raw $\mathrm{CH}_{4}$ flux approximately 10:1 for typical midday mid-summer conditions. In addition, all laser-based instruments are subject to spectroscopic effects due to changes in temperature, pressure and $\mathrm{H}_{2} \mathrm{O}$ content. These effects are different from density and dilution effects captured in the WPL terms. Many approximations or shortcuts typically acceptable in flux processing and correction schemes used for relative large $\mathrm{H}_{2} \mathrm{O}$ and $\mathrm{CO}_{2}$ fluxes, would lead to errors that are no longer negligible for the calculation of the much smaller $\mathrm{CH}_{4}$ fluxes. Recommendations below help minimise these issues via specific processing steps.

First, when using custom-built systems with different instruments using different settings and clocks, or utilising different data streams, the safest strategy is to fully compute and fully correct $H$ and $L E$ fluxes first. Only then these can be used in WPL terms applied to a fully frequency-corrected $\mathrm{CH}_{4}$ covariance. This process is analogous to using Eq. (44) in Webb et al. (1980), but with specific emphases on the following:

1. Since $H$ and $L E$ need to be measured very accurately for the correction of the open-path $\mathrm{CH}_{4}$ fluxes, avoid any distortion to sonic anemometer. The distortion effects are not practically correctable as of today.

2. $H$ must be corrected for sonic $T$, cross wind, any drifts in mean $\mathrm{T}$, and for frequency response. LE must be corrected for time delay, frequency response, WPL-H term, and any drifts in mean $\mathrm{H}_{2} \mathrm{O}$.

3. For the above, the time lags between $w$ and $T, \mathrm{H}_{2} \mathrm{O}$, and $\mathrm{CH}_{4}$ must be run individually. This is important to assure that all fluxes in WPL equation are fully frequency corrected.

4. Similarly, frequency corrections need to be applied to $\mathrm{H}, \mathrm{LE}$, and $\mathrm{CH}_{4}$ fluxes based on the dimensions of the actual measuring devices prior to the correction. These may differ for $\mathrm{CH}_{4}, \mathrm{~T}$, and $\mathrm{H}_{2} \mathrm{O}$.

Second, when using manufactured stations with synchronized clocks, data collection streams and integrated processing program (such as EddyPro), several correction schemes are available in the program configurations, but they have to yield the same or very similar $\mathrm{CH}_{4}$ flux results.

Regardless of the chosen correction scheme, the H used for the WPL terms should not be computed from the temperature probe of the LI-7700, but from the sonic T. The LI-7700 temperature probe output is not designed to have a $10 \mathrm{~Hz}$ time response in all conditions and is intended for calibration and validation procedures only.

When using custom processing codes, spectroscopic correction multipliers must be added to WPL terms. The procedure of computing spectroscopic multipliers is described in detail in pages 5-1 to 5-18 of the LI-7700 user manual. Explanations of the nature of spectroscopic correction for open-path $\mathrm{CH}_{4}$ measurements, relevant derivations, and resulting multipliers is provided in McDermitt et al. (2011). Additional details on the place of spectroscopic corrections in overall flux processing scheme are provided on page 217 of Burba (2013). LI-COR provides an algorithm and verification worksheet for applying a spectroscopic correction on request.

When using EddyPro, the spectroscopic corrections are applied automatically as a part of the overall $\mathrm{CH}_{4}$ flux processing. EddyPro also uses high-resolution lookup tables to assure best possible calculations of the spectroscopic multipliers. The proper setup, configuration and operation of the analyser is described above. Proper setup and configuration will help achieve the best quality of input parameters used for computing density terms and spectroscopic effects. This will minimize WPL-related uncertainties and lead to better resolved $\mathrm{CH}_{4}$ flux measurements.

Differences in path lengths, separations, and time responses for $\mathrm{CH}_{4}, \mathrm{H}_{2} \mathrm{O}$, and sonic $\mathrm{T}$ may not be negligible when computing in final $\mathrm{CH}_{4}$ flux. Such errors would be very difficult to verify or correct. Using density corrections after Webb et al. (1980) resolves these issues.

If a long-tube closed-path device is used for LE measurements, consider adding an alternative fast $\mathrm{H}_{2} \mathrm{O}$ instrument (open-path or short-tube enclosed) to obtain a more reliable LE. The uncertainties in WPL-LE term using an $\mathrm{LE}$ value from a long-tube $\mathrm{H}_{2} \mathrm{O}$ analyser could be larger than the typical $\mathrm{CH}_{4}$ flux itself.

Analytical frequency response correction methods are more appropriate for correcting open-path $\mathrm{CH}_{4}$ flux covariance than in-situ methods based on determining cut-off frequency from spectral and cospectral assessments.

During quality control routine, and especially during spectral and co-spectral analyses, make sure that temperature-, $\mathrm{H}_{2} \mathrm{O}$-, and pressure-dependant variations in open-path $\mathrm{CH}_{4}$ density are not accidentally counted as 
a noise. Otherwise, perfectly fine $\mathrm{CH}_{4}$ data would be removed by quality control filters, especially during periods when $\mathrm{CH}_{4}$ flux was relatively small while temperature, $\mathrm{H}_{2} \mathrm{O}$ or pressure variations were relatively large.

Remove all data during cleaning cycles before flux calculations or any aggregated analyses of fast data, such as spectral and co-spectral analyses, noise calculations, etc.

Burba G., 2013. Eddy covariance method for scientific, industrial, agricultural, and regulatory applications: a field book on measuring ecosystem gas exchange and areal emission rates, LI-COR Biosciences, Lincoln, NE, USA, 331 pp.

Chamberlain S.D., Verfaillie J., Eichelmann E., Hemes K.S., and Baldocchi D.D., 2017. Evaluation of Density Corrections to Methane Fluxes Measured by Open-Path Eddy Covariance over Contrasting Landscapes. BoundaryLayer Meteorology, 165, 197-210. 